Illinois State University

ISU ReD: Research and eData

Theses and Dissertations

3-8-2018

\title{
Changes In Teacher Thinking And Action In Response To The Next Generation Science Standards
}

Angela R. Bowden

Illinois State University, arholt1981@gmail.com

Follow this and additional works at: https://ir.library.illinoisstate.edu/etd

Part of the Curriculum and Instruction Commons, and the Science and Mathematics Education Commons

\section{Recommended Citation}

Bowden, Angela R., "Changes In Teacher Thinking And Action In Response To The Next Generation Science Standards" (2018). Theses and Dissertations. 823.

https://ir.library.illinoisstate.edu/etd/823

This Dissertation is brought to you for free and open access by ISU ReD: Research and eData. It has been accepted for inclusion in Theses and Dissertations by an authorized administrator of ISU ReD: Research and eData. For more information, please contact ISUReD@ilstu.edu. 


\title{
CHANGES IN TEACHER THINKING AND ACTION IN RESPONSE \\ TO THE NEXT GENERATION SCIENCE STANDARDS
}

\author{
Angela R. Bowden
}

\section{Pages}

This study examined the role of K-12 science teachers' understandings and perceptions of the Next Generation Science Standards, implementation of the new standards in the classroom, and potential barriers to implementation as reform stakeholders had envisioned. Grounded in the relevant literature and working from the Teacher-Centered System Reform (TCSR) framework, this study employed a quantitative approach to data collection. The TCSR Model framed this study by linking teachers' demographic and professional profile, teaching experience, professional development, district-level, school-level, and classroom-level contexts and illuminates the dynamic effect the factors have on teachers' thinking and their practice. The study recognizes teachers' knowledge and beliefs, their personal backgrounds, and the contextual factors that influence their practices and provides a context for improvement built from the interrelatedness of the varying perspectives of reform.

KEYWORDS: Next Generation Science Standards; Curriculum; Instruction; Assessment; Professional Development; Teacher-Centered System Reform Model 


\title{
CHANGES IN TEACHER THINKING AND ACTION IN RESPONSE
}

TO THE NEXT GENERATION SCIENCE STANDARDS

\author{
ANGELA R. BOWDEN
}

\begin{abstract}
A Dissertation Submitted in Partial
Fulfillment of the Requirements for the Degree of

DOCTOR OF EDUCATION

School of Teaching and Learning

ILLINOIS STATE UNIVERSITY
\end{abstract}


(C) 2018 Angela R. Bowden 


\section{CHANGES IN TEACHER THINKING AND ACTION IN RESPONSE}

TO THE NEXT GENERATION SCIENCE STANDARDS

ANGELA R. BOWDEN

COMMITTEE MEMBERS:

Steven B. Mertens, Chair

Allison Antik-Meyer

Gary Weilbacher 


\section{CONTENTS}

Page

CONTENTS

TABLES

FIGURES

CHAPTER I: INTRODUCTION 1

Background of the Problem 2

Study Context $\quad 3$

Statement of the Problem 4

$\begin{array}{ll}\text { Purpose } & 5\end{array}$

Research Questions $\quad 5$

Significance of Research Questions $\quad 6$

$\begin{array}{ll}\text { Conceptual Framework } & 6\end{array}$

Definition of Terms 99

$\begin{array}{ll}\text { Study Design } & 10\end{array}$

Summary 11

CHAPTER II: REVIEW OF RELATED LITERATURE 12

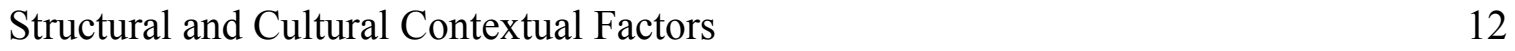

Education Reform in the United States 12

$\begin{array}{ll}\text { Standards-Based Reform } & 14\end{array}$

$\begin{array}{ll}\text { Science Education Reform } & 20\end{array}$

$\begin{array}{ll}\text { Reform within the Classroom } & 27\end{array}$

Teacher-Centered Systemic Reform 28 
Support for K-12 Science Teachers 31

$\begin{array}{ll}\text { Professional Development } & 31\end{array}$

$\begin{array}{ll}\text { Summary } & 32\end{array}$

CHAPTER III: METHODOLOGY 35

$\begin{array}{ll}\text { Research Design } & 35\end{array}$

Population and Sampling Procedures 36

$\begin{array}{ll}\text { Instrumentation } & 38\end{array}$

Variables in the Study 39

$\begin{array}{ll}\text { Pilot Study } & 40\end{array}$

$\begin{array}{ll}\text { Ethical Considerations } & 40\end{array}$

$\begin{array}{ll}\text { Data Analysis } & 41\end{array}$

CHAPTER IV: FINDINGS 43

$\begin{array}{ll}\text { Study Sample } & 44\end{array}$

$\begin{array}{ll}\text { Data Analysis } & 48\end{array}$

$\begin{array}{ll}\text { Results } & 48\end{array}$

$\begin{array}{ll}\text { Research Question One } & 48\end{array}$

Research Question Two $\quad 56$

$\begin{array}{ll}\text { Research Question Three } & 64\end{array}$

$\begin{array}{ll}\text { Research Question Four } & 72\end{array}$

$\begin{array}{ll}\text { Research Question Five } & 78\end{array}$

CHAPTER V: DISCUSSION

$\begin{array}{ll}\text { Summary of Findings } & 82\end{array}$ 
$\begin{array}{ll}\text { Research Question One } & 82\end{array}$

$\begin{array}{ll}\text { Research Question Two } & 86\end{array}$

$\begin{array}{ll}\text { Research Question Three } & 91\end{array}$

Research Question Four $\quad 95$

Research Question Five $\quad 97$

Limitations of the Findings $\quad 100$

Implications of the Findings $\quad 101$

$\begin{array}{ll}\text { Teacher Thinking and Changes in Practice } & 101\end{array}$

$\begin{array}{ll}\text { Inquiry Versus Three-Dimensional Learning } & 101\end{array}$

$\begin{array}{lr}\text { Content Knowledge } & 102\end{array}$

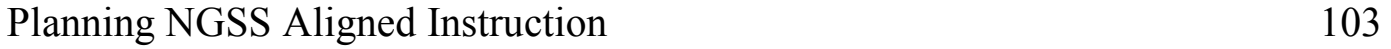

$\begin{array}{ll}\text { Future Research Directions } & 104\end{array}$

$\begin{array}{ll}\text { State Assessments } & 104\end{array}$

$\begin{array}{ll}\text { Planning NGSS Aligned Instruction } & 104\end{array}$

$\begin{array}{ll}\text { Professional Learning } & 105\end{array}$

$\begin{array}{ll}\text { Reform Evaluation and Guidance } & 106\end{array}$

$\begin{array}{ll}\text { Summary } & 107\end{array}$

$\begin{array}{ll}\text { REFERENCES } & 109\end{array}$

$\begin{array}{lr}\text { APPENDIX A: SURVEY } & 126\end{array}$ 


\section{TABLES}

Table

Page

1. Current Role in Education 45

2. School Configuration 46

3. Content Area $\quad 47$

4. Years of Teaching Experience $\quad 47$

5. Education Level 48

6. Familiarity with the NGSS Items 49

7. Mean Scores on Preparedness Level and Professional Development Activities as a Function of Participant Group

8. Total Amount of Professional Development Received 53

9. Mean Scores on Four Measures of Familiarity with the NGSS as a Function of Participant Group $\quad 54$

10. Attitudes of Respondents Concerning the Next Generation Science Standards 57

11. Mean Scores on Attitudinal Responses Regarding the NGSS as a Function of a Participant Group $\quad 60$

12. Mean Scores on Attitudinal Responses Regarding the NGSS as a Function of a Participant Group

13. Mean Scores on Attitudinal Responses Regarding the NGSS as a Function of a Participant Group

14. Mean Scores on Attitudinal Responses Regarding the NGSS and Professional Development as a Function of a Participant Group 
16. School-Level Changes $\quad 65$

$\begin{array}{ll}\text { 17. District-Level Changes } & 67\end{array}$

18. Mean Scores on Responses Regarding Classroom Changes as a Function $\begin{array}{ll}\text { of a Participant Group } & 68\end{array}$

19. Mean Scores on Responses Regarding District Changes as a Function $\begin{array}{ll}\text { a Participant Group } & 69\end{array}$

20. Barriers to Implementation of the NGSS

21. Mean Scores on Responses to Barriers to Implementation as a Function of a Participant Group $\quad 76$

22. Correlations among Familiarity with NGSS and Changes to Classroom Practices $(\mathrm{N}=83)$

23. Correlations among Attitudinal Responses to the NGSS and Changes to Practices $(\mathrm{N}=83)$ 


\section{FIGURES}

$\begin{array}{lll}\text { Figure } & \text { Page }\end{array}$

1. Graphic representation of the Teacher-Centered System Reform Model 7 


\section{CHAPTER I: INTRODUCTION}

Michael Fullan candidly argues that "educational change depends on what teachers do and think - it is as simple and as complex as that" (2007, p. 129). Despite the national context of education created by public and private entities including government agencies, professional organizations, and philanthropic foundations striving to reform education, classroom practices seem nearly impervious to change (Tyack \& Tobin, 1994; Woodbury \& Gess-Newsome, 2002). Yet, the local context in which K-12 teachers operate varies considerably; personal, cultural, and organizational factors contribute to the inconsistent implementation of educational reform (Bidwell, 2001; Cuban, 1993). The interaction between these contextual factors is effectuated in a classroom practitioner's thinking and actions. K-12 teachers' thinking and actions are intrinsically linked, and teachers, rightfully so, have been dubbed "key agents of improvement," as their actions in the classroom must change if teaching and student learning is to improve (Cohen \& Ball, 1990, p. 233). Despite previous reforms intended to change teachers' regular classroom practices, teachers' active response to reform varies widely (Cuban, 2013).

Standards-based reform (SBR) presupposes that creating high quality content standards improves teaching and learning by providing consistent and purposeful learning expectations (Smith \& O’Day, 1990). There is evidence that standards drive the curriculum in many classrooms (Loeb et al., 2008). Stecher et al. $(2000 ; 2008)$ found standardized testing influences curriculum, particularly when there is a lack of alignment between the standards and assessment, teachers may narrow the curriculum to adapt instruction to the test.

This study focused on K-12 science teachers' understandings and perceptions of the Next Generation Science Standards (NGSS Lead States, 2013). The Next Generation Science Standards (NGSS) are the most recent standards-based reform of science education in the United 
States (Penuel, Harris, \& DeBarger, 2015; NGSS Lead States, 2013d). National security concerns, economic competitiveness, outdated standards, and mediocre results on national and international standardized assessments are cited as the rationale for overhauling American science education (Mehta, 2013; NGSS Lead States, 2013e). Considerable debate has taken place since the dawn of standards-based reform, as to whether these policies catalyze beneficial change in schools and classrooms (Darling-Hammond, 2004; Desimone, 2013; Diamond, 2007; Loeb, Knapp, \& Elfers, 2008). If the NGSS are implemented as the authors intended, changes to classroom practice should be evident and substantial (Pruitt, 2014). By examining science educators' responses to the content and classroom implementation of the NGSS, this quantitative study may provide insight into K-12 science teachers' responses to the reform implementation process.

\section{Background of the Problem}

Since the 1950s, multiple attempts have been made to overhaul science curricula and teaching in U.S. public schools; the resultant changes, however, have been mediocre at best (Cuban, 2013). Even with well-funded and resolute efforts, schools are known as notoriously impervious to change (Boyd, 1988). Despite nearly three decades of constant efforts to reform American classrooms, studies that have examined teacher practices have reported limited changes in response to these reforms (Boyd, 1988; Cuban, 1993; Tyack \& Tobin, 1994). States

that have adopted the NGSS are expecting classroom teachers to shift pedagogical practices and deepen content knowledge as needed to meet the higher demands of the student performance expectations; the states are expecting the individual practitioner to be the change agent in their reform efforts (Priestley, 2011). Pruitt (2014) claims that classroom practices will change substantially if the NGSS are implemented with fidelity. 


\section{Study Context}

The NGSS were designed to reflect a new conception for U.S. science education (NGSS Lead States, 2013a). Previous science standards and benchmarks pressed for disciplinary content and inquiry to be taught together while state testing continued keep them separate and classroom practices followed suit (Pruitt, 2014). Although relatively recent national science education standards included inquiry, most notably the Benchmarks for Science Literacy (1993), a great deal of emphasis remained on superficial understanding of science concepts (American Association for the Advancement of Science, 1994; NGSS Lead States, 2013a). The intent of the NGSS is to integrate the three dimensions into the performance expectations and changes how students apply the content knowledge they learn by linking content and inquiry (NGSS Lead States, 2013a; Pruitt, 2014).

If the standards are implemented as the authors intend, significant shifts may be required to many K-12 science teachers' daily lessons and classroom practices (NGSS Lead States, 2013a; Pruitt, 2014). Policy makers have attempted to restructure U.S. science education several

times before, with only minimal resultant impact at the classroom level (Cuban, 2013). A reform effort which does not take into account the everyday classroom practices of K-12 science teachers will lack the direction educators need to change (Hiebert \& Stigler, 2000; Sarason, 1996). It is possible that some teachers do not perceive the new standards as a catalyst for real change in their classrooms. This study aims to provide insight into science teachers' understanding, beliefs and actions related to the most recent attempt to restructure science education and how these perceptions perpetuate into their daily practices. 


\section{Statement of the Problem}

Standards-based reform is rooted in the assumption that educators will be convinced that new standards are an improvement over previous standards and amend their practice to align to the new standards (Loeb et al., 2008). A myriad of studies provides evidence of the failure by school reforms to influence classroom practices (Cuban, 1993, 2013; Diamond, 2007). Other research suggests that new models of instruction do indeed reach the classroom and influence the materials and strategies K-12 science teachers use (Coburn, 2004). As K-12 science teachers are exposed to multiple forms of instructional models, they may respond in different ways; some will choose one method over others (McLaughlin, 1987), others will respond only symbolically (Metz, 1989), while still others will hybridize multiple approaches into their existing repertoire (Cuban, 1993; Tyack \& Cuban, 1995). Grounded in this research, this study focused on K-12 science teachers' understandings, interpretations, and most importantly, actions in response to the NGSS.

As K-12 science teachers are confronted with new information and instructional methods, they construct understanding through the lens of their existing views and practices; teachers mediate new curriculum and instructional models, like the integration of the science and engineering practices with disciplinary content, through their established beliefs and understandings of disciplinary content, students, teaching, and learning (Coburn, 2004; Gregoire, 2003; Reiser, Fumagalli, Novak \& Shelton, 2016; Spillane, Reiser, \& Reimer, 2002). Other studies suggest the organizational environment of the school acts as a buffer between reform pressures and classroom practices by making symbolic changes to procedures and structures as needed, so schools may meet various and sometimes conflicting demands (Driscoll, 1995). An organization's routine and environment are constructed over time, partially from small shifts in 
actions by those in that environment (Porac, Thomas, \& Baden-Fuller, 1989). The local context and the complex organizational environment of the public school may, in part, account for whether a reform is implemented as envisioned by those driving the reform (Cuban 1993; Vaughan, 1996).

\section{Purpose}

The purpose of this study was to examine the changes to classroom practices in response to NGSS implementation from the self-reported perspectives of K-12 science teachers. This national study surveyed educators' familiarity with and perceptions of the NGSS, changes in practices at the classroom, school, and district levels, and perceived barriers to implementation. This study intended to explore the factors that contribute to or inhibit the changes to K-12 science teachers' curriculum, instructional practices, and assessments in response the NGSS reform.

\section{Research Questions}

The following questions guided the research study:

1. What is the level of familiarity with and understanding of the Next Generation Science Standards among K-12 science teachers?

2. What are the attitudes and levels of agreement concerning the Next Generation Science Standards among K-12 science teachers?

3. What changes, if any, have K-12 science teachers made to their classroom practices (pedagogy, curriculum, and assessment) in response to the Next Generation Science Standards reform?

4. What barriers prevent K-12 science teachers from implementing the Next Generation Science Standards as intended by those who developed the standards? 
5. What are the relationships between K-12 science teachers' familiarity, attitudes and levels of agreement with the standards, barriers to implementation, and the degree of change to classroom practices in response to the Next Generation Science Standards reform?

\section{Significance of Research Questions}

Keys and Bryan (2001) suggested a line of research that focuses on standards-based reform practices within the context of the beliefs and understandings of K-12 teachers.

Furthermore, Desimone (2013) suggests that reactions to reform based on content area should be investigated. Although qualitative methods have traditionally been used to examine changes to teacher practices in response to reform (Ramberg, 2014), this study utilized quantitative methods to contribute to the understanding of how practitioner beliefs and contextual factors affect the classroom level implementation of the NGSS. The NGSS are intended to be a new vision of science education in the United States (Pruitt, 2014). Not only are classroom K-12 science teachers' perceptions of the new standards relevant, it is also imperative to uncover what barriers exist that may prevent the implementation of the NGSS.

\section{Conceptual Framework}

The Teacher-Centered System Reform (TCSR) model (Woodbury \& Gess-Newsome, 2002), combined with a thorough review of relevant literature guided this study (Figure 1). The TCSR model recognizes that K-12 science teachers' thinking and subsequent actions are influenced by a multitude of contextual and personal factors (Gess-Newsome, Southerland, Johnston \& Woodbury, 2003; Woodbury \& Gess-Newsome, 2002). The relationship between teachers' beliefs and actions has been studied through various lenses, with conflicting results 
(Enderle et al., 2014; Jeanpierre, Oberhauser, \& Freeman, 2005; Lee, Hart, Cuevas, Enders, 2004; Pajares, 1992).

\begin{tabular}{|l|l|l|l|}
\hline $\begin{array}{l}\text { Demographic } \\
\text { Profile } \\
\text { teaching } \\
\text { experience }\end{array}$ \\
$\begin{array}{l}\text { Nature and extent } \\
\text { of teachers' } \\
\text { preparation to } \\
\text { teach }\end{array}$ \\
$\begin{array}{l}\text { Nature and extent } \\
\text { of teachers' } \\
\text { continued learning } \\
\text { efforts }\end{array}$
\end{tabular}

Figure 1. Graphic representation of the Teacher-Centered System Reform Model (Woodbury \& Gess-Newsome, 2002).

Cuban (2013) argues that the adoption of new standards and instructional pedagogy, like the recent adoption of the NGSS, is a fundamental change in teaching. Watzlawick, Weakland, and Fisch (2011) defined such a shift as a second order change, or "a change to an altogether different state" (p. 10). While Pruitt (2014) echoes this argument within the context of the NGSS, what if K-12 science teachers perceive these changes as mere amendments to current structures? What if K-12 science teachers do not truly perceive the new standards as ushering in 
a new approach to the teaching and learning of science? A new set of standards may be perceived by some K-12 science teachers to be a first order change, merely an incremental shift in current practices (Watzlawick et al., 2011); the distinction may not be as clear cut as it seems to reformers. If K-12 science teachers perceive the new standards as a minor change, such interpretations may contribute to what select scholars identify as dynamic conservatism, as teachers are continually reeled in by their organization's nearly invisible continuity and status quo (Argyris, Putnam, \& McLain-Smith, 1985; Coburn, 2004; Schön, 1973). While K-12 science teachers can be agents of change, they are a cog in a larger social institution and many local environmental factors influence their practices (Fullan, 2007; Priestley, 2011; Ramberg, 2014). Classroom practices are significantly influenced by individual beliefs about teaching, the content being taught, and student learning (Enderle et al., 2014). Wilson (2013) recognizes K-12 science teachers' beliefs and knowledge are factors that must not be ignored and are crucial to research examining the effects of teacher professional development. Furthermore, professional learning is a critical mediator in the effectiveness of policy reform for teachers and their practice (Desimone, 2009). Teachers' thinking shapes their understandings of curriculum and instructional models (Bryan, 2003; Gess-Newsome, 1999; Pajares, 1992). Standards-based reform implementation at the classroom level — the planning, collaboration, the acquisition and familiarization of new curriculum and instructional resources-requires a significant and sustained effort by educators (Massall \& Perrault, 2014; Penuel et al., 2015). Once realignment of classroom level practices has occurred, it is equally important to adhere to the new changes, as program stability is a criterion associated with improved student achievement (Newmann, Smith, Allensworth, \& Bryk, 2001). 


\section{Definition of Terms}

The following statements provide definitions for understanding and creating uniformity of terms used throughout this research study.

Curriculum materials: School or district adopted textbooks or curriculum aligned to academic standards and assessments; supplemental materials used to extend the adopted curricular materials as required to meet student needs (Stern \& Roseman, 2004; Wilson, Taylor, Kowalski, \& Carlson, 2010).

Teacher beliefs: In this study, teacher beliefs include the attitudes and levels of agreement about students, teaching, and learning, which are derived from one's experiences, are highly subjective, and emotionally pervaded (Crawford, 2007).

Teacher content knowledge: I define content knowledge in the same manner as Crawford (2007), as "the conceptions and understandings of science content" (p. 617), and Prawat (1992), "assumptions about the origin of knowledge, how it changes, and how truth is established with the disciplinary domain" (p. 365).

Teacher instructional practices: The actions of well-designed plans closely aligned to academic standards and assessments; created through the collaboration of colleagues to ensure curricular coherence; student data is used to make planning decisions; the curriculum is designed to provide learning experiences that develop deep understanding of the disciplinary core ideas, instructional plans provide opportunities to apply content knowledge through scientific and engineering practices, and connect crosscutting concepts across disciplines as the NGSS requires (Pruitt, 2014). 
Teacher thinking: The term teacher thinking is used to describe the intersection between practitioner knowledge and beliefs; this complex interaction mediates the decisions K-12 science teachers make about curriculum or instructional strategies (Keys \& Bryan, 2001).

Reform: For this study, reform is defined as a local or national effort to proffer a fundamentally different schooling experience for students; for example, an effort to establish a new set of standards or instructional model (Woodburry \& Gess-Newsome, 2002).

\section{Study Design}

The interaction between personal and contextual factors are represented in a practitioner's thinking and actions (Woodbury \& Gess-Newsome, 2002). This study examined the role of K-12 science teachers' understandings and perceptions of the NGSS, implementation of the new standards in the classroom, and potential barriers to implementation of the standards as reformers had envisioned. Grounded in the relevant literature and working from the TCSR framework, this study employed a quantitative approach to data collection. The study investigated how the adoption and implementation of the NGSS has influenced K-12 science teachers and how this influence varies. Quantitative research examines causes and outcomes by collecting numerical data (Creswell, 2008). This study used an anonymous, online questionnaire to survey K-12 science teachers who are members of the National Science Teachers Association; the organization boasts a membership of over 55,000 science educators, administrators, and industry representatives (National Science Teachers Association, 2016). Though the science educators who completed the survey teach in diverse situations, many may require similar changes to current curriculum, instructional and assessment practices to meet the demands of the NGSS. 
A survey consisting of five sections of categorical personal and contextual related items, Likert-scale items, and open-ended questions was created from qualitative pilot study data, a comprehensive review of the literature, and the Teacher-Centered Systemic Reform (TCSR) model framework. The instrument was designed to measure K-12 science teachers' level of familiarity of the NGSS, beliefs and levels of agreement concerning the new science standards, changes to classroom, school, and district practices resultant of the NGSS, and perceived barriers preventing implementation of the standards.

\section{Summary}

If an educational reform is to truly take hold, those who are driving the change must consider the context into which the reform is to be implemented (Kliebard, 2002). New learning standards will not automatically change what K-12 science teachers do in the classroom (Cuban, 2008). Historically, the environment in which K-12 science teachers work and the individual agency of a teacher has been of minimal concern to policymakers, though evaluation policies recently adopted by several states seek to challenge self-determination amongst teachers (Croft, Roberts, \& Stenhouse, 2016).

Standards-based reforms have been less than successful in changing K-12 science teachers' behaviors; findings that examine changes to teachers' instructional practices are mixed at best (Desimone, 2013; Grant, Peterson, \& Shojgreen-Downer, 1996). Previous attempts at restructuring science education have floundered (Cuban, 2013). For changes in science classroom practices to be permanent, teachers must have the capacity and willingness to shift their perceptions as well as their methods (Achinstein, Ogawa, \& Spiegelman, 2004; Fairman \& Firestone, 2001). The NGSS echo the multifaceted goals of science education of the previous century. Will K-12 science teachers' responses to the NGSS be different than previous reforms? 


\section{CHAPTER II: REVIEW OF RELATED LITERATURE}

This chapter includes discussions related to the reform policy process, standards-based reform practices within the context of the beliefs and actions of teachers, and standards-based reform within the science content area. To evaluate the proliferation of the NGSS in the classroom, all factors that may support or inhibit teacher enactment of the reform must be considered. The literature reviewed provides empirical, theoretical, and conceptual grounding for this study is framed by the TCSR model (Figure 1).

\section{Structural and Cultural Contextual Factors}

\section{Education Reform in the United States}

Educational reform efforts tend to be political in origin, as influential groups vie to promote and secure their ideals in public schools (Kliebard, 2004). Labaree (1987) argues the cyclical nature of school reform is a result of two competing ideologies amongst those in decision making positions, one that "elevates liberty and promotes free markets" while the other aims to "elevate equality and promote participatory politics" which manifest themselves in U.S. schools as reforms, like inclusion and voucher policies (p. 491). Interestingly, with a few key exceptions like supporting the use of vouchers, Republican and Democratic platforms for education are remarkably similar (Boyd, 1988; Tyack \& Hansot, 1981). Policy adoption and implementation tends to operate on a slower timeline than policy talk, so actual classroom implementation of a reform policy may be discordant with the cycle of elected officials' party platforms (Tyack \& Cuban, 1995).

Many Americans hold an intense and unrealistic faith in education's ability to perfect the future (Apple, 2012; Tyack \& Cuban, 1995). In the United States, a pattern has formed in which we believe school reform will remedy our societal and economic challenges; in reality, reforms 
rarely match their originators' aspirations (Cuban, 2013; Tyack \& Cuban, 1995). Indeed, many Americans hold truth to Lyndon B. Johnson's (1964) message, that "the answer to all our national problems comes down to a single word: education" (para. 15).

Along with other arguments, education reform cycles have long been perpetuated by the premise of an international economic competitiveness crisis (Mehta, 2013; NGSS Lead States, 2013e). The historian Cremin (1990) argues

to contend that problems of international competitiveness can be solved by educational reform...is not merely utopian and millennialist, it is at best foolish and at worst a crass effort to direct attention away from those truly responsible for doing something about competitiveness and to lay the burden instead on the schools (p. 103).

When a policy does not quickly cure what it is prescribed to remedy, educators are often blamed for the failure of reform and labeled as resistant (Fullan, 2007; Tyack \& Cuban, 1995). Reforms aimed at fundamentally changing ingrained classroom practices have found minimal success (Diamond, 2007). Americans are accustomed to expecting fast results, and when progress is not immediately seen, the effort is considered a failure (Cuban, 2013). Once this discourse has begun, the cycle begins anew.

Education policy reform consists of three phases: the discovery of a problem and the resultant discussion, the development of a remedy through policy action, and implementation amongst the target institutions (Tyack \& Cuban, 1995). The debate over the purpose of school repeatedly incites policy talk, but the route from policy talk to classroom implementation is complicated, unpredictable, and lengthy (Reese, 2002).

When reforms pass in constant succession with the intent to change classroom practices and possibly conflict with previous reforms, some educators modify them to fit with what 
already is done (Coburn, 2004; Cohen, 1990; Spillane, 2000; Tyack \& Cuban, 1995). Uneven implementation of a reform and the variability of impact on different groups within the student population may further exacerbate the delayed result of a reform policy (Tyack \& Cuban, 1995). The option of modification within SBR suggests all students will not necessarily study topics at the same depth or rigor (Spillane, 2000); this may be essential for equity amongst all students. Several studies suggest some educators may attempt to create continuity within their classroom and adapt curricular and instructional reforms to work in their school; thus, perhaps reforms should be deliberately designed for adaptation within local contexts (Coburn, 2004; Gregoire, 2003; Spillane, Reiser, \& Reimer, 2002).

\section{Standards-Based Reform}

Standards have been a recurrent facet of the United States' educational system for decades (Hamilton, Stecher, \& Yuan, 2008; Massell \& Perrault, 2014; Mehta, 2013; Ravitch, 2010); teaching to standards are part of the daily grind for today's K-12 science teachers. Though standards-driven education can be traced back to John Franklin Bobbitt and others in the early 20th century, the term standards-based reform (SBR) has been used with increased frequency since the early 1980s (Mehta, 2013). Most educational historians consider the release of A Nation at Risk in 1983 as the generative event behind the modern SBR movement (Cuban, 2008; Ravitch, 2010).

Though the use of the term standards-based reform has increased over the last 35 years, its connotation has varied (Wilson \& Floden, 2001). However, most descriptions of SBR generally include the following components: student academic expectations, assessment of student learning in relation to the academic expectations, reorganization of the administration or system of governance, educational system component coherence (often described as 
"alignment"), and accountability measures (Hamilton et al., 2008). In recent years, student expectations, assessment, and accountability measures have been favorite levers of educational reformists (Ravitch, 2010). Student performance on assessments supposedly aligned to the new, more challenging standards is now a component of teacher and administrator evaluations. Those in policymaking positions have found utility in a few tenets of SBR but ignore others, creating confusion for researchers and others as to what SBR encompasses (Hamilton et al., 2008).

Others argue we are now in a new era in education, where testing, data, and accountability reign supreme and the true purpose of education has become obscured (Ravitch, 2010). Unfortunately, even to some K-12 teachers, especially those who teach non-tested subject areas, the purpose of education has become somewhat cryptic. Standards may be necessary, testing can be useful, but when student data becomes more important than the actual students themselves, the main reason for education has been lost (Cuban, 2009; Ravitch, 2010).

Standards. The anchor of any SBR initiative is the document of statements that delineate desired student outcomes. Standards can be a guide as to what students should learn; they are teachers' curricular aims (Popham, 2014; Ravitch, 2010). Most proponents of SBR maintain the standards in question, whether they are math content standards or social studies curriculum standards, be clear, organized, and rigorous (Hamilton et al., 2008; Massell \& Perrault, 2014). Multiple types of standards systems proliferate education, including content standards, performance standards and expectations, curriculum standards, and system performance standards (National Council on Education Standards and Testing, 1992; National Council for the Social Studies, 2010; NGSS Lead States, 2013b).

The most recent notable reincarnation of SBR are the Common Core State Standards (CCSS) (Massell \& Perrault, 2014). Released in 2010, 42 states have adopted the CCSS content 
standards for English/Language Arts and Mathematics (Achieve, 2013). Content standards describe the knowledge and skills to be taught. Similarly, curriculum standards, like the National Curriculum Standards for Social Studies (NCSS), describe what students should know and are able to do and are usually organized by disciplinary content (NCSS, 2010).

In addition to disciplinary content standards, performance standards or expectations are also available for most content areas. The performance expectations of the NGSS define the level of understanding students are to achieve and to which they will be held accountable and incorporate all three dimensions of learning; the disciplinary content, science and engineering practices, and crosscutting concepts (NGSS Lead States, 2013a).

System component coherence. Second only to the standards and their related assessments, system component coherence, commonly referred to as alignment, is centric to SBR. For the practitioner, the extent of coherence between the adopted standards, classroom curriculum materials, and assessments is of pivotal importance. Each rendition of SBR insists upon the alignment of instructional practices, materials, and assessments; the alignment of incentives and consequences are additions from the accountability era of the 1990s (Hamilton et al., 2008; Massell \& Perrault, 2014). The hyper-focus on high-stakes test scores by policymakers and the lack of an agreed upon procedure for system component coherence has reduced the process of alignment to the matching the materials used to teach the standards to the high-stakes test (Ravitch, 2010). It appears some stakeholders are benefitting from a lack of an established protocol for system alignment (Cision, 2014). Some scholars argue as long as the textbook industry is producing commercially available products, whether they be hardcopy or on a digital platform, for schools and districts to purchase, the technical alignment of the system will be considered sound (Ravitch, 2010; Taylor, 2016). 
Restructuring of education governance. SBR is grounded in the premise that schools will perform better with clear objectives and strict punitive measures, though how the improved performance outcomes are obtained has largely been left to local administration (Cuban, 2009). Many states delegate the operation of schools to local authorities, yet continue to barrage districts and the educators with policies aimed at placating interest groups and attempting to cure the country's social and economic ills (Cuban, 2008). The United States education system has struggled to find the right combination of local control of schools and remote authority; when a reform fails to take hold, policymakers are quick to lament about local officials' incompetence or defiance (Cuban, 2008; Fibkins, 2015). Nevertheless, sustained change in classroom practices is solely contingent upon the classroom teacher (Cuban, 2009; Priestley, 2011).

Assessment and accountability. Although assessment of student understanding has multiple uses, assessment's primary purpose should be to inform teachers' instructional practices (Black \& Wiliam, 2010; Popham, 2014). Discourse related to appropriate assessment practices stem from differing philosophies of the purposes of assessment. The relatively weak state of the K-12 education workforce, despite the considerable clout of teacher unions have been powerless against the cycling of accountability legislation of the late $20^{\text {th }}$ and $21^{\text {st }}$ centuries (Mehta, 2013). K-12 science teachers' evaluations have become more heavily tied to assessments, the overall purpose of assessment seems to be shifting. An original contention of the SBR movement is that assessments are used to monitor student achievement, hold K-12 science teachers and administrators accountable, and improve teacher quality (Black and Wiliam, 2010; Hamilton et al., 2008). Thirty years after A Nation at Risk (1983) which called attention to students' low test scores on international tests, assessment driven instruction has become a dominant feature in schools (Hamilton et al., 2008; Ravitch, 2010). Clearly, the standardized-testing movement has 
changed classroom practices. High-stakes assessments and accountability measures have become so important that reducing instructional time for non-tested content areas, including science, has become accepted practice (Hamilton et al., 2008). While SBR has proven to be a relatively effective lever for shifting the practices of educators, some of the fears of SBR opposition, including the misuse of test scores, the narrowing of the curriculum to tested subjects and topics, and excessive test preparation have been realized (Hamilton et al., 2008; Ravitch, 2010). Critics of SBR accuse those in decision making positions of creating policies laced with scare tactics, including tying teachers' evaluations and administrators' employment contracts to achievement measures to force educators to comply (Cuban, 2009). Nevertheless, two main tenets of SBR, the adoption of curricular aims in the major content areas and assessment, seems to be permanently etched into the United States educational system.

Impact of standards-based reform. Fibkins (2015) argues most reformers are so disconnected from the day-to-day realities of education their policies are doomed to fail from inception. SBR proponents in decision-making positions are now finding ways to force their ideologies upon schools; they are attempting to give more control to administrators and reduce classroom teachers' independence (Labaree, 2012). The SBR movement has evolved to encompass more that its original tenets; data-driven instruction, punitive accountability practices, and high-stakes testing, are now commonplace (Cuban, 2008).

Though the social and organizational practices of school, such as class size and teacher behavior toward students have significantly modernized over the last century, curricular and instructional practices have been slower to change (Cuban, 2008). Even if a reform's purpose is well intentioned and appears to be successfully implemented at first glance, it tends to break down at the classroom level (Kliebard, 2002). Research suggests that traditional and 
contemporary practices are hybridized and scarcely practiced as intended (Cuban, 2009).

Schools, administrators, and K-12 science teachers regularly ignore, evade, and attenuate mandated reform measures, as most educators are not willing to risk the loss of control required for implementing a reform at the classroom level (Kliebard, 2002). The daily interactions among students and K-12 science teachers are rarely examined or scrutinized, though some states are currently attempting to demystify and control what goes on once the classroom door is closed by tying teachers' and building administrators' evaluations to standardized test scores (Cuban, 2008). Though not all SBR advocates support the use of incentives connected to testing results, the requirement of technical alignment between standards, curricular materials, and assessments has nevertheless advanced their agenda (Hamilton et al., 2008).

Perceived benefits of standards-based reform. Rigorous standards designed to advance student learning beyond rote memorization of facts was an original component of the SBR movement (Hamilton et al., 2008; Ravitch, 2010). Research suggests curricular materials and instructional practices aligned to standards are associated with improved student outcomes (Lauer et al., 2005). However, high-stakes testing has become such a focus in today's schools that the assessment and accountability components of SBR are being implemented in isolation from other elements, resulting in the benefits of SBR becoming overshadowed by the challenges (Hamilton et al., 2008; Ravitch, 2010).

Challenges. At the turn of the last century, Dewey (1901) argued:

No matter what the accepted precept and theory is, no matter what the legislation of the school board or the mandate of the school superintendent, the reality of education is found in the personal and face-to-face contact of teacher and child. The conditions that underlie and regulate this contact dominate the educational situation. (p. 337) 
Classroom K-12 science teachers are rarely involved in the planning phase of educational reform but are regularly called upon to carry out the plans of others, resulting in truncated teacher buy-in and commitment to the reform (Fibkins, 2015). However, technological advances have afforded districts and state education agencies the ability to trace student standardized test scores back to individual teachers, resulting in a SBR movement that has become distorted or essentially displaced by test-based accountability (Ravitch, 2010). Widespread modification of curriculum or instructional practices used to deliver the curriculum is an arduous undertaking; it involves more than simply swapping instructional strategies or replacing one unit or lesson format for another (Kliebard, 2002). Policymakers who are removed from the day-to-day practices of classroom now have the ability to scrutinize achievement outcomes of individual K-12 science teachers and students, though many have little understanding of the trials and tribulations of K12 science teachers. School practices have been altered by SBR components, but not necessarily in beneficial ways. The SBR outgrowths of high-stakes testing, hyper-accountability measures, and the narrowing of the curriculum have seemingly eclipsed the beneficial components, such as the alignment of standards and classroom curricular resources.

\section{Science Education Reform}

The National Science Foundation (NSF) was established in 1950 as a federal effort to improve U.S. scientific research programs and bolster K-12 science education (Hlebowitsh \& Wraga, 1989). The movement was the recognition by those in the political and economic sectors that science, engineering, and math had helped the United States win World War II, though the Cold War and the launch of Sputnik in 1957 increased reformers' urgency for improvements (Cuban, 2013). Reformists argued that American schools' curricula had been so negatively swayed by child-centered developmentalists that they were failing to provide the nation with the 
professionals needed to keep up with military adversaries and economic competitors (Cuban, 2008).

Early NSF education related funding produced textbooks and materials developed by leading academics and scientists that incorporated the content and process of doing science within one set of materials (Cuban, 2013). Despite the expenditure of millions of dollars and collaboration among the most prominent scientists of the day, science classrooms were largely unchanged (Stake \& Easley, 1978). Professional development was provided for classroom K-12 science teachers and the texts were piloted in classrooms, though teacher feedback was rarely heeded by the curriculum developers (Cuban, 2013). The resultant change to science classrooms was minimal, as pointedly articulated by Wayne Welch (1979), a long-time researcher of NSF funded curricula:

What have we learned from our curricular experiences of the past 20 years? Several things have emerged in this review. First, the resources of the science profession could be marshaled and directed toward a perceived problem in the schools. Second, considerable curriculum development has occurred and has dominated the attention of the science education profession. Third, the educational system is extremely stable and efforts to change it have little effect. Fourth, curriculum effects account for very little of the variance in student learning.... While there may be new books on the shelves and clever gadgets in the storage cabinets, the day-to-day operation of the class remains largely unchanged. A teacher tells his or her students what is important to learn and so the class progresses. (p. 303)

Inquiry. Wilson et al. (2010) provide strong evidence that inquiry-based instruction can out-perform traditional teaching strategies when facilitated by an experienced and well-prepared 
teacher. Though a concerted effort has been made to prepare K-12 science teachers for the inquiry-based classroom (Crawford, 2007; Lee et al., 2004; Schneider, Krajcik, \& Blumenfeld, 2005), studies reveal that teaching inquiry or scientific reasoning is the still most needed area for improvement amongst K-12 science teachers (Zhang, Parker, Koehler, \& Eberhardt, 2015). K12 science teachers' use of inquiry in the classroom was emphasized throughout the National Science Education Standards (1996) (National Research Council, 1996), but the document lacked a clear definition. Science inquiry, inquiry learning, and inquiry teaching were the various terms used in the standards, though each had its own distinctions (Anderson, 2002). Interpreting multiple definitions for classroom use proved perplexing to many K-12 science teachers (Anderson, 2002; Blumenfeld, Krajcik, Marx, \& Soloway, 1994). Nevertheless, a general pattern of support for inquiry in the classroom is evident within education research (Anderson, 2002). Though inquiry-based instruction is sometimes ambiguously defined as constructivist strategies, open inquiry, and guided scientific inquiry, all constructivist-oriented teaching and learning is more interactive and complex than the traditional relationship between teacher and student (Oliveira et al., 2012; Prawat, 1992). With the embedding of the science and engineering practices into the performance expectations of the NGSS, the developers attempted to require students to provide evidence they can apply inquiry skills while understanding content (Pruitt, 2014).

Although a variety of curriculum materials have been developed to facilitate inquiry practices, some K-12 science teachers struggle to implement them as intended (Cuban, 2013; Schneider et al., 2005). Though some studies show a positive correlation between K-12 science teachers' use of inquiry-based materials and administrative support, K-12 science teachers had considerable difficulty implementing inquiry-based science curricula, citing a lack of knowledge, 
skills, and beliefs required to teach science as inquiry (Germann \& Aram, 1996; Martens, 1992; Oliveira et al., 2012). Hands-on activities are not necessarily synonymous with teaching through inquiry (Wilcox, Kruse, \& Clough, 2015). Although this premise is well documented in science education literature, it may not be as well adhered to and realized among classroom educators. Anderson (2002) questions whether an inquiry approach is achievable on a widespread, sustained basis. Unless explicitly connected to disciplinary content in such way that students can construct meaning from the activity, hands-on science is not inquiry (Crawford, 2000). While project and activity-based learning can increase interest and motivation among students, if the purpose of the tasks is not to construct meaning, sense making, and promote critical thinking, such activities are not appropriate use of class time or budget. Though easier to implement in the classroom, the meaning making and application process required for deep understanding of science content and practices does not generally take place with direct instruction or cookbook-type investigations (NGSS Lead States, 2013; Schraw, Crippen, \& Hartley, 2006).

However, constructivist instructional models place greater demands on the practitioner; K-12 science teachers are unlikely to complicate their classroom practices without a substantial shift in thinking (Prawat, 1992). While there is evidence that students retain content and achieve better understanding when taught through the use of inquiry, this instructional model does require more time (Minner, Levy, \& Century, 2010). Moreover, Stern and Roseman (2004) found that although textbooks were the primary tool used to teach science concepts in many middle school classrooms, most commercially available textbooks and curricular materials available at the time of the study did not support students' understanding of key science concepts. Oliveira et al. (2012) suggest that higher performing schools use inquiry-based science instruction and put forth more effort to keep students engaged. High quality science curricular 
materials that build upon students' prior knowledge and provide sufficient examples of complex concepts will improve student engagement (Stern \& Roseman, 2004). Wilson et al. (2010) suggest students significantly benefit from using an inquiry-based approach to instruction, though the average practitioner may cite a lack of professional learning experiences for the continued use of textbooks and lecture.

The Next Generation Science Standards. New technological advances, poor performance by U.S. students on international tests, a dwindling share of technology patents, and a reduction of American high-tech exports are cited as evidence to overhaul American science education (NGSS Lead States, 2013d). The Next Generation Science Standards (NGSS) are based on the new vision for science education articulated in the Framework for K-12 Science Education (NGSS Lead States, 2013b). Twenty states and the District of Columbia have adopted the NGSS since the release in April 2013, though 40 states have expressed interest in the standards (Academic Benchmarks, 2015; Branch, 2013). Several education organizations have conveyed support for the NGSS, including the National Science Teachers Association, the American Federation of Teachers, and the National Education Association (NGSS Lead States, 2013c). Organizations from the science and engineering communities have also endorsed the new standards, including the American Chemical Society and the American Society of Mechanical Engineers (NGSS Lead States, 2013c).

A set of standards are a political document and an attempt to create accord amongst stakeholders; consensus among educators, scientists, and communities requires agreement of the goals of science education (Anderson, 2002). The central mission of the NGSS development team was to improve science education, and in turn, society (NGSS Lead States, 2013d; Tyack \& Cuban, 1995). Though Cuban (2013) argues "any newly published science framework will be 
only the initial link in the structural policy-to-practice chain of intended-taught-learned-tested curricula that characterizes U.S. schooling" (p. 52). Cuban's (2013) findings suggest that developing a new science curriculum with the intent to significantly change established classroom practices does not automatically reform teaching or learning. Cuban (2013) in Inside the Black Box of Classroom Practice, provides an excellent example of the discrepancies between beliefs and actions of a practitioner. The practitioner was observed in the mid-1990s, taught fourth and fifth grade and had thirty years of classroom experience:

She described using lectures and "hands-on" experiences as her primary instructional techniques. Throughout the interview, she used the term "hands-on eleven time in reference to her classroom. She claimed she had a "full science program" and emphasized "hand-on/minds-on" learning, where students could complete an investigation to answer their own questions, and "get critical thinking across to them." She noted the use of textbooks as supplemental materials to lectures and state achievement tests as influential to the content covered in her class. (Cuban, 2013, p. 48) When he observed her classroom, he found reading information as the primary teaching strategy, with a few brief demonstrations. Reform does not necessarily equal change. Requiring the K-12 science teachers to decipher exceedingly confusing directives of what to teach, how to teach, and how to assess in the classroom with minimal support and professional learning opportunities may sound the death knell for a reform.

The Framework (National Research Council, 2011) emphasizes the importance of connecting students' classroom experiences to their interests and everyday lives. The performance expectations of the NGSS organize the three dimensions into workable intended outcomes for K-12 science teachers and set the tone for the creation of learning progressions and 
a coherent instructional program. The three-dimensional learning model of the NGSS integrates disciplinary content and inquiry, therefore, if instruction is aligned to the NGSS, students will have the opportunity to engage in multiple practices for a deeper understanding of disciplinary content throughout a learning progression (Pruitt, 2014).

While inquiry practices are predominant in recent reform documentation, the misconceptions and multiple meanings of inquiry make it less commonplace in the science classroom (Demir \& Abell, 2010). The integration of content and science and engineering practices is an important part of the vision of the NGSS and what is means to be proficient in science (NGSS Lead States, 2013f; National Research Council, 2011; Pruitt, 2014). For the student, the science and engineering practices dimension requires the development and use of scientific ideas to solve problems and explain phenomena of the natural world (NRC, 2015). For the teacher, science and engineering practices dimension of the NGSS provides an inquiry-based model of instruction (NGSS Lead States, 2013f; NRC, 2012). The scientific and engineering practices of the NGSS are considered synonymous with inquiry (NRC, 2011). Not providing students with opportunities to engage in inquiry-based activities can suggest to students that science is a merely set of sequestered facts (National Research Council, 2011). An approach to instruction based on driving questions, real world phenomena, and student led investigations is nearly impossible by a traditional, teacher-centered model (Blumenfeld et. al, 1994). Though the science and engineering practices of the NGSS were designed to clarify how inquiry is to be enacted in the classroom, the professional development required to dispel teachers' engrained misconceptions may be significant (Clough \& Kruse, 2010). 


\section{Reform within the Classroom}

Kliebard (2002) argues reforms which require significant shifts in the day-to-day practices of K-12 teachers will most likely fail. K-12 teachers respond to the pressures from the institutional environment in multiple ways, though societal conceptions of teaching and learning tend to hold K-12 teachers' classroom practices in place when faced with reforms (Bidwell, 2001; Metz, 1989). Some experienced educators argue reforms labeled as new solutions re-cycle through as new reformists rebrand them (Tyack \& Cuban, 1995). Veteran teachers who have witnessed the ebb and flow of reform can become disillusioned and alienated by the process, actions reformists may deem as resistance (Tyack \& Cuban, 1995). However, as schools change with reform trends, the student population is different, situated in a different time, and therefore the context is different, so the cycle of reform does not wholly repeat itself (Elmore \& McLaughlin, 1988; Slavin, 1989). Thus, the implementation of a similar reform policy may not necessarily yield the same results. According to Cuban (2013) science teachers within the same building may be observed teaching varying versions of the same standards and predominant pedagogy.

Determining the success or failure of a new set of standards or intended curriculum is exceedingly difficult when hybridized into an existing contextualized curriculum that varies from one classroom to the next. Though history suggests otherwise, reformers continue to assume changing school structures will alter the teaching contingent, which will ultimately lead to improved and permanent changes in classroom practices (Cuban, 2013). For better or worse, when policies or practices deviate too far from what our cultural understanding of school is, staunch opposition tends to follow (Tyack \& Cuban, 1995). Certain contemporary reform measures, such as online schooling programs, seem to be aimed at significantly amending 
current school structures. Though despite nearly a century of a reform agenda by those who have the monetary and societal clout to get decision makers' attention, the locus of schooling the teacher and daily classroom practices, has been very slow to change (Boyd, 1988; Tyack \& Cuban, 1995).

\section{Teacher-Centered Systemic Reform}

The TCSR model recognizes teachers' knowledge and beliefs, their personal backgrounds, and the contextual factors that influence their practices and provides a framework built from the interrelatedness of the varying perspectives of reform (Woodbury \& GessNewsome, 2002). Teachers' thinking and actions are intrinsically linked and their actions in the classroom must change if teaching and student learning is to improve (Cohen \& Ball, 1990, p. 233). The model provides an appropriate framework to organize the contextual and personal factors that influence practitioner thinking and actions, and in turn, reform efforts (Woodbury \& Gess-Newsome, 2002). Thus, examining teachers' perspectives on a reform effort is vital to understanding how a reform will be enacted within the classroom. Tapping into teachers' thinking is valuable for those organizing or providing professional learning for teachers, so teachers have professional learning opportunities that are truly useful for their practice.

The TCSR model suggests, in essence, that school change is primarily about teacher change (Woodbury \& Gess-Newsome, 2002). A practitioner's beliefs related to students, learning, teaching, and the purpose of education may be the most deeply rooted barrier to changing classroom practices (Anderson, 2002). Though it is possible for K-12 science teachers to alter deep-rooted ways of operating, such changes require relevant and sustained professional learning experiences that provide opportunities for collaboration with colleagues and personal reflection (Anderson, 2002). Professional development is often perceived by teachers as 
irrelevant to the real problems of classroom practice (Lieberman \& Mace, 2008). Teachers focus on what works in their classrooms, particularly classroom management and student engagement; practical knowledge supersedes theoretical knowledge (Marx et al., 1996). Supovitz and Turner (2000) found that only after eighty hours of professional development, teachers reported using practices presented in the training they attended. Collaborative opportunities for professional learning and development are crucial to K-12 science teachers' understanding of innovative instructional models, though practicing the new methods in their own classroom is critical; opportunities to reflect upon their practices may allow teachers to shift their thinking and become more accepting of new methods (Schön, 1987). The lack of time spent on effective teacher learning, including collaboration amongst colleagues, may definitively influence the inconsistent implementation of a reform policy (Spillane, 2001).

\section{Teacher Thinking and Action}

The TCSR model situates teacher thinking as a pivotal reform factor and acknowledges the influence personal and contextual factors have on the classroom-level enactment of a reform (Woodbury \& Gess-Newsome, 2002). Teacher thinking is empirically grounded in the following premises: a) practitioner knowledge and beliefs work concurrently and are difficult to isolate from one another, and b) beliefs are powerful and exceedingly difficult to change, even when challenged by conflicting evidence (Pajares, 1992). Traditionally, K-12 science teachers, and to an extent, building administrators, almost exclusively decide whether a policy is reflected in the experiences of students (Spillane, 2000). K-12 science teachers continue to maintain a moderate degree of autonomy within the four walls of their classrooms and may choose to hybridize new practices with time-tested favorites (Tyack \& Cuban, 1995). K-12 science teachers tend to merge ideas and practices learned through professional development into their current 
pedagogical repertoire, the innovations "filtered through a very traditional approach to instruction" (Cohen, 1990, p. 311). The personal factors component of the TCSR framework includes teachers' demographics, professional experiences, original preparation program, and continuing professional learning, all of which contribute to teachers' thinking and actions (Woodbury \& Gess-Newsome, 2002). Educators tend to adhere to old policies and continue to use practices simply because they have always been done in a certain way, not necessarily because the practices yield superior results (Guskey \& Bailey, 2009).

Cuban (2013) considers the adoption of new standards and instructional pedagogy as fundamental change. Similarly, Watzlawick et al., 1974/2011 defined this type of instructional shift as a second order change, or "a change to an altogether different state" (p. 10). Updated standards may be perceived by K-12 science teachers to be a first order change (Watzlawick et al., 1974/2011), an incremental shift in current practices. Standards-based reform is based upon systemic reform (Grant, Peterson, \& Shogreen-Downer, 1996). K-12 science teachers may view new standards as only minor change, which may contribute to the organizational environment's dynamic conservatism (Schön, 1973), where K-12 science teachers are continually bombarded by the organization's existing climate (Argyris, Putnam, \& McLain-Smith, 1985). Contrary to misguided and misinformed assumptions of some policymakers, the vast majority of educators are not lazy or wholly resistant to change, but do prefer to keep to their school's status quo (Fibkins, 2015). The intended results of the NGSS is a discernable shift in patterns of science education (NGSS Lead States, 2013a; Penuel et al., 2015; Pruitt, 2014). The NGSS are a second order change; if implemented as the authors intended, new ways of thinking, organization, and actions are required. 


\section{Support for K-12 Science Teachers}

K-12 science teachers require a sound organizational foundation provided by administrators and policymakers to do their best (Cuban, 2013). Assessments linked to new standards have a tendency to motivate school administrators to focus on updating content and instruction; when reinforced by other policies, districts can successfully influence the content of instruction, though changing teachers' pedagogical strategies tend to be more difficult (Fairman

$\&$ Firestone, 2001). Local district leaders must have the capacity to support educators' abilities to implement reforms as proficiently as possible, especially when the reforms call for a significant shift in how content is taught within the classroom (McLaughlin, 1987; Spillane \& Thompson, 1997). By adopting the NGSS, state policymakers are, in essence, expecting teachers to change their established classroom practices to align with a new set of expectations, possibly without taking into account the contextual factors that exist and influence a teacher's thinking and actions.

\section{Professional Development}

Grant, Peterson, and Shojgreen-Downer (1996) found standards-based reforms are less than successful at changing teachers' behaviors and instructional practices. There is evidence that fundamental shifts in education cannot be achieved quickly, and professional learning experiences must build upon existing effective practices (Anderson, 2002; Black \& Wiliam, 1998). K-12 science teachers are not passive participants; they must have the capacity for and be open to changing their methods and perspectives (Fairman \& Firestone, 2001). Shaped by their knowledge and beliefs, teachers ultimately decide how to enact mandated policies in their classrooms (Spillane, 2000). 
A central tenet of SBR is a system of support created to help teachers enact the reform (Smith \& O’Day, 1990). Though elementary, middle, and secondary science teachers have divergent dealings with the disciplinary content they teach, nevertheless, all must possess enough science content knowledge to provide meaningful educational experiences for students (GessNewsome, 1999; Penuel et al., 2015). Professional learning focused on the development of content knowledge was found to have a substantive impact of student learning (Kennedy, 1998). In other words, a practitioner can only shift practices once she develops a deeper understanding of the content (Spillane, 2000). Cohen and Hill (1998) found professional development opportunities associated with the effective implementation of standards were directly related to the content students were taught and multiple instructional models. Though a science practitioner's content knowledge may be a predictor of the impact of instruction on student achievement, curricular materials and instructional methods tend to be the conveyor of choice for reformers focused on improving student learning (Supovitz, 2001; Supovitz \& Turner, 2000). Woodbury's (2000) findings suggest the combination of K-12 science teachers' understanding of the need for reform and their content knowledge affects their response to reform implementation.

\section{Summary}

The study's framework was structured around the interconnectedness of the various perceptions of change and provides a systemic representation of education reform. The TCSR model recognizes the interaction among teachers' thinking, their backgrounds, established classroom practices, and the contexts of their work as the critical influences on reform implementation efforts (Woodbury \& Gess-Newsome, 2002). Teacher thinking permeates their decisions, though how this thinking influences classroom practices is not fully understood (Pajares, 1992). This study examined educators' attitudes and perceptions of the NGSS, changes K-12 science 
teachers have made to their classroom practices, and barriers to implementation. Keys and Bryan (2001) suggest standards-based reform practices within the context of the beliefs and understandings of teachers be examined. Woodbury and Gess-Newsome (2002) found that responses to reforms were affected by teachers' content knowledge and their perceptions of whether reform was necessary. This study will explore the factors that contribute to or inhibit the changes to science K-12 science teachers' response the NGSS reform. This study may offer insights for researchers, policymakers, K-12 science teachers, and administrators. The findings may inform professional development providers and other supports for classroom K-12 science teachers.

Will the fate of the NGSS be any different from previous attempts at reforming the science classroom? Cuban (2013) found the following patterns among previous reforms to improve science education:

- Persistent uncertainty over the primary purpose of science education, how best to teach the subject and assess student learning.

- Plans for restructuring science curricula have consistently come from the top of the policymaking pyramid.

- Top-down designs for restructuring science education have run afoul within the multilayered system of U.S. schools. (p. 74)

Although NGSS three-dimensional design is grounded in the most current research on science education, NGSS documentation iterate the competing purposes of science education of previous standards (Cuban, 2013; NGSS Lead States, 2013b; NRC, 2011). Although teachers were involved in the collaborative development and revision process, the NGSS reform was not initiated by teachers and therefore is considered a top-down reform (Cuban, 2013; NGSS Lead 
States, 2013). The design of the NGSS may be progressive in nature, as instruction is built upon student questioning and exploration of phenomena, the funding of the NGSS by the Carnegie Foundation. Such private funding of the NGSS effort is similar to the funding other reforms efforts of the $20^{\text {th }}$ century, who have been described as highly educated civic elites whose aims are to improve education (Tyack, 1974). The weakness of the non-political reform movement may be evident by the relatively low adoption rate by state education agencies, with only 20 states fully adopting the NGSS (Mehta, 2013). As other states draw upon the research of the NGSS and Framework to rewrite their standards, the true impact of the reform may yet to be understood (Reiser et al., 2017). 


\section{CHAPTER III: METHODOLOGY}

This study investigated five research questions related to the implementation of the Next Generation Science Standards from the self-reported perspectives of K-12 science teachers:

1. What is the level of familiarity with and understanding of the Next Generation Science Standards among K-12 science teachers?

2. What are the attitudes and levels of agreement concerning the NGSS among K-12 science teachers?

3. What changes, if any, have K-12 science teachers made to their classroom practices (pedagogy, curriculum, and assessment) in response to the NGSS reform?

4. What barriers prevent classroom K-12 science teachers from implementing the NGSS as intended by those who developed the standards?

5. What are the relationships between K-12 science teachers' familiarity, attitudes and levels of agreement with the standards, barriers to implementation, and the degree of change to classroom practices in response to the NGSS reform?

The research questions were developed to examine the personal and organizational factors that diffuse into teachers' thinking and practices and how they relate to the implementation of the NGSS. The purpose of this chapter was to delineate the research design of the study, provide an explanation of the sample selection, describe the survey instrument and data collection process, and provide an explanation of the statistical procedures to be used for the data analysis.

\section{Research Design}

A cross-sectional survey research design - the data to be used collected at one point in time - was used for this study (Creswell, 2014). Although qualitative studies have been 
conducted to develop a general understanding of the complex system that is the school classroom (Black \& Wiliam, 2010; Cuban, 2013), this quantitative study provided cross-sectional data related to the perceptions and actions of K-12 science teachers during the transition to the NGSS. The purpose of survey research was to collect data from a selected sample of individuals to make inferences or generalizations about a population too large to observe directly (Creswell, 2014). The survey was distributed electronically. Online surveys are an efficient, cost effective, and confidential method to collect information (Creswell, 2014; Rossi, Wright, \& Anderson, 2013). Though some scholars are skeptical of the use of surveys to collect data on teacher practices, surveys are a generally accepted tool in educational research (Desimone, 2009; Rossi et al., 2013). A survey research design is an appropriate method for a study that is ideally representative of a larger population.

Educators' responses to efforts to significantly change the schooling experience for students may vary; the interaction between personal and contextual factors are concretized in a practitioner's thinking and actions (Woodbury \& Gess-Newsome, 2002). Therefore, teachers' self-reported understandings and attitudes are relevant to a comprehensive understanding of how they respond to reform (Education Week, 2001; Pop et al., 2010; Spillane \& Zeuli, 1999).

\section{Population and Sampling Procedures}

The NGSS were designed to reflect a new conception for U.S. science education (Pruitt, 2014). If the standards are implemented as the developers intended, significant shifts may be required to many K-12 science teachers' classroom practices (NGSS Lead States, 2013a; Pruitt, 2014). This study examined how K-12 science teachers perceive the most recent reform effort to affect the classroom and what changes, if any, have K-12 science teachers made to their classroom practices. Though the science educators who were invited to complete the survey 
teach in diverse situations, all are in a similar predicament; many teachers are likely amending their curriculum and practices to meet the demands of the NGSS. Teachers' perspectives have been shaped by the complex reality in which they reside (Gess-Newsome, Southerland, Johnston \& Woodbury, 2003; Glesne, 2011). By gaining access to the perspectives of multiple members of the same organization, patterns of individual perspectives may lead to better understanding of an issue or problem (Creswell, 2008; Glesne, 2011).

The population for this study was K-12 science teachers who are members of the National Science Teachers Association (NSTA). The organization boasts a membership of over 55,000 science educators, administrators, and industry representatives (NSTA, 2016). An email list has been created specifically for the sharing of information related to the NGSS. The email listserv provides a platform for professional discussions and collaboration (NSTA, 2016). The sample, a non-representative subset of the population were the teachers who subscribed to the NGSS listserv. The number of NSTA members who subscribed to the email listserv is unknown, so determining an accurate sample size is difficult. There is considerable variation on what is an acceptable response rate for online surveys. There is a distinct lack of education research that directly addresses this metric. The medical field provided more insight. Keeney, McKenna, and Hasson (2010) consider a response rate of 70\% to be acceptable. Vanderhoek et al. (2013) indicate a $44.2 \%$ response rate is well within acceptable range. Although this type of sampling is considered a convenience sample due to the accessibility of the list by the researcher, the email list server subscribers most likely reflect the characteristics of the population and the NGSS list server provides an appropriate sampling frame for potential respondents. 


\section{Instrumentation}

The items on the researcher-designed survey instrument were compiled from a comprehensive review of related literature and discussions with K-12 science teachers in the field. The survey was organized into five sections based upon the TCSR framework. The TCSR model framework connects teachers' knowledge, beliefs, personal and contextual factors and elucidates the influence these factors have on classroom practices (Woodbury \& Gess-Newsome, 2002).

The survey (Appendix A) consisted of eight categorical questions, 36 Likert-scale type questions, and four open-ended questions. Section 1 consisted of eight questions and was designed to collect pertinent professional and contextual factors from the participants. Section 2 consisted of seven items and two open-ended questions that asked about respondents' familiarity with the components of the NGSS and professional development attendance. The scale for six questions of Section 2 consisted of a 4-point Likert metric (strongly disagree, disagree, agree, and strongly agree). The scale for one question in survey Section 2 had four categories (less than one day, 1-2 days, 3-5 days, and more than 5 days) to determine the amount of professional learning respondents had attended. Section 3 consisted of 9 items related to teacher attitudes and levels of agreement with the NGSS. The scale in Section 3 was measured on a 4-point scale (strongly disagree, disagree, agree, and strongly agree). Section 4 consisted of three subsections and asked respondents about changes made at the classroom, school, and district level as a result of the NGSS. The first subsection included three items questions related to classroom-level practices. Each item was measured on a 4-point response metric (not at all, minimally, moderately, and extensively). One open-ended question was included in the subsection and asked participants to provide an example of a change made to instructional strategies, 
curriculum, or assessments to align with the NGSS. The second and third subsections asked participants about school-level and district-level changes that have been made to align with the NGSS. The response scale of the subsections included an additional category (I do not know). Section 5 included eight items that asked respondents about factors that have acted as barriers to the implementation of the NGSS. One open-ended question was included in Section 5 that asked teachers to describe the primary barriers that have limited the implementation of the NGSS.

\section{Variables in the Study}

Teachers' personal factors, the demographic and professional information of the participants, were obtained from Section 1 of the instrument and served as the independent variables - the variable that affects or influences the outcome - for the subsequent analyses (Creswell, 2014). A one-way analysis of variance (ANOVA) is an appropriate statistical test as it examines the variance between groups and the variance within groups (Creswell, 2008). A series of ANOVAs were conducted to examine the variance between and within group responses to Likert-scale items related to the familiarity with the NGSS standards, attitudes and level of agreement with the NGSS, changes to teacher practices, and barriers to implementation of the new standards.

A dependent variable is a characteristic influenced by the independent variable (Creswell, 2008). The dependent variables for this study include the items related to familiarity with the NGSS standards, attitudes and level of agreement, changes to teacher practices, and barriers to implementation in Sections 2 and 3 of the survey. The ordinal-level data from these sections will be treated as interval data for analysis purposes, as it has become common practice in educational research (Creswell, 2008). Though some researchers consider Likert-type scales as 
strictly ordinal data (Jamieson, 2004), others consider the errors for treating such item responses as interval data to be minimal (Jaccard \& Wan, 1996).

\section{Pilot Study}

A pilot study was conducted to determine the reliability, validity, and functionality of the researcher-designed instrument; the questionnaire was administered to a small subsample of the target population (Creswell, 2014). The instrument was piloted by seven science teachers that were independent of the larger sample. The teachers who piloted the survey teach in central Illinois public schools and were invited to complete the questionnaire via email. Participants of the pilot teach at various grade levels and content areas. As a result of the pilot, several changes were made to the content of the survey. Two questions were removed from Section 1 of the survey. The response scales of Section 4 and 5 were slightly adjusted for consistency purposes. Minor wording changes to the survey were made based on the results of the pilot to clarify items and correct typographical errors. Cronbach's alpha was used to assess the measurement reliability of the items of each scale of the pilot and yielded satisfactory results of 0.82 (Tavakol \& Dennick, 2011).

\section{Ethical Considerations}

Teacher identifiers will not be requested or collected as part of the survey. A letter of informed consent will be included as the first page of the online survey (Appendix B). Consent will be assumed if the participant completes and submits the survey, as the research presents no more than minimal risk of harm to subjects and involves no procedures from which consent is normally required outside of the research context. The recruitment and consent letters inform participants on how their rights and privacy will be maintained. It is important to keep respondents' identity confidential to maintain and ensure their privacy; utilizing an anonymous 
survey method follows the strictest interpretation of anonymity (Glesne, 2011). To obtain this classification, the investigator cannot know the identities of any responding participants, even if there is no ability to link participant identities to their responses (Glesne, 2011).

\section{Data Analysis}

Several statistical tests were conducted to identify the nature and extent of any possible relationships or statistical significance among the study's variables. Initial data cleaning consisted of reviewing survey responses for completeness and correctness. The SPSS statistical program was used to analyze the data.

Descriptive, univariate statistical analyses were conducted to obtain a clear understanding of the sample of survey respondents. Group frequencies for the categorical variables and measures of central tendency and score dispersion (variance, standard deviation and range) for the continuous variables were calculated.

Research question one was addressed by examining the level of familiarity with and understanding of the NGSS (dependent variable) and grade level currently teaching (independent variable), content area current teaching (independent variable), degree level (independent variable) and years of teaching experience (independent variable). A series of ANOVAs was conducted to examine the variance between and within group responses to the items in Section 1.

Research question two was addressed by examining the levels of agreement amongst teachers concerning the NGSS (dependent variable) and grade level currently teaching (independent variable), content area currently teaching (independent variable), degree level (independent variable) and years of teaching experience (independent variable). A series of ANOVAs was conducted to examine the variance between and within group responses. 
A second series of ANOVAs was conducted to evaluate differences between the amount of professional development experiences attended by participants and responses to Likert-scale items in sections two, three, four, and five.

Research question three was addressed by investigating the changes K-12 science teachers have made to their classroom practices in response to the NGSS (dependent variable) and the grade level currently teaching (independent variable), content area currently teaching (independent variable), degree level (independent variable) and years of teaching experience (independent variable). A series of ANOVAs was conducted to examine the variance between and within group responses.

Research question four was addressed by investigating the barriers that are preventing K12 science teachers from implementing the NGSS (independent variable) by grade level currently teaching (independent variable), content area currently teaching (independent variable), degree level (independent variable) and years of teaching experience (independent variable). A series of ANOVAs was conducted to examine the variance between and within group responses.

The purpose of the fifth research question in this study was to identify what relationships, if any, existed between K-12 science teachers' familiarity, attitudes and levels of agreement with the standards, barriers to implementation, and the degree of change to classroom practices in response to the NGSS reform. The final set of analyses used Pearson's correlation coefficient to calculate the association between the degree of change in classroom practices (dependent variable) and teacher familiarity with the NGSS (independent variable), teacher attitudes and levels of agreement concerning the NGSS (independent variable), and barriers to implementation of the NGSS (independent variable) as measured by the survey instrument. 


\section{CHAPTER IV: FINDINGS}

The purpose of this study was to better understand the reform policy implementation process from the self-reported perspectives of K-12 science teachers. Specifically, this national study centered on educators' familiarity with and perceptions of the NGSS, implementation of the new standards in the classroom, and potential barriers to implementation. This survey study was designed to explore the factors that contribute to or inhibit the changes to K-12 science teachers' curriculum and instructional practices in response the NGSS reform. The variance amongst responses was based on years of teaching experience, the level of education obtained by the participant, whether they taught general science or content area specific courses, grade level(s) taught and the amount of professional learning experiences attended.

This quantitative study was directed by five research questions concerning the implementation of the Next Generation Science Standards (NGSS) from the self-reported perspectives of K-12 science teachers:

1. What is the level of familiarity with and understanding of the Next Generation Science Standards among K-12 science teachers?

2. What are the attitudes and levels of agreement concerning the NGSS among K-12 science teachers?

3. What changes, if any, have K-12 science teachers made to their classroom practices (pedagogy, curriculum, and assessment) in response to the NGSS reform?

4. What barriers prevent classroom K-12 science teachers from implementing the NGSS as intended by those who developed the standards? 
5. What are the relationships between K-12 science teachers' familiarity, attitudes and levels of agreement with the standards, barriers to full implementation, and the degree of change to classroom practices in response to the NGSS reform?

\section{Study Sample}

The online survey was distributed nationwide by a professional organization's NGSSoriented listserv in October 2017. Participants were solicited to complete the survey over a twoweek timespan; a total of three reminder emails were sent. The NGSS listserv guidelines were strictly adhered to throughout its use of inviting teachers to participate in the study. Surveys were collected over the two-week period the survey was available. Although classroom teachers were the population of interest, instructional coaches and higher education faculty also completed the survey. A response rate is difficult to determine due to the unknown number of subscribers to the NGSS listserv. Repeated attempts to collect this information from the professional science teachers' organization failed. Participants retained their anonymity throughout the process. No names, emails or other identifiers were collected. Participants received no compensation for their participation.

A total of 110 surveys were considered usable for the study. Section 1 of the survey consisted of eight demographic and professional items (Appendix C). The respondent's educational role demographics are shown in Table 1 . Of the 110 respondents, $80 \%(n=88)$ identified themselves as classroom teachers. 
Table 1

Current Role in Education

\begin{tabular}{lcc}
\hline Groups & Number & Percent \\
\hline Classroom Teacher & 88 & 80 \\
Higher Education Faculty Member & 10 & 9 \\
Instructional Coach & 4 & 3.6 \\
District Office Personnel & 4 & 3.6 \\
Other & 4 & 3.6 \\
\hline Total & 110 & $100 \%$ \\
\hline
\end{tabular}

Teachers in 33 states completed the survey, representing 14 of the 20 states (74\%) that have adopted the NGSS (NSTA, 2014); teachers from Delaware, Hawaii, Kentucky, Maryland, Nevada, and Vermont did not participate in the survey. Open-ended questions in subsequent sections of the survey provided insight into the responses of participants from states that have not adopted the NGSS explained that their state has adopted standards similar to the NGSS or that they are changing their practices even though their state has not adopted the standards.

Eighty-five percent $(n=75)$ of the 88 classroom teachers who completed the survey work at a public school. Thirteen percent $(n=11)$ teach at a private or parochial school, while the remaining two percent $(n=2)$ teach at a charter school. The school configurations of the survey respondents is shown in Table 2. Forty-five percent of participants $(n=40)$ reported teaching at the secondary level, while the remaining responses expound the myriad of school configurations that exist across the country. 
Table 2

School Configuration

\begin{tabular}{lcc}
\hline School Configurations & Number & Percent \\
\hline $9-12$ & 40 & 45 \\
$6-8$ & 14 & 16 \\
PreK-8 & 7 & 8 \\
PreK-5 & 7 & 8 \\
PreK-12 & 6 & 7 \\
Other & 6 & 7 \\
$5-8$ & 4 & 5 \\
$7-8$ & 2 & 2 \\
PreK-6 & 2 & 2 \\
\hline Total & 88 & $100 \%$ \\
\hline
\end{tabular}

The number and percentages related to teachers' responsibility for specific content areas are shown in Table 3. Nineteen percent $(n=17)$ of respondents marked general science, while the remaining teachers selected at least one disciplinary content area. Over a third of the participants $(33 \%)$ indicated they were responsible for teaching more than one content area. 
Table 3

Content Area

\begin{tabular}{lcc}
\hline Content Areas & Number & Percent \\
\hline Life Sciences & 18 & 20 \\
General Science & 17 & 19 \\
Physical Sciences & 12 & 14 \\
Life Sciences, Physical Sciences, \& Earth Sciences & 10 & 11 \\
Life Sciences \& Physical Sciences & 9 & 10 \\
Earth Sciences & 8 & 9 \\
Physical Sciences and Earth Sciences & 5 & 6 \\
General Science \& Content Specific Courses & 5 & 6 \\
Life Sciences \& Earth Sciences & 4 & 5 \\
\hline Total & 88 & $100 \%$ \\
\hline
\end{tabular}

Of the 88 classroom teachers who completed the survey, $74 \%(n=65)$ indicated they have 10 or more years of professional experience; $39 \%(n=34)$ teachers selected 20 or more years of experience on the survey (Table 4). The majority of respondents $78 \%(n=69)$ have earned a master's degree (Table 5).

Table 4

Years of Teaching Experience

\begin{tabular}{lcc}
\hline Years of Experience & Number & Percent \\
\hline 0-4 years & 6 & 7 \\
5-9 years & 17 & 19 \\
10-14 years & 13 & 15 \\
15-19 years & 18 & 20 \\
20+ years & 34 & 39 \\
\hline Total & 88 & $100 \%$ \\
\hline
\end{tabular}


Table 5

Education Level

\begin{tabular}{lcc}
\hline Degree & Number & Percent \\
\hline Bachelors & 13 & 15 \\
Masters & 69 & 78 \\
Doctorate & 6 & 7 \\
\hline Total & 88 & $100 \%$ \\
\hline
\end{tabular}

Teachers' demographics and experiences, their personal factors, contribute to their thinking and actions (Woodbury \& Gess-Newsome, 2002), and thus examining the variance between and within group responses to the survey responses was warranted.

\section{Data Analysis}

Sections two, three, four and five of the online survey were comprised of questions organized by research question (Appendix C). Cronbach's alpha was used to assess the measurement reliability of the items of each response scale, and all items yielded satisfactory results of 0.70 or higher (Tavakol \& Dennick, 2011). Twenty percent $(n=22)$ of the 110 completed surveys were not included in the subsequent analyses, as the respondents indicated that they were not classroom teachers. Although the responses of higher education faculty and instructional coaches provided insight into the NGSS reform process, their responses are beyond the scope of this study.

\section{Results}

\section{Research Question One}

Descriptive statistics. The first research question addressed respondents' level of familiarity with the NGSS. Six items were included in this section of the survey. A 4-point Likert scale with ordered responses of 1-strongly disagree, 2-disagree, 3-agree, and 4-strongly 
agree was used to determine participants' reported understanding of the dimensions and performance expectations of the NGSS. Table 6 contains the mean scores and standard deviations for the items included in Section 2 of the survey.

Table 6

Familiarity with the NGSS Items

\begin{tabular}{lccc}
\hline Item & $\mathrm{N}$ & Mean & SD \\
\hline $\begin{array}{l}\text { 1. Familiarity with performance expectations } \\
\text { of grade level }\end{array}$ & 88 & 3.32 & 0.74 \\
2. Familiarity with S\&E Practices & 88 & 3.40 & 0.80 \\
3. Familiarity with Cross Cutting Concepts & 88 & 3.38 & 0.73 \\
4. Familiarity with Disciplinary Core Ideas & 88 & 3.38 & 0.76 \\
5. Comfortability with NGSS to create full & 87 & 2.82 & 0.93 \\
$\quad \begin{array}{l}\text { instructional plans } \\
\text { 6. Preparedness level and professional }\end{array}$ & 86 & 2.70 & 1.00 \\
\hline
\end{tabular}

For question one of the survey, respondents were asked to determine their level of familiarity with the performance expectations of the NGSS for their grade level. Participants reported a mean of $3.32(\mathrm{SD}=0.74)$ representing responses of slightly higher than agree on the response scale. These results indicate that participants are generally familiar with the performance expectations component of the NGSS.

For question two, respondents were asked to determine their level of familiarity with the science and engineering practices dimension of the NGSS. Participants reported a mean of 3.40 $(\mathrm{SD}=0.80)$ representing slightly higher than agree on the response scale. Item two reported the highest mean of Section 2.

For question three of the survey, respondents were asked to determine their level of familiarity with the cross cutting concepts dimension of the NGSS. Participants reported a mean 
of 3.38 ( $\mathrm{SD}=0.73)$ representing slightly higher than agree on the response scale. The results indicate that respondents are slightly less familiar with the cross cutting concepts dimension of the NGSS than the science and engineering practices dimension.

For question four of the survey, respondents were asked to determine their level of familiarity with the disciplinary core ideas dimension of the NGSS. Participants reported a mean of $3.38(\mathrm{SD}=0.76)$ representing slightly higher than agree on the response scale. On average, respondents are equally familiar with two of the three dimensions of the NGSS.

For question five, participants were asked to assess their comfort level using NGSS to create full instructional plans. Participants reported a mean of $2.82(\mathrm{SD}=0.93)$ representing less than agree on the response scale. The results indicate though respondents are familiar with the components of the NGSS, they are less confident using the NGSS to create instructional plans for the classroom at the time of survey completion.

For question six of the survey, participants were asked to evaluate their level of preparedness to teach to the NGSS as a result of their professional development activities. Respondents reported a mean score of $2.70(\mathrm{SD}=1.00)$ representing less than agree on the response scale. The mean score for this item was the lowest in this section of the survey.

Creation of index scores. Prior to discussing the results of the analyses of variance, it is necessary to describe the creation of the indices used in the subsequent analyses. According to Vogt and Johnson (2011), an index is a type of composite score in which "a group of individual measures that, when combined, are meant to indicate some more general characteristic" (p. 178). The online survey was comprised of several sections of questions that were used to create indexes so as to better assess the concept in question. A familiarity index was created with the six questions in Section 2 (questions 9-14) by summing the individual responses to the six 
questions and dividing by six, thus creating an average familiarity score for each respondent. Similar indexes were created from the nine questions (questions 18-27) in Section 3 (Attitudes index), and the eight questions in Section 5 (questions 37-44) in Section 5 (Barriers index).

Differences between and within groups. The items for the section were developed from the components of the NGSS. A 4-point Likert scale with ordered responses of 1-strongly disagree, 2-disagree, 3-agree, and 4-strongly agree was used to measure the reported familiarity with the three dimensions of the NGSS, the performance expectations, and the use of the components for planning purposes. The responses were treated as interval-level items, as there may be variation between respondents' level of agreement within the response level of the scale for each item.

A series of ANOVAs was conducted to evaluate the differences between responses to the six items in Section 2 of the survey related to the level of familiarity and understanding of the components of the NGSS and professional and demographic variables collected from participants. An ANOVA is the appropriate analyses for these variables as the independent variable is measured at the interval level and the categorical dependent variable has more than two categories (Salkind, 2017). One statistically significant result was found (Table 7). Table 7

Mean Scores on Preparedness Level and Professional Development Activities as a Function of Participant Group

\begin{tabular}{lccccccccc}
\hline & \multicolumn{1}{c}{ Content Area Groups } \\
& \multicolumn{1}{c}{ Physical Science } & \multicolumn{2}{c}{$\begin{array}{c}\text { General } \\
\text { Science }\end{array}$} & \multicolumn{2}{c}{$\begin{array}{c}\text { Multiple } \\
\text { Content }\end{array}$} & \multicolumn{2}{c}{ ANOVA } \\
Familiarity Item & $\mathrm{M}$ & $\mathrm{SD}$ & $\mathrm{M}$ & $\mathrm{SD}$ & $\mathrm{M}$ & $\mathrm{SD}$ & $\mathrm{F}_{(4,81)}$ & $\mathrm{p}$-value \\
\hline $\begin{array}{l}\text { Preparedness Level } \\
\text { and PD Activities }\end{array}$ & $1.92_{\mathrm{a}, \mathrm{b}}$ & 1.00 & $3.06_{\mathrm{a}}$ & .85 & $2.88_{\mathrm{b}}$ & 1.00 & 3.73 & .008 \\
\hline
\end{tabular}

Note: Means in a row sharing subscripts are significantly different. 
The independent variable — content area currently teaching — included five groups (general science, life sciences, physical sciences, earth science, and multiple content areas). The dependent variable was survey item six-preparedness level as a result of professional development activities. The ANOVA was significant, $F_{(4,81)}, p=.008$. Post hoc comparisons (Bonferroni) found significant differences in the means between the physical science teachers, the general science teachers, and the teachers who indicated they taught multiple science content areas.

Open-ended question one. Eighty-nine percent $(n=76)$ of classroom teachers provided a response for the open-ended question in Section 2 of the survey. The question prompted respondents to provide an example of how they used the NGSS performance expectations to create an instructional plan. Though most of the responses provide insight into the planning practices of the responses, many participants did not directly refer to the performance expectations of the NGSS. Nevertheless, six themes related to creating instructional plans were identified amongst the participant responses.

Seventeen percent $(n=13)$ of responses mentioned referring to the disciplinary core ideas (DCIs) for curriculum planning instead of the performance expectations. Fourteen percent $(n=11)$ of responses were related to developing assessments that aligned with the performance expectations. Within the responses that mentioned assessments, rubrics and performance assessments were found to be sub-themes. Restructuring, redesigning, and rewriting curriculum was mentioned ten times. Eight percent $(\mathrm{n}=6)$ of responses described using backwards design as their method for planning new units and lessons. Nine percent $(\mathrm{n}=7)$ of respondents mentioned the use of phenomena to anchor and guide instruction. Lastly, bundling performance expectations to create units of study was mentioned four times by survey respondents. Three 
respondents responded negatively to the use of the NGSS performance expectations for planning purposes. One respondent described the performance expectations as useless for instruction.

Professional development activity. One question within Section 2 of the survey asked respondents to indicate the total amount of professional development they received/attended related to classroom implementation of the NGSS. The frequencies of respondents' completion of professional development activities are shown in Table 8.

Table 8

Total Amount of Professional Development Received

\begin{tabular}{lcc}
\hline Level of PD & Number & Percent \\
\hline Less than one day & 19 & 21.6 \\
1 - 2 days & 19 & 21.6 \\
3 - 5 days & 14 & 15.9 \\
More than 5 days & 36 & 40.9 \\
\hline Total & 88 & 100.0 \\
\hline
\end{tabular}

Although 41\% $(n=36)$ of participants marked they had attended more than five days of professional development, $43 \%(n=38)$ indicated they had received two days or less. Nearly $60 \%$ of all respondents reported the attendance of fewer than five days of professional development related to the implementation of the NGSS. For subsequent statistical tests, this survey item will be treated as an ordinal variable, due to the response metric not representing equal distances between the categories (Creswell, 2008).

Differences between and within groups. A series of ANOVAs was conducted to evaluate differences between the amount of professional development attended by participants (Question 16) and responses to items related to familiarity with NGSS components. Four statistically significant results were found, all of which were found between the group who 
reported less than one day of professional development and respondents who reported more than five days of professional development attendance.

The first statistically significant result was found with the independent variable as the reported amount of professional development respondents had attended and responses to the survey question that queried participants' familiarity with the NGSS performance expectations as the dependent variable (Table 9). The ANOVA was significant, $F_{(3,84)}, p=.004$. Post hoc comparisons (Bonferroni) found significant differences in the means between the group who attended less than one day of professional development and the group of respondents who attended five or more days of professional development with a mean difference between treatment groups of 0.74 .

Table 9

Mean Scores on Four Measures of Familiarity with the NGSS as a Function of Participant Group

\begin{tabular}{lcccccc}
\hline & \multicolumn{5}{c}{ Professional Development Groups } \\
& Less than One Day & Five or More Days & \multicolumn{2}{c}{ ANOVA } \\
Familiarity Item & $\mathrm{M}$ & $\mathrm{SD}$ & $\mathrm{M}$ & $\mathrm{SD}$ & $\mathrm{F}_{(3,84)}$ & $\mathrm{p}$-value \\
\hline $\begin{array}{l}\text { Performance } \\
\text { Expectations }\end{array}$ & 2.84 & .83 & 3.58 & .65 & 4.82 & .004 \\
$\begin{array}{l}\text { Crosscutting Concepts } \\
\text { Disciplinary Core }\end{array}$ & 2.94 & .91 & 3.64 & .64 & 4.34 & .007 \\
$\begin{array}{l}\text { Ideas } \\
\text { Creating Instructional }\end{array}$ & 2.84 & .90 & 3.67 & .64 & 5.99 & .001 \\
Plans & 2.42 & .90 & 3.05 & .89 & 3.45 & .020 \\
\hline
\end{tabular}

The second statistically significant result was found between the reported amount of professional development respondents had attended (independent variable) and survey responses to the question that asked respondents about their familiarity with the NGSS crosscutting concepts dimension as the dependent variable (Table 9). The ANOVA was significant, $F_{(3,84) \text {, }}$ 
$p=.007$. Post hoc comparisons (Bonferroni) found significant differences in the means between the group who attended less than one day of professional development and the group of respondents who attended five or more days of professional development. The mean difference between the groups was 0.69 .

The third statistically significant result was found between the level of professional development respondents had attended and (independent variable) survey responses to the question that asked about their familiarity with the NGSS disciplinary core ideas dimension as the dependent variable (Table 9). The ANOVA was significant, $F_{(3,84)}, p=.001$. Post hoc comparisons (Bonferroni) found significant differences in the means between the group who attended less than one day of professional development and the group of respondents who attended five or more days of professional development with a mean difference of 0.82 .

The fourth statistically significant result was found between the reported amount of professional development respondents attended (independent variable) and their comfortability with creating full instructional plans aligned to the NGSS (Table 9). The ANOVA was significant, $F_{(3,83),} p=.020$. Post hoc comparisons (Bonferroni) found significant differences in the means between the group who attended less than one day of professional development and the group of respondents who attended five or more days of professional development. The mean difference between the two groups was 0.82 .

Open-ended question two. The second open-ended question (Question 17) asked survey participants to describe a NGSS professional development experience that was beneficial to their practice; 77 classroom teachers responded to the question. Four themes related to professional development opportunities were identified from the responses: institutions of higher education, professional organizations, workshops, and education agencies. 
Seventeen percent $(\mathrm{n}=13)$ of respondents described attending a workshop, institute, or grant project that prepared them to teach to the NGSS. Among these open-ended responses, the NASA Endeavour Project, the American Museum of Natural History, Next Generation Science Exemplar, Bozeman Science, National Cascades and Olympic Science Partnership, and the Museum of Science and Industry were specifically mentioned. The nine participants who mentioned professional organizations described webinars, excellence in science leadership cohorts, summer trainings, as well as state and national conference attendance as experiences beneficial to them for preparing to teach to the NGSS. Nine respondents referred to courses or programs provided by institutions of higher education as beneficial to the implementation of the NGSS in the classroom. Several respondents mentioned receiving grants or fellowships in order to attend the programs. Four respondents described their attendance of professional development provided by local or state education agencies. Several responses described the benefits of collaboration with other teachers. Five respondents reported not receiving any professional development related to the NGSS. Others described how the professional development provided was abbreviated or rushed. Others noted lack of funding of professional development for science teachers, even with the release of the NGSS.

\section{Research Question Two}

Descriptive statistics. Research question two queried respondents' attitudes and levels of agreement regarding various aspects of the NGSS. Nine questions (questions 18-26) were posed to survey respondents in Section 3 of the survey. A 4-point Likert scale with ordered responses of 1-strongly disagree, 2-disagree, 3-agree, and 4-strongly agree was used to measure the reported attitudinal responses to items that addressed standards-based reform as related to the 
NGSS. Table 10 shows the mean scores and standard deviations for the items included in Section 3 of the survey.

Table 10

Attitudes of Respondents Concerning the Next Generation Science Standards

\begin{tabular}{|c|c|c|c|}
\hline Item & $\mathrm{N}$ & Mean & SD \\
\hline $\begin{array}{l}\text { 1. The NGSS are easy to understand and use for development of } \\
\text { full instructional plans. }\end{array}$ & 87 & 2.80 & 0.88 \\
\hline $\begin{array}{l}\text { 2. Confidence to implement the NGSS as intended by those who } \\
\text { developed the standards. }\end{array}$ & 87 & 2.86 & 0.91 \\
\hline $\begin{array}{l}\text { 3. Changes brought about by the NGSS will be beneficial to } \\
\text { students. }\end{array}$ & 87 & 3.49 & 0.63 \\
\hline $\begin{array}{l}\text { 4. The NGSS will lead to permanent changes in teacher and } \\
\text { classroom practices. }\end{array}$ & 87 & 3.22 & 0.74 \\
\hline $\begin{array}{l}\text { 5. The three-dimensional design of the NGSS requires changes } \\
\text { in current practices. }\end{array}$ & 87 & 3.44 & 0.70 \\
\hline 6. The NGSS encompasses what science education should be. & 87 & 3.21 & 0.73 \\
\hline $\begin{array}{l}\text { 7. The NGSS better specifies what inquiry is and what it required } \\
\text { in the science classroom. }\end{array}$ & 86 & 3.16 & 0.78 \\
\hline $\begin{array}{l}\text { 8. The Framework for } K-12 \text { Science Education provides } \\
\text { information required to implement the NGSS. }\end{array}$ & 85 & 2.74 & 0.91 \\
\hline $\begin{array}{l}\text { 9. The NGSS can only be implemented when it is known what } \\
\text { the standardized assessment will encompass. }\end{array}$ & 87 & 2.38 & 0.97 \\
\hline
\end{tabular}

For the first question in the attitudinal section of the survey (question 18), respondents were asked to determine their level of agreement regarding the usability of the NGSS to develop instructional plans. Participants reported a mean of $2.80(\mathrm{SD}=0.88)$ representing disagree on the response scale. The mean response for this question was the third lowest in the attitudinal section of the survey.

For the second question in Section 3 of the survey (question 19), participants were asked to rate their confidence level in implementing the NGSS as the developers of the standards 
intended. Participants reported a mean of $2.86(\mathrm{SD}=0.91)$ representing disagree on the response scale. The coefficient of variation for this survey item was 0.32 , which indicates a low distribution of responses to the question.

The third question in the attitudinal section of the survey (question 20) asked participants whether the changes being brought about by the NGSS are beneficial to students. Respondents reported a mean of $3.49(\mathrm{SD}=0.63)$ representing agree on the response scale and indicating that respondents agree that the changes brought about by the NGSS are beneficial to students.

The fourth question in Section 3 of the survey (question 21) asked participants whether the NGSS will lead to permanent changes in teacher and classroom practices. The mean for the survey item was $3.22(\mathrm{SD}=0.74)$ indicating respondents agree with the survey item and the distribution of responses was low.

Survey question five in the attitudinal section of the survey (question 22) asked if the three-dimensional design of the NGSS (practices, crosscutting concepts, and disciplinary core ideas) requires teachers to change current classroom practices. The mean score of this survey item was $3.44(\mathrm{SD}=0.70)$ representing agree on the response scale and indicating a relatively high level of agreement amongst respondents.

Question six on the attitudinal section of the survey (question 23) asked respondents if the NGSS encompasses what science education should be at the grade level the practitioner is currently teaching. The mean for this survey item was $3.21(\mathrm{SD}=0.73)$ representing agree on the response scale. The coefficient of variation for this survey item is 0.23 , which indicates a very low distribution of responses to the question.

The seventh question in Section 3 of the survey (question 24) addressed inquiry in the science classroom. The item asked respondents whether the NGSS better specifies what inquiry 
is and what it requires in the classroom. Participants reported a mean of $3.16(\mathrm{SD}=0.78)$

representing agree on the response scale.

Question eight in Section 3 of the survey (question 25) asked respondents if the Framework for K-12 Science Education is required to implement the NGSS in the classroom. This item's mean was second lowest in the section at $2.74(\mathrm{SD}=0.91)$. The statistics indicate a lower level of agreement and a larger distribution by respondents for the survey item. Two participants chose not to answer this survey item.

The last question in the attitudinal section of the survey (question 26) asked respondents whether the NGSS can only be implemented when they know what the standardized assessment will encompass. Respondents reported a mean score of $2.38(\mathrm{SD}=0.97)$ representing disagree on the response scale, which was the lowest mean score of the section; the standard deviation of 0.97 for this survey item was the highest in Section 3 of the survey. One respondent chose not to answer the question.

Differences between and within groups. A series ANOVAs was conducted between the nine survey items in Section 3 that asked about respondents' attitudes related to the NGSS and professional and demographic variables collected from participants in Section 1 of the survey. The attitudinal scale items were developed based on existing research and pilot data related to teachers' perceptions and responses to reforms. A 4-point Likert scale with ordered responses of 1-strongly disagree, 2-disagree, 3-agree, and 4-strongly agree was used to measure the reported attitudinal responses to items that addressed standards-based reform as related to the NGSS. The responses were treated as interval-level items, as there may be variation between respondents' level of agreement within the response level of the scale for each item. 
Three cases of statistical significance were found. A statistically significant result was found between grade configuration (independent variable), and survey item responses to whether the Framework for K-12 Science Education is required to implement the NGSS in the classroom (Table 11). The ANOVA was significant, $F_{(3,84),},=.050$. Post hoc comparisons (Bonferroni) found a statistically significant difference in the means between the grouped respondents who teach at the elementary level and the grouped respondents who teach at a school configuration classified as other. The mean difference between the two groups was 1.00 .

Table 11

Mean Scores on Attitudinal Responses Regarding the NGSS as a Function of a Participant Group

\begin{tabular}{lccccccc}
\hline & \multicolumn{4}{c}{ Grade Configuration Groups } \\
& \multicolumn{3}{c}{ Elementary } & \multicolumn{2}{c}{ Other } & \multicolumn{2}{c}{ ANOVA } \\
Attitudinal Item & $\mathrm{M}$ & $\mathrm{SD}$ & $\mathrm{M}$ & $\mathrm{SD}$ & $\mathrm{F}_{(3,84)}$ & p-value \\
\hline $\begin{array}{l}\text { Framework } \\
\text { Requirement }\end{array}$ & 3.44 & .73 & 2.44 & .98 & 2.73 & .050 \\
\hline
\end{tabular}

School configurations that were categorized as elementary included grades PreK-5 and PreK-6; nine respondents identified themselves as teachers in schools with these grade configurations. Other grade configurations included one 4-8 school, PreK-8, PreK-12, and other configurations not and specifically categorized on the survey. The survey did not collect specific grade level responsibilities from respondents in this category. Twenty-two percent $(n=19)$ selected PreK-8, PreK-12 or other as their school configuration. Although the percentage of the sample size represented in the statistical significance is small at $33 \%$, the results of the test may still be noteworthy. 
A second statistically significant result was found between the content area selected by respondents (independent variable) and responses to the item asking whether the NGSS will lead to permanent changes in teacher and classroom practices (Table 12). The ANOVA was significant, $F_{(4,82)}, p=.029$. Post hoc comparisons (Bonferroni) reported a statistically significant difference in the means between the group who teach the physical sciences and those who teach multiple content areas, with a mean difference between the two groups of 0.72 .

Table 12

Mean Scores on Attitudinal Responses Regarding the NGSS as a Function of a Participant Group

\begin{tabular}{lcccccc}
\hline & \multicolumn{4}{c}{ Content Area Groups } \\
& Physical Science & Multiple Content & \multicolumn{2}{c}{ ANOVA } \\
Attitudinal Item & $\mathrm{M}$ & SD & $\mathrm{M}$ & SD & $\mathrm{F}_{(4,82)}$ & p-value \\
\hline Permanent Changes & 2.75 & .75 & 3.47 & .76 & 2.86 & .029 \\
\hline
\end{tabular}

A third statistically significant result was found between the content area selected by respondents (independent variable) and responses to whether the NGSS encompasses what science education should be at the grade level respondents taught (Table 13). The ANOVA was significant, $F_{(4,82)}, p=.007$. Post hoc comparisons (Bonferroni) reported a statistically significant difference in the means between the earth science group and the group member responses who teach multiple content areas, with a mean difference between the two groups of 0.88 . 
Table 13

Mean Scores on Attitudinal Responses Regarding the NGSS as a Function of a Participant Group

\begin{tabular}{lcccccc}
\hline & \multicolumn{4}{c}{ Content Area Groups } & \multicolumn{2}{c}{ ANOVA } \\
& Earth Science & Multiple Content & \multicolumn{2}{c}{ ANOV-value } \\
Attitudinal Item & $\mathrm{M}$ & $\mathrm{SD}$ & $\mathrm{M}$ & $\mathrm{SD}$ & $\mathrm{F}_{(4,82)}$ & $\mathrm{p}$-val \\
\hline $\begin{array}{l}\text { What Science Should } \\
\text { Encompass }\end{array}$ & 3.00 & 1.00 & 3.50 & .57 & 2.86 & .007 \\
\hline
\end{tabular}

Thirty-three survey participants (38\%) identified themselves as teachers who teach multiple content areas. Earth science was selected by $9 \%(n=8)$ of respondents, while $14 \%$ $(n=12)$ selected the physical sciences as the content area taught. The statistical significance reported in Tables 13 and 14 may be due to a small sample. However, the results may indicate a variance among science teachers' attitudes toward the NGSS reform.

A series of ANOVAs was conducted to evaluate differences between and within groups of respondents by the amount of professional development activities attended and survey items in Section 3 that asked about respondents' attitudes related to the NGSS to the questions related to familiarity with NGSS components. Three cases of statistical significance were found.

One statistically significant result was reported between the amount of professional development attended by respondents (independent variable) and survey item responses to whether the changes brought about by the NGSS will be beneficial to students (Table 14). The ANOVA was significant, $F_{(3,83)}, p=.010$. Post hoc comparisons (Bonferroni) found a statistically significant difference in the means between respondents who attended more than five days of professional development and the groups who selected less than one day and one to two days of professional development on the survey. 
Table 14

Mean Scores on Attitudinal Responses Regarding the NGSS and Professional Development as a Function of a Participant Group

\begin{tabular}{lcccccc}
\hline & \multicolumn{3}{c}{ Professional Development Groups } \\
& Less than One Day & Five or More Days & \multicolumn{2}{c}{ ANOVA } \\
& $\mathrm{M}$ & $\mathrm{SD}$ & $\mathrm{M}$ & $\mathrm{SD}$ & $\mathrm{F}_{(3,83)}$ & $\mathrm{p}$-value \\
\hline Attitudinal Item & 3.26 & .73 & 3.75 & .44 & 4.01 & .010 \\
$\begin{array}{l}\text { Changes Beneficial to } \\
\text { Students }\end{array}$ & & & & & & \\
$\begin{array}{l}\text { Permanent Changes } \\
\text { What Science Should }\end{array}$ & 2.79 & .71 & 3.44 & .61 & 3.92 & .011 \\
Encompass & 2.74 & .87 & 3.50 & .56 & 5.25 & .002 \\
\hline
\end{tabular}

A second statistically significant result was found between the amount of professional development attended by respondents (independent variable) and survey responses to whether the NGSS will lead to permanent changes in teacher and classroom practices (Table 14). The ANOVA was significant at $F_{(3,83),} p=.011$. Post hoc comparisons (Bonferroni) found a statistically significant difference in the means between respondents who attended more than five days of professional development and the group who selected less than one day professional development attendance on the survey.

The third statistically significant result was found between the amount of professional development attended by respondents (independent variable) and survey responses to whether the NGSS encompasses what science education should be at the grade level they taught (Table 14). The ANOVA was significant, $F_{(3,83)}, p=.002$. Post hoc comparisons (Bonferroni) found a statistically significant difference in the means between respondents who attended more than five days of professional development and the group who selected less than one day professional development attendance on the survey. 


\section{Research Question Three}

Descriptive statistics. Research question three asked respondents about changes to classroom-level, school-level, and district-level practices in response to the NGSS. Eight questions were posed to survey respondents in Section 4 of the survey. A 4-point response metric with ordered responses of 1-not at all, 2-minimally, 3-moderately, and 4-extensively was used to measure the reported attitudinal responses to items that asked the respondents their level of agreement to statements related to classroom-level practices. Table 15 shows the mean scores and standard deviations for the items included in the subsection of the survey.

Table 15

Changes to Classroom-Level Practices

\begin{tabular}{lccc}
\hline Item & $\mathrm{N}$ & Mean & SD \\
\hline $\begin{array}{l}\text { 1. I have changed my classroom instructional strategies and } \\
\text { practices to align with the expectations of the NGSS. }\end{array}$ & $85^{\text {a }}$ & 3.00 & .86 \\
$\begin{array}{l}\text { 2. I have changed my classroom curriculum materials to align } \\
\text { with the NGSS. }\end{array}$ & 85 & 2.83 & .95 \\
$\begin{array}{l}\text { 3. I have changed my classroom assessments to align with the } \\
\text { expectations of the NGSS. }\end{array}$ & 85 & 2.81 & .99 \\
\hline
\end{tabular}

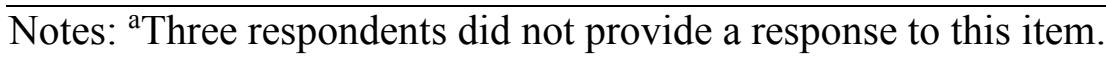

The first question in the subsection (question 27) asked respondents were to determine their level of agreement with statements related to classroom-level changes in response to the NGSS. Participants reported a mean of $3.00(\mathrm{SD}=.86)$ representing moderately on the response metric for question one, which asked about changes in instructional strategies and practices. The standard deviation of $\mathrm{x}$ indicates that the responses were clustered around the mean for the survey item.

The second question of the subsection (Question 28) asked respondents if they have changed their curriculum materials to align with the NGSS. A mean score of $2.83(\mathrm{SD}=.95)$, 
slightly less than moderately on the response metric was reported by respondents. Frequency results indicated that $28 \%$ of respondents selected not at all or minimally on the response metric, while $71 \%$ reported at least moderate changes to classroom curriculum.

The third question of the subsection (Question 29) asked participants about the changes made to classroom assessments to align with the NGSS. Sixty-eight percent of respondents $(n=61)$ chose moderately or extensively on the response metric, while thirty-two percent $(n=27)$ participants selected not at all or minimally for the survey item.

The second part of Section 4 of the survey asked respondents about school-level and district-level changes in response to the NGSS. A 5-point response metric with ordered responses of 0-I do not know, 1-not at all, 2-minimally, 3-moderately, and 4-extensively was used for the school-level and district-level changes section.

The first question in the school-level subsection (Question 31) asked whether the respondent's curriculum map was aligned to the NGSS. Respondents reported a mean of 2.47 $(\mathrm{SD}=1.15)$ representing an average score between minimally and moderately on the response metric for the item (Table 16). Thirty-five percent $(n=30)$ of respondents chose moderately, while $20 \%(n=17)$ selected extensively. Three percent of respondents $(n=4)$ chose I don't know for the item.

Table 16

School-Level Changes

\begin{tabular}{lccc}
\hline Item & $\mathrm{N}$ & Mean & SD \\
\hline $\begin{array}{l}\text { 1. Your school's curriculum map is aligned with the } \\
\text { expectations of the NGSS. }\end{array}$ & $85^{\text {a }}$ & 2.47 & 1.15 \\
2. Curriculum materials at the school level are aligned with the & 85 & 2.35 & 1.02 \\
$\quad$ NGSS. & & & 0.98 \\
3. Assessments at the school level are aligned with the NGSS. & 85 & 2.09 &
\end{tabular}

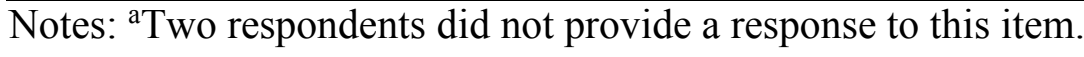


The second question in the school-level subsection (Question 32) expands upon an item in the classroom-level subsection. The item asked respondents whether curriculum materials at the school-level were aligned with the NGSS. Forty-six percent $(n=39)$ of respondents selected moderately or extensively. Fifty one percent $(n=43)$ chose not at all or minimally, while 3\% $(n=3)$ selected $I$ do not know. The survey item reported a mean score of $2.35(\mathrm{SD}=1.02)$ representing a response of minimally (Table 16).

The third question in the subsection (Question 33) was also connected to a classroomlevel item. The school-level question asked whether assessments at the school-level were aligned to the NGSS. The mean score of the item was 2.09 with a standard deviation of 0.98 (Table 16). Six percent $(n=5)$ of participants chose extensively. Fifty-nine percent of respondents $(n=50)$ selected not at all or minimally for the item, while nearly $30 \%(n=26)$ chose moderately. Five percent $(n=4)$ respondents selected I do not know.

Two questions in the second subsection asked about district-level changes in response to the NGSS (questions $34 \& 35$ ). The mean scores of the district-level questions are the lowest among survey items related to research question three. Both items are related to items in the classroom-level and school-level subsections. The first item in the district-level subsection asked respondents if curriculum materials at the district-level were aligned to the NGSS. Sixteen percent of respondents $(n=14)$ selected I do not know for this item. Thirty-two percent of respondents $(n=27)$ indicated that the curriculum at the district-level is moderately or extensively aligned to the NGSS. Fifty percent of respondents $(n=43)$ marked minimally or not at all for this item. The mean score of the item was reported at $1.85(\mathrm{SD}=1.20)$ representing a response of minimally (Table 17). 
The second question in the district-level subsection asked respondents whether assessments were aligned to the NGSS. Responses of moderately or extensively accounted for $16 \%(n=14)$. Fifty-nine percent of participants $(n=50)$ selected not at all or minimally. Twentytwo percent $(n=21)$ reported I don't know for the district-level assessment survey item. Participants reported a mean score of $1.48(\mathrm{SD}=1.11)$ representing minimally of the response scale (Table 17).

Table 17

District-Level Changes

\begin{tabular}{lccc}
\hline Item & $\mathrm{N}$ & Mean & SD \\
\hline $\begin{array}{l}\text { 1. Curriculum materials at the district level are aligned with the } \\
\text { NGSS. }\end{array}$ & $85^{\mathrm{a}}$ & 1.85 & 1.20 \\
2. Assessments at the district level are aligned with the NGSS. & 85 & 1.48 & 1.11 \\
\hline
\end{tabular}
Notes: ${ }^{\text {a }}$ Two respondents did not provide a response to this item.

Differences between and within groups. A series of ANOVAs was conducted between the survey items related to changes to classroom-level, school-level, and district-level practices in response to the NGSS and the professional and demographic variables collected from participants in Section 1 of the survey. Five occurrences of statistical significance were reported. All cases of statistical significance were found when grade level configuration was set as the independent variable for the statistical test. School configurations that were categorized as elementary include grades configurations PreK-5 and PreK-6; nine respondents identified themselves as teachers in schools with these grade configurations. Forty participants chose grades 9-12 as their school's grade configuration.

The first statistically significant result was found between grade level configuration selected by respondents (independent variable) and classroom-level curriculum changes in 
response to the NGSS (Table 18). The ANOVA was significant, $F_{(3,81)}, p=.026$. Post hoc comparisons (Bonferroni) found a statistically significant difference in the means between the elementary and high school groups. The mean difference between the groups was 1.02. Sixtyseven percent of respondents $(n=6)$ in the elementary category selected extensively, while 33\% $(n=3)$ chose the moderately category. Forty-four percent of respondents $(n=17)$ within the high school group chose moderately, 21\% $(n=8)$ selected extensively, while the remaining 35\% respondents $(n=14)$ selected minimally or not at all for the item.

Table 18

Mean Scores on Responses Regarding Classroom Changes as a Function of a Participant Group

\begin{tabular}{|c|c|c|c|c|c|c|}
\hline \multirow[b]{3}{*}{ Classroom Changes } & \multicolumn{5}{|c|}{ Grade Configuration Groups } & \\
\hline & \multicolumn{2}{|c|}{ Elementary } & \multicolumn{2}{|c|}{ High School } & \multicolumn{2}{|c|}{ ANOVA } \\
\hline & M & $\mathrm{SD}$ & M & SD & $\mathrm{F}_{(3,81)}$ & p-value \\
\hline Curriculum Materials & 3.63 & .52 & 2.61 & 1.02 & 3.24 & .026 \\
\hline Assessment Alignment & 3.63 & .52 & 2.55 & .98 & 3.11 & .031 \\
\hline
\end{tabular}

The second statistically significant ANOVA was $F_{(3,81)}, p=.031$ (Table 18). Post hoc comparisons (Bonferroni) found a statistically significant difference in the means between the elementary and high school categories. The mean difference between the groups was 1.07. Sixty-seven percent of respondents $(n=6)$ in the elementary category selected moderately while $33 \%(n=3)$ chose extensively. Forty-three percent $(n=17)$ of respondents within the high school group chose moderately, $15 \%(n=6)$ selected extensively, and $40 \%(n=16)$ chose minimally or not at all for the school-level assessment alignment item.

The third and fourth instances of significance were found for the survey items related to two district-level change due to the NGSS. The third case was for the survey item that asked whether the district's curriculum materials were aligned to the NGSS. The ANOVA was 
significant at $F_{(3,81)}, p=.003$ (Table 19). Post hoc comparisons (Bonferroni) found a statistically significant difference in the means between several grade level configuration groups. Frequency results indicated a varied distribution in responses to the district-level items. Sixteen percent $(n=14)$ selected I do not know for the district-level curriculum alignment item. Fifty-one percent $(n=43)$ of responses indicated curriculum materials at the district level were minimally or not at all aligned to the NGSS. Seven percent of respondents $(n=6)$ chose extensively for the survey item.

Table 19

Mean Scores on Responses Regarding District Changes as a Function of a Participant Group Grade Configuration Groups

\begin{tabular}{lcccrrr} 
& \multicolumn{2}{c}{ Elementary } & \multicolumn{2}{c}{ Other } & \multicolumn{2}{c}{ ANOVA } \\
District Changes & $\mathrm{M}$ & $\mathrm{SD}$ & $\mathrm{M}$ & $\mathrm{SD}$ & $\mathrm{F}_{(3,81)}$ & $\mathrm{p}$-value \\
\hline Curriculum Materials & 3.13 & 1.13 & 1.32 & 1.29 & 5.03 & .003 \\
Assessment Alignment & 2.50 & 1.51 & 1.00 & .94 & 4.03 & .010 \\
\hline
\end{tabular}

The fourth case of significance was found for the district-level assessment alignment survey item. The ANOVA was significant at $F_{(3,81)}, p=.010$ (Table 19). Post hoc comparisons (Bonferroni) found a statistically significant difference in the means between the elementary group and the other group category. The elementary category included PreK-5 and PreK-6 responses. Other included one 4-8 school, as well as PreK-8, PreK-12, and other configurations not and specifically categorized on the survey. The mean difference between the two groups was 1.51 for the district-level assessment alignment survey item.

A series of ANOVAs was conducted to evaluate differences between and within groups of respondents by the amount of professional development activities attended and survey items related to changes to classroom-level, school-level, and district-level practices in response to the 
NGSS. Although no reportable cases of statistical significance were found by the ANOVA test, differences between groups were found in the Bonferroni post hoc comparisons.

Open-ended question three. The open-ended question in survey Section 4 (question 30) asked survey participants to provide an example of a change made to instructional strategies, curriculum, or assessments to align them with the NGSS. Seventy-five respondents provided examples of changes made to instructional strategies, curriculum, and assessments to align their practices with the NGSS. Although the descriptions provided by respondents varied widely, four major themes were identified: assessments, specific dimensions or components of the NGSS, the use of phenomena, and investigations.

Assessments were mentioned by $32 \%$ ( $n=24)$ respondents. Project-based and problembased assessments, the use of rubrics, common assessments, formative assessments, and less use of traditional multiple choice written tests were sub-themes. One respondent described the use of non-traditional assessment techniques that center around focused feedback and "big ideas". The respondent described the use of the science and engineering practices of the NGSS as a guide for narratives for students. The respondent teaches in a state that has not officially adopted the NGSS. Another respondent describes the required use of district wide assessments that are still content-based. The respondent notes that the assessment is not aligned with classroom practices.

Twenty-nine percent $(n=22)$ of respondents specifically mentioned one or more dimensions of the NGSS or a component, such as the use of models, within their descriptions of the changes made to their classroom practices. One respondent described the change as instructional strategies rely less on superficial coverage and more on developing deep understandings related to the standards and cross cutting concepts. Another described focusing on the practices of science and engineering as a means to engage students with science content. 
A respondent from Illinois also noted the incorporation of engineering practices, but also mentioned the cutting of other material. A respondent from New York described the use of the engineering practices as a mechanism to reimagine assessments in the unit for each grade. Similarly, a respondent from Arizona, a state that has not adopted the NGSS, explained the attempt to encourage students to explore "the engineering piece" and incorporating more math and trying to tie STEM into the curriculum. A respondent from Illinois noted that many of the changes to align from the NGSS come from the alignment to the science and engineering practices. The respondent mentioned the use of the student evidence statements, which was not a theme among respondents. A middle grades practitioner described the use of the performance expectations as a default assessment as the "revamping of entire biology courses based on the NGSS" and the adoption of a project-based inquiry curriculum took place.

The use of a phenomenon to guide an instructional plan or unit was common. Twentythree percent $(n=17)$ respondents mentioned the use of phenomena in their open-ended question responses. A Michigan practitioner described the use of a phenomenon:

They then whiteboard their thoughts or create a model to show what their current thinking is, discuss, preform more activities/labs to allow for more understanding of the phenomenon, adjust their models, more discussions (student led).

One respondent described the use of one or more phenomena "to engage students and to drive the questions" while another explained the use of phenomena "through which I teach the SEPs, DCIs, and CCCs" or the three dimensions of the NGSS. Another called the "driving a lesson from phenomena and students' questions is a big shift" and noted some content areas have not been "touched yet" while shifting practices has been a priority. 
Many respondents described or mentioned the use of investigations or inquiry in their open-ended question response. Several respondents described the use of problem-based projects, independent research, investigation, problem solving, and inquiry-based practices. A respondent from Missouri described the instructional process of a middle grades class:

I dedicated about a week to having my $6^{\text {th }}$ graders construct a model to explain what was happing in a video of a candle carousel. I gave them no instruction until nearly the end of the "unit." It was a change, but I really liked watching my students work through the topic on their own. Eavesdropping on their conversation was very informative. Spending that amount of time not only helped them understand convection, but using this same strategy over time will help my students in all areas.

Similarly, a respondent from South Dakota described the change in practices by "having students design and complete inquiries as the basis of some assessments."

Other respondents described the challenges they have faced with NGSS implementation. One respondent mentioned the use of "hands on inquiry" but also noted the difficulty "as some students have very little practice stating their opinion," while another cited a classroom textbook as the only curricular materials available.

\section{Research Question Four}

Descriptive statistics. The purpose of research question four was to examine the barriers that may prevent a practitioner from implementing the NGSS in the classroom. Eight items were included in Section 5 of the survey (questions 36-43). A 4-point response metric with ordered responses of not at all, occasionally, moderately, and extensively was used to determine participants' level of agreement with the survey items in the section. Table 20 contains the mean scores and standard deviations for Section 5 survey items. 
Table 20

Barriers to Implementation of the NGSS

\begin{tabular}{|c|c|c|c|}
\hline Item & $\mathrm{N}$ & Mean & SD \\
\hline 1. Large class size. & $84^{\mathrm{a}}$ & 2.14 & 1.08 \\
\hline 2. Administration support. & $85^{\mathrm{b}}$ & 2.40 & 1.07 \\
\hline 3. Physical space not conducive to new expectations. & $82^{\mathrm{c}}$ & 2.05 & 1.06 \\
\hline $\begin{array}{l}\text { 4. Lack of availability or access to curriculum materials } \\
\text { aligned to NGSS. }\end{array}$ & $85^{\mathrm{b}}$ & 2.63 & 1.12 \\
\hline $\begin{array}{l}\text { 5. Difficulty aligning current curriculum materials and } \\
\text { instructional strategies to the student performance } \\
\text { expectations. }\end{array}$ & $83^{d}$ & 2.47 & 1.05 \\
\hline $\begin{array}{l}\text { 6. Lack of disciplinary content knowledge required to teach to } \\
\text { new standards. }\end{array}$ & $83^{d}$ & 1.59 & .88 \\
\hline 7. Lack of professional development opportunities. & $83^{\mathrm{d}}$ & 2.55 & 1.21 \\
\hline 8. Lack of support or collaboration from colleagues. & $81^{\mathrm{e}}$ & 2.36 & 1.21 \\
\hline
\end{tabular}

Notes: ${ }^{\text {a}}$ Four respondents did not provide a response to this item.

$\mathrm{b}$ Three respondents did not provide a response to this item.

${ }^{c}$ Six respondents did not provide a response to this item.

${ }^{\mathrm{d}}$ Five respondents did not provide a response to this item.

e Seven respondents did not provide a respond to this item.

The first question (question 36) asked respondents to determine whether they consider large class size a barrier to the implementation of the NGSS. Participants reported a mean of $2.14(\mathrm{SD}=1.08)$ representing a response of occasionally on the response metric. The frequency distribution for the survey item indicated over $40 \%$ of respondents selected moderately or extensively on the response scale, while $39 \%$ chose not at all.

The second question in Section 5 of the survey (question 37) asked respondents whether administration support was a barrier to implementing the NGSS as the developers of the standards intended. Participants reported a mean of $2.40(\mathrm{SD}=1.07)$ representing occasionally on the response scale. Twenty-two percent $(n=19)$ of respondents indicated administration support 
extensively acted as a barrier to the NGSS implementation process, while $17 \%(n=14)$ selected moderately. Twenty-two percent $(n=19)$ also chose not at all for the item.

The third item in the section (question 38) asked respondents if the physical space of their classroom was not conducive to implementing the NGSS. Participants reported a mean of 2.05 $(\mathrm{SD}=1.06)$ representing occasionally on the response metric. The frequency distribution reported $43 \%(n=35)$ of respondents chose not at all, while $37 \%(n=30)$ participants selected moderately or extensively for the survey item.

The fourth item in Section 5 (question 39) is related to other survey sections and asked respondents whether a lack of curriculum materials was a barrier to the implementation of the NGSS. Participants reported a mean of $2.63(\mathrm{SD}=1.12)$ representing occasionally on the response metric. Over $55 \%(n=47)$ of respondents selected moderately or extensively for the survey item. Twenty percent $(n=17)$ of participants did not perceive access to NGSS curriculum materials as a barrier to implementation.

Item five (question 40) asked respondents whether difficulty aligning their current curriculum and instructional strategies to the performance expectation of the NGSS was perceived as a barrier. Participants reported a mean of $2.47(\mathrm{SD}=1.05)$ representing occasionally on the response metric. Twenty percent of respondents perceived the difficulty of aligning current materials as an extensive barrier to NGSS implementation. Furthermore, 28\% $(n=23)$ of participants selected moderately and 30\% (n=25) chose occasionally for the survey item. Twenty-two percent did not perceive the alignment of current materials and strategies to be a barrier to NGSS implementation.

The sixth item in Section 5 of the survey (question 41) asked whether a lack of disciplinary content knowledge required to teach to the new standards was a barrier to NGSS 
implementation. Participants reported a mean of $1.59(\mathrm{SD}=0.88)$ representing not at all on the response metric. Over $62 \%(n=52)$ of respondents selected not at all, while $20 \%(n=17)$ participants chose occasionally, and $12 \%(n=10)$ selected moderately for the survey item. Five percent $(n=4)$ of responses indicated a lack of disciplinary content knowledge was a barrier to NGSS implementation.

Section item seven (question 42) is related to items in Section 2 of the survey. The item queried respondents if the lack of professional development opportunities was a barrier to the implementation of the NGSS. Participants reported a mean of $2.55(\mathrm{SD}=1.21)$ representing occasionally on the response metric. Although $30 \%(n=24)$ of respondents selected not at all on the item's response scale, $55 \%(n=46)$ indicated a moderate or extensive lack of professional development opportunities related to the NGSS.

The eighth item in Section 5 of the survey (question 43) asked respondents if a lack of support or collaboration among colleagues was a barrier to NGSS implementation. Participants reported a mean of $2.36(\mathrm{SD}=1.21)$ representing occasionally on the response scale. While nearly $30 \%$ ( $n=24)$ of respondents indicated lack of support or collaboration with colleagues was not a barrier, $49 \%(n=40)$ chose occasionally or moderately for the survey item. Twenty-one percent $(n=17)$ of respondents reported the lack of support or collaboration from colleagues as an extensive barrier to the implementation of the NGSS.

Differences between and within groups. A series of ANOVAs was conducted to evaluate differences between and within groups of respondents by the amount of professional development activities attended and survey items related to factors that acted as barriers to full implementation of the NGSS. Once instance of statistical significance was reported between the independent variable as the amount of professional development attended by respondents and the 
lack of professional development opportunities as the dependent variable (Table 21). The ANOVA was significant at $F_{(3,79)}, p=.005$. Post hoc comparisons (Bonferroni) found a statistically significant difference in the means between respondents who attended more than five days of professional development and the group who selected less than one day professional development attendance on the survey.

Table 21

Mean Scores on Responses to Barriers to Implementation as a Function of a Participant Group

\begin{tabular}{lcccccc}
\hline & \multicolumn{4}{c}{ Professional Development Groups } \\
& Less than One Day & Five or More Days & \multicolumn{2}{c}{ ANOVA } \\
Barriers & $\mathrm{M}$ & $\mathrm{SD}$ & $\mathrm{M}$ & $\mathrm{SD}$ & $\mathrm{F}_{(3,79)}$ & p-value \\
\hline $\begin{array}{l}\text { Lack of professional } \\
\text { development }\end{array}$ & 3.26 & .93 & 2.06 & 1.17 & 4.66 & .005 \\
\hline
\end{tabular}

Open-ended question four. The open-ended question in survey Section 5 (question 44) asked survey participants to describe the primary barriers to implementation of the NGSS. Eighty-eight percent of respondents $(n=77)$ described a myriad of factors that have limited their ability to implement the NGSS. Furthermore, many limiting factors are connected, which may exacerbate a practitioner's ability to implement the NGSS as intended.

The most prevalent barrier mentioned in participants' responses was the lack of time for the activities related to implementing a new reform. Thirty percent of respondents $(n=23)$ mentioned the need for more time to plan, amend existing materials or locate new curriculum resources, and partake in professional development activities. Other respondents reported limited time available work with colleagues and for program evaluation. Still others described only limited time available for science instruction within their class schedule. 
A factor associated with the time barrier is the reported lack of curriculum resources. As one respondent described, "good curricular materials aligned with NGSS are hard to find. Lots of worksheets that claim they are NGSS aligned." Another described the extensive amount of time it takes "to create solid units that show the 3D approach the Framework and NGSS standards are calling for." Others struggled with the commitment level of colleagues, which slowed changes in practices even more. One respondent described the process as "getting teachers to buy-in and drink the Kool-Aid."

Another barrier connected to both time and the deficiency of curriculum resources is the lack of quality NGSS professional development activities available to teachers. The explanation one respondent provided elucidates the predicament that many teachers across the country may be in:

I myself have spent a lot of my own personal time teaching myself about the new standards, how to implement them, and what a NGSS classroom looks like. Other teachers in my district have not had such training, because the district has not provided much in the way of professional development or time to prepare new lessons.

Funding was another reported barrier connected to other limiting factors to NGSS implementation. Most curriculum resources and professional development cost money, and some respondents reported lack of interest and apprehension among administrators and districts to spend money on science, despite being in the midst of a reform. Other respondents have found themselves in philosophical battles with administration, colleagues, and parents. One practitioner described such conflicts: 
The desires of parents, who think that memorizing a book will prepare them for high school. The high school that is not truly implementing the standards saying that they need to prepare students for college entrance tests.

The final pattern found in respondents' descriptions of barriers to the implementation of the NGSS are difficulty with the standards. Unclear expectations for specific content areas, confusing organization and design of the standards were also reported as barriers to NGSS implementation.

\section{Research Question Five}

Research question five concerned the relationships between K-12 science teachers' familiarity, attitudes, and levels of agreement with the NGSS, barriers to full implementation, and the degree of change to classroom practices in response to the NGSS reform. Correlation coefficients were computed between the three sets of variables. Using the Bonferroni approach to control for Type I error across the correlations, a $p$-value of less than $0.05(0.5 / 10=.05)$ was required for significance (Green \& Salkind, 2014).

The first set of correlations was computed between practitioner familiarity items in Section 2 of the survey (Appendix A) and the degree of change to classroom practices in response to the NGSS reform. The results of the correlational analyses presented in Table 22 show that five out of the 18 correlations of interest were statistically significant with correlation coefficients greater than or equal to 0.35 . 
Table 22

Correlations among Familiarity with NGSS and Changes to Classroom Practices $(N=83)$

\begin{tabular}{|c|c|c|c|c|c|c|c|c|c|}
\hline Measure & 1 & 2 & 3 & 4 & 5 & 6 & 7 & 8 & 9 \\
\hline $\begin{array}{l}\text { 1. Changed classroom } \\
\text { practices }\end{array}$ & - & & & & & & & & \\
\hline $\begin{array}{l}\text { 2. Changed curriculum } \\
\text { materials }\end{array}$ & .77 & - & & & & & & & \\
\hline 3. Changed assessments & .24 & .75 & - & & & & & & \\
\hline $\begin{array}{l}\text { 4. Familiarity with } \\
\text { Performance } \\
\text { Expectations }\end{array}$ & .29 & .26 & .28 & - & & & & & \\
\hline $\begin{array}{l}\text { 5. Familiarity with } \mathrm{S} \& \mathrm{E} \\
\text { Practices }\end{array}$ & .26 & .09 & .15 & .65 & - & & & & \\
\hline $\begin{array}{l}\text { 6. Familiarity with Cross } \\
\text { Cutting Concepts }\end{array}$ & .24 & .16 & .23 & .86 & .79 & - & & & \\
\hline $\begin{array}{l}\text { 7. Familiarity with } \\
\text { Disciplinary Core Ideas }\end{array}$ & .32 & .26 & .31 & .83 & .77 & .88 & - & & \\
\hline $\begin{array}{l}\text { 8. Preparedness Level and } \\
\text { PD Activities }\end{array}$ & $.53 *$ & $.46^{*}$ & $.54^{*}$ & .48 & .44 & .47 & .53 & - & \\
\hline $\begin{array}{l}\text { 9. Comfortability level to } \\
\text { create instructional plans }\end{array}$ & $.44^{*}$ & .28 & $.42 *$ & .49 & .45 & .56 & .53 & .70 & - \\
\hline
\end{tabular}

The results suggest weak to moderate correlations (Salkind, 2017) between changes in instructional practices, curriculum materials, and assessments and preparedness as a result of professional development as well as comfortability level to create full instructional plans and changes to classroom instructional practices and assessments.

The second set of correlations was computed between practitioner attitudes and levels of agreement regarding the NGSS items in Section 3 of the survey (Appendix A) and changes in classroom instructional practices, curriculum materials, and assessments. The results of the correlational analyses presented in Table 23 show that eight out of the 27 correlations of interest were statistically significant with correlation coefficients greater than or equal to 0.35 . 
Table 23

Correlations among Attitudinal Responses to the NGSS and Changes to Practices $(N=83)$

\begin{tabular}{|c|c|c|c|c|c|c|c|c|c|c|c|}
\hline Measure & 1 & 2 & 3 & 4 & 5 & 6 & 7 & 8 & 9 & 10 & 11 \\
\hline $\begin{array}{l}\text { 1. Changed classroom } \\
\text { practices }\end{array}$ & - & & & & & & & & & & \\
\hline $\begin{array}{l}\text { 2. Changed } \\
\text { curriculum } \\
\text { materials }\end{array}$ & .78 & - & & & & & & & & & \\
\hline $\begin{array}{l}\text { 3. Changed } \\
\text { assessments }\end{array}$ & .78 & .75 & - & & & & & & & & \\
\hline $\begin{array}{l}\text { 4. NGSS easy to use } \\
\text { to plan }\end{array}$ & $.43^{*}$ & $.37 *$ & $.40^{*}$ & - & & & & & & & \\
\hline $\begin{array}{l}\text { 5. Confidence in } \\
\text { implementation }\end{array}$ & .26 & .16 & .30 & .76 & - & & & & & & \\
\hline $\begin{array}{l}\text { 6. NGSS changes } \\
\text { beneficial }\end{array}$ & .29 & .26 & .29 & .44 & .30 & - & & & & & \\
\hline $\begin{array}{l}\text { 7. NGSS changes } \\
\text { permanent }\end{array}$ & $.43^{*}$ & $.45^{*}$ & $.37 *$ & .41 & .32 & .70 & - & & & & \\
\hline $\begin{array}{l}\text { 8. 3-D design requires } \\
\text { changes }\end{array}$ & .30 & .24 & .22 & .25 & .15 & .54 & .54 & - & & & \\
\hline $\begin{array}{l}\text { 9. NGSS encompasses } \\
\text { science education }\end{array}$ & $.39 *$ & .30 & $.41^{*}$ & .37 & .35 & .64 & .62 & .44 & - & & \\
\hline 10. NGSS and inquiry & .22 & .15 & .26 & .48 & .47 & .46 & .49 & .35 & .52 & - & \\
\hline $\begin{array}{l}\text { 11. Framework } \\
\text { required }\end{array}$ & .23 & .30 & .30 & .62 & .54 & .46 & .47 & .29 & .41 & .60 & - \\
\hline $\begin{array}{l}\text { 12. NGSS } \\
\text { implementation } \\
\text { and standardized } \\
\text { assessment }\end{array}$ & -.04 & .00 & -.10 & -.15 & -.12 & -.29 & -.23 & -.06 & -.19 & -.28 & -.15 \\
\hline
\end{tabular}

In general, the results suggest if a practitioner agreed that the NGSS are easy to understand and use for the development of full instructional plans and agreed the NGSS will lead to permanent changes in classroom practices, they tend to have changed classroom instructional practices, curriculum, and assessments. In addition, teachers who agreed the NGSS encompasses 
what science education should be at the grade level taught, they tend to have changed classroom instructional practices and assessments.

A third set of correlation coefficients were computed among the eight items in Section 5 concerning barriers to implementation of the NGSS (Appendix A) and changes to classroom practices. Results indicated no statistically significant correlations between any item related to barriers to NGSS implementation and changes to classroom practices. 


\section{CHAPTER V: DISCUSSION}

This study investigated educators' familiarity with and perceptions of the Next

Generation Science Standards (NGSS), changes in practices at the classroom, school, and district levels, and perceived barriers to implementation. The quantitative study was directed by five research questions concerning the implementation of the NGSS from the self-reported perspectives of K-12 science teachers. The results of the analyses addressing these questions is discussed below. The Teacher-Centered System Reform (TCSR) model (Woodbury \& GessNewsome, 2002) framed this study by linking teachers' demographic and professional profile, professional development experiences, district-level, school-level, and classroom-level contexts and illuminates the dynamic effect the factors have on teachers' thinking and their practice.

\section{Summary of Findings}

\section{Research Question One}

The first research question addressed the level of familiarity with and understanding of the NGSS among K-12 science teachers. Six items in the survey were used to determine the level of familiarity with the NGSS among K-12 science teachers (questions 10-15). Four items asked respondents to determine their level of familiarity with the major components of the NGSS. One item was related to respondents' comfort level with using the NGSS to create full instructional plans. The final item asked respondents to determine their degree of preparedness to teach to the NGSS as a results of professional development activities.

Respondents reported a mean of agree on the response scale for all familiarity items in Section 2 of the survey. Each item was related to a major component of the NGSS. The highest reported mean $(\mathrm{M}=3.40, \mathrm{SD}=0.80)$ of the section was for the item that asked about respondents' familiarity with the science and engineering practices. The lowest reported mean $(\mathrm{M}=3.30$, 
$\mathrm{SD}=0.74$ ) was for the item that asked respondents about their familiarity with the performance expectations for their grade level. This result may be of concern to the authors of the NGSS, as the performance expectations (PEs) are considered to be the assessment targets of the standards (NRC, 2015).

The items that asked respondents about their comfortability in using the NGSS for instructional planning $(\mathrm{M}=2.82, \mathrm{SD}=0.93)$ and preparedness level as a result of professional development activities $(\mathrm{M}=2.70, \mathrm{SD}=1.00)$ were considerably lower than the familiarity items. Both items reported means on disagree on the response scale and also had the highest standard deviations of the section. The higher standard deviations would suggest respondents are less in agreement with these two items than those that asked about respondents' familiarity with the NGSS components.

Four statistically significant results were found among the series of ANOVAs conducted for the items related to research question one. The items of significance were those that asked respondents about their familiarity with the NGSS PEs, familiarity with the cross-cutting concepts (CCCs), familiarity with the disciplinary core ideas (DCIs), and comfort level with creating NGSS aligned instructional plans. All significant differences were found between the group who reported attendance of less than one day of professional development and those who reported five or more days of professional learning. The results suggest that professional development may be more important to ensure the utilization of the PEs for planning and the incorporation of the CCCs into students' learning experiences, as they are new features of the NGSS. The statistical significance between the groups for the item related to familiarity with the DCIs was marginally unexpected, as this dimension of the NGSS are akin to previous content standards. The lowest mean score $(\mathrm{M}=2.70, \mathrm{SD}=1.00)$ of the section and significant result of the 
item that asked respondents about their comfortability with creating NGSS aligned instructional plans suggest that although respondents were familiar with the components of the NGSS, they are less confident in interpreting and using the standards for planning purposes.

The open-ended question in section two asked respondents to provide an example of how they have used the performance expectations (PEs) component of the NGSS to create instructional plans. Although most respondents described how they used the NGSS to plan instruction, many did not specifically mention the PEs within their responses. Of the 80 openended responses provided, 26\% ( $n=21)$ contained information related to PEs; many described bundling multiple PEs to create units of instruction. Other NGSS components were mentioned, including the dimensions and student evidence statements. For example, one respondent mentioned preferring to use the disciplinary core ideas (DCIs) for planning purposes instead of the PEs. Other respondents described the use of storylines, a tool created to assist teachers with the organization of learning progressions (Roseman, Fortus, Krajcik, \& Reiser, 2015).

Professional development activity. Two questions in the second section of the survey asked respondents about the professional development received related to classroom implementation of the NGSS. The first question prompted respondents to indicate the total amount of professional development they have attended. The second was an open-ended question which asked respondents to describe a professional development experience that was beneficial to them. Though the descriptive statistics indicated that $41 \%$ of the sample had attended more than five days of professional development, this result may be skewed due to the method used to collect survey data. Members of a professional organization may have more opportunities to participate in professional development due to organization publications and conferences. It is unclear if this question result truly reflects the status of the larger population. 
Ninety percent $(\mathrm{n}=79)$ of participants provided responses to the open-ended question that prompted them to describe a professional learning experience they considered beneficial to the implementation of the NGSS. Professional learning systems like the Next Generation Science Exemplar System (NGSX) are "designed to help teachers begin to take the core shifts of the Framework and NGSS back into their own classrooms" (Reiser et al., 2017, p. 294) and provide longitudinal learning opportunities. While several respondents mentioned cohort experiences like NGSX and Bozeman Science, others considered self-study and informal reading with colleagues as professional development. State agencies and districts may not be in the financial or logistical position to provide such learning experiences to all teachers of science under their authority. Eleven responses mentioned NSTA or state science teachers' associations, which may provide convenient and cost-effective alternatives. Other respondents mentioned other professional learning systems like the NASA Endeavor Project, which may be less aligned to the NGSS than other programs. Thus, professional development systems like NGSX may be more likely to bring about changes that reflect the vision of NGSS than others.

Sixty-one percent $(n=54)$ reported they teach in a state that has adopted the NGSS; $32 \%$ of those teachers reported two or fewer days of professional learning. This result, with the potentially skewed sample due to the use of NSTA's listserv to collect the data, suggest more than $30 \%$ of teachers have had minimal professional development related to the NGSS. Meanwhile, other respondents who selected no to their state's NGSS adoption status seem intent on the alignment of their classroom practices to the new standards, even at the aversion of colleagues.

Eleven percent $(n=9)$ responses to referred to graduate level courses or programs. Though professional learning provided by higher education institutions are likely to be of high quality, 
the learning objectives of graduate programs may not be specifically aimed at the implementation of the NGSS. However, professional learning procured from participation in graduate level courses may impact teacher thinking and actions, which may alter teacher thinking and provide professional knowledge that may be beneficial in the classroom implementation of the NGSS.

\section{Research Question Two}

Research question two addressed the attitudes and levels of agreement concerning the NGSS among K-12 science teachers. Nine items on the survey addressed respondents' attitudes and levels of agreements related to the NGSS (questions 18-26). The survey items were based on literature findings and the components of the NGSS. Five items reported a mean score that represented agree on the section's Likert scale, while respondents reported a mean that represented disagree for the remaining four items.

The first question in the section asked respondents whether they considered the NGSS easy to understand and use for planning instruction. Respondents reported a mean score of disagree $(\mathrm{M}=2.80, \mathrm{SD}=0.88)$. Coupled with the reported frequency of over $40 \%$ of survey participants' attendance in five or more days of professional learning, the result suggests teachers do not consider the NGSS particularly intuitive for planning purposes. Similarly, a mean score of $2.86(\mathrm{SD}=0.91)$ was reported for the item that asked about respondents' confidence level to implement the NGSS as intended by the developers. On average, teachers appear to be less than confident in their ability to implement standards aligned instruction despite their reported familiarity with the components of the NGSS.

For the item that asked whether the changes brought about by the NGSS were perceived as beneficial to students, respondents reported a mean score of $3.49(\mathrm{SD}=0.63)$. These results are 
the highest mean score and the lowest standard deviation of the section. This result reflects the standards-based reform (SBR) tenet that teachers will agree that the new standards are better than previous standards (Loeb et al., 2008). As the TCSR model suggests, many factors contribute to teachers' practice, what is considered as beneficial to students may act as motivation to overcome the perceived barriers to NGSS implementation (Woodbury \& Gess-Newsome, 2002). Item four of this section asked whether respondents believed the NGSS would lead to permanent changes in practices. Results indicate that on average, respondents believe that changes to practices due to the NGSS will be permanent. Fifty-nine percent of respondents reported 15 or more years of experience; previous research suggests that veteran teachers tend to believe that reforms are cyclical in nature and do not lead to permanent changes in the classroom (Tyack \& Cuban, 1995). The item that asked whether the organization of the standards requires changes to current practices also yielded a mean score of agree, at $3.44(\mathrm{SD}=0.70)$. Perhaps the unique three-dimensional design of the NGSS has contributed to the positive-leaning attitudinal responses to the survey.

The NGSS science and engineering practices dimension requires students to apply scientific knowledge to solve problems or explain natural phenomena (NGSS Lead States, 2013a). The first dimension of the NGSS were intended to clarify misconceptions among educators as to what qualifies as inquiry (NGSS Lead States, 2013f; Pruitt, 2014). Survey respondents reported a mean score of $3.16(\mathrm{SD}=0.78)$ or agree for the survey item that asked whether the NGSS better specifies what inquiry is and what is required within the classroom. While there is concern among NGSS reform stakeholders that educators may perceive the science and engineering practices dimension as a re-labeling of inquiry or the scientific method, survey results suggest the NGSS provides teachers with an improved description of inquiry, at 
least on a preliminary level (NRC, 2015; Reiser, 2013). Prescriptive, hands-on activities may be engaging to students, but does not qualify as NGSS aligned instruction; deep understanding of content through student-directed investigations that require the use of the practices would more likely meet the approval of NGSS authors (NRC, 2015; Wilcox et al., 2015).

The appendices of the NGSS and the NRC's Guide to Implementing the Next Generation Science Standards (2015) explicitly identify the Framework for K-12 Science Education as a companion document to the standards. However, for the survey item that asked whether the Framework provides information required to implement the NGSS, the respondents reported a mean of $2.74(\mathrm{SD}=0.91)$ or disagree on the scale. Furthermore, the Framework is not mentioned in any response to the open-ended questions. The Framework provides the research base and describes the overarching goals of the NGSS (NGSS Lead States, 2013a; NRC, 2015; Pruitt, 2014). The document is over 300 pages in length and may be considered by busy teachers as arduous and time-consuming to read. With many shorter and more intuitive documents available related to the practical implementation of the NGSS, and teachers may consider reviewing the Framework as redundant or unnecessary.

An unexpected result was the response to the survey item related to standardized assessment. Respondents reported a mean score of $2.38(\mathrm{SD}=0.97)$ representing disagree on the response scale. Sixty-two percent of respondents disagreed or strongly disagreed that the NGSS can only be implemented when it is known what will be included on the corresponding standardized assessment. While many open-ended responses were related to assessment, most were related to classroom-level assessments. Teachers' lack of a precondition toward a standardized assessment may succor implementation, as states have been slow in the transition to NGSS-aligned assessments. Currently, only Illinois, Kansas, Nevada, and the District of 
Columbia consider their assessments fully aligned to the NGSS (Loewus, 2017). The philosophy of the NGSS and companion Framework document is through discovery and the pursuit of deep understanding of phenomena, students will want to continue to their learning and pursue careers in science and engineering (NRC, 2015). However, only 20 states have adopted the NGSS. Although open-ended responses suggest that teachers in non-adoptive states are attempting to align their practices, reforms are dependent on the contextual factors of an entire school system and whether the NGSS will take permanent hold on science education and yield the intended results remains to be determined (Fullan, 1991).

Significant differences were found between professional development attendance, grade level, and content area groups and items in Section 3 of the survey. A significant difference between means was found for the group who teach at PreK-6 schools and the group that teach at 4-8, PreK-8, and PreK-12 schools for the item that asked if the Framework provides information required to implement the NGSS. The number of respondents within the groups were small, 9 $(10 \%)$ and $19(22 \%)$, compared to the sample $(N=88)$, which could account for the significant result. However, a mean difference of $1.00(\mathrm{SD}=0.91)$ suggests that a difference in perspective may exist among teachers regarding the importance of the Framework, considering the item's mean score of $2.74(\mathrm{SD}=0.91)$ or disagree was one of the lowest in the section.

Two statistically significant results were found for the item that asked respondents whether the NGSS will lead to permanent changes in practices. The first result was found for respondents' selected content area groups. A difference in means was found between teachers who are responsible for multiple content areas $(36 \%, n=32)$ and those who teach physical science $(14 \%, n=12)$. While $90 \%(n=30)$ of respondents who teach multiple content areas agreed or strongly agreed for the item, $41 \%(n=5)$ of teachers who teach physical science disagreed with 
the item. Although the difference in means may be in part attributed to the size difference between groups, the result does indicate that not all teachers agree that the NGSS will lead to permanent changes in practice. Similarly, a significant difference was found between the group who attended less than one day of professional learning and those who attended five or more days for the same item. Ninety-four percent of the group $(n=36)$ who attend five or more days of professional development agreed or strongly agreed that the NGSS will lead to permanent changes in practices, while $37 \%$ of the group $(n=19)$ who attended less than one day of professional development disagreed with the item. Results suggest teachers who have attended more NGSS professional learning experiences perceive the standards as beneficial to students and the components as permanent fixtures of science education.

Professional development seems to be a contributing factor to respondents' perceptions of the NGSS. A significant result was found between respondents who attended five or more days of professional development and those who have attended less than one day. Forty-two percent of respondents $(n=8)$ who attended less than one day of professional learning related to the NGSS disagreed that the NGSS encompasses what science education should be at their grade level, while $97 \%$ of the group who attended five or more days $(n=36)$ of professional development agreed or strongly agreed with the item.

Nine percent of respondents $(n=8)$ selected earth science as the content area they teach. While the small subgroup may have attributed to the statistical significant result, there nevertheless seems to be some disagreement among earth science teachers regarding the NGSS. Of the eight earth science teacher respondents, four disagreed that the NGSS encompasses what science education should be. Furthermore, an opened ended response provides further insight into the perceptions of the earth science cohort: 
The NGSS approach to modeling does not play nice with numerous aspects of earthspace science, where the systems are not well controlled, and students who have no experience with "everyday, common materials/events" that would help them understand how to, for instance, model fusion in the core of a star. Great for physics teacher, though. Interestingly, the respondents who identified themselves as physics teachers do not seem to agree with this teacher's summation; five out of nine respondents who identified themselves as a physics teacher chose disagree as their response to the item.

\section{Research Question Three}

The third research question addressed what, if any, changes have K-12 science teachers made to their classroom practices (pedagogy, curriculum, and assessment) in response to the NGSS reform. The primary purpose of this study was to determine the extent to which teachers are amending their classroom practices to meet the expectations of the NGSS. Teacher thinking about teaching, students, the NGSS, and educational reform in general are engendered from personal and contextual factors. Their thinking is ultimately enacted in their classroom practices.

Three Likert-type survey items (questions 27-29) inquired about the extent of changes teachers have made to their instructional strategies, curriculum materials, and assessments in response to the NGSS. While the descriptive statistics indicated teachers are changing their instruction more than curriculum materials or assessments, the open-ended responses provided further detail.

The use of phenomena to drive instruction was mentioned twelve times within responses. Several respondents mentioned the science and engineering practices in general while others specified individual practices:

Many of the changes to align with the NGSS have come from aligning the with science 
and engineering practices. For example, my students are expected to do a lot more with developing and using models than they have in the past. In using the evidence statements, I have a more specific picture of how models should be used and assessed in the classroom, which means altering my instruction and their assessments.

Assessment was a major theme among open-ended question responses, though the corresponding response scale item result reported the lowest mean score $(\mathrm{M}=2.81, \mathrm{SD}=0.99)$ of the section. A number of teachers described moving away from the use of multiple choice items to more performance-based assessments. While responses described the changes taking place, they also highlighted the challenges teachers are facing. According to one respondent:

Driving a lesson from phenomena and students' questions is a big shift. We are working on shifting practices rather than content so there are some content areas that we haven't touched yet. Assessments are still very much our older formative and summative assessments. We have yet to have students develop their own investigations for assessment purposes.

Statistical test results suggest different degrees of change among and within groups. For example, fourteen of 39 respondents (36\%) who teach at the high school level indicated no or minimal curriculum changes while 17 (44\%) responded they had extensively changed curriculum. A multitude of factors may attribute to these uneven shifts and dichotomous responses to the NGSS in the classroom. Teachers' access to NGSS aligned materials for a particular grade band or content area may attribute to the differences seen among respondents. Open ended responses also indicate there are teachers who are responding symbolically to the NGSS: 
Mostly, I read through the NGSS when I was a teacher in NJ in order to figure out what numbers to put on my lessons. My overall approach to designing labs, writing assessments, and how I teach has not significantly changed as a result of the release of NGSS.

Even after attending professional learning experiences, some teachers seem to be misinformed as how to use the standards to prepare students for standardized assessments, which are being developed from the performance expectations, not the individual dimensions of the NGSS. After receiving some good professional development focused just on NGSS, I realized what the little grey boxes mean of the performance expectations. Since discovering this, I have referred to those grey boxes to help me outline what I want to see in my students during a unit.

Teachers may not be inherently resistant to the NGSS, but may not think change is necessary, potentially due to the lack of exposure or understanding of how an NGSS aligned classroom is different from their current practices. Further exploration into why teachers choose to respond only symbolically toward reforms is warranted. Studies that utilize individual interviews or focus groups methods may glean a more complete rationale behind this reform phenomenon.

The varying responses to reform evident within survey results support previous findings related to education reform. It appears that the NGSS have been communicated to most teachers, but the extent to which changes have been made to classroom materials, instructional approaches, and assessments varies. One or more factors may act as deterrents for teachers from who would otherwise be adjusting their practices to align with the NGSS.

In order to explore the perceived horizontal and vertical alignment within respondents' school systems, five items queried the changes made at the school and district-levels. The 
response scale for the five school and district level items was adjusted to account to respondents who may not be informed about the status of changes at these levels. The extent to which the curriculum map, materials, and assessments have changed at the school and district-level may substantively impact teachers' receptivity and ability to align their classroom-level practices to the NGSS. If changes are under way at a larger scale than individual classrooms, more funds may be available for teachers to participate in professional development and purchase new curriculum materials.

The means of the school-level and district-level change survey items were lower than the corresponding classroom-level items, while the standard deviations were higher. Changes to curriculum materials and assessments at all levels still seem to be works in progress. Fifty percent of respondents $(n=43)$ indicated minimal alignment of curriculum at the district level, while $16 \%(n=14)$ did not know about the status of curriculum alignment at that level. The reported mean of items related to changes to assessments were the lowest at the classroom, school, and district levels. In larger districts, teachers may not be privy to this information or only when it directly affects them. Yet, the vertical alignment of curriculum and instructional practices is pivotal to the success of the NGSS reform. The Guide to Implementing the Next Generation Science Standards (2015) provides guidance on the role teachers have within an aligned system:

Teachers will need to understand their part in the multiyear scope and sequences and support students in building on their prior knowledge, while they learn new topics or deepen their understanding of those they have been taught before (p. 54).

The lack of assessment alignment within schools and districts may be partly attributed to the slow development of state assessment systems. As states begin to administer tests for 
accountability measures, districts may be more willing to direct funding and resources toward aligning curriculum and assessments to the NGSS.

The lack of change in instructional approach, curriculum materials, and assessments at any level may be attributable to one or more factors. These barriers may make changing classroom practices challenging even if a teacher is receptive and willing to do so.

\section{Research Question Four}

Research question 4 identified the barriers that prevent classroom K-12 science teachers from implementing the NGSS as intended by those who developed the standards. While it is pertinent to understand what changes are being made due to the NGSS, it is equally important to explore factors teachers considered to be barriers to the NGSS transition process. By revealing teachers' perceptions of impediments to implementation of the NGSS, this study's results may assist those who are in positions to assist teachers with the transition. Administrators and professional development providers require insights as to what specific factors teachers perceive as limitations to reform, so they may remove or minimize those barriers.

Seven of the eight items (questions 36-43) in the barrier to implementation survey section reported mean scores that fell into the occasionally category on the response scale (Table 23). Each of these items also reported a standard deviation of greater than one, which indicates higher variation among item responses. The lack of availability or access to curriculum materials aligned to the NGSS had the highest reported mean of the section, followed closely by the lack of professional development opportunities and administration support. Responses to the section's open-ended question (question 44) provided further insight to the barriers teachers have encountered as they attempt to align their classroom practices to the NGSS. Multiple factors were mentioned in many open-ended responses, which suggests that many teachers must 
navigate more than one barrier as they transition their classroom practices to align with the NGSS. Each teacher is situated within a unique set of contextual factors that may facilitate or impede the implementation of reform. These varying circumstances coupled with teachers' distinct backgrounds may be largely attributable to the uneven implementation of previous reforms.

One barrier to implementation that was not included on the forced response items of the survey was a lack of time needed to transition practices to the NGSS. The survey items were based on findings in the research related to SBR implementation. While the Guide to Implementing the Next Generation Science Standards (2015) encourages a slow and gradual transition to the NGSS, some teachers seem to be struggling to find the time to do so. Seventeen of 73 open-ended responses (23\%) specifically mentioned time as a limiting factor to the implementation of the NGSS. Many of these responses mentioned additional barriers to the limited time available to transition classroom materials to align with the NGSS.

A lack of disciplinary content knowledge was not perceived as a barrier among respondents. However, there is research that suggests there is another level of understanding that is unique from pure content knowledge (Gess-Newsome, 2015). This skill is the ability to deliver content in a way that is accessible to students at their current level of understanding and the ability to build on that knowledge base. Pedagogical content knowledge may be particularly important in an NGSS aligned classroom, which is driven by student models and ideas of content (NRC, 2015). One respondent acknowledged the change in the role of the science teacher:

I changed the focus of my classroom from "what I am doing" during class to "what the students are doing during class." It shifts from the teacher delivering the information to the students discovering the information. 
While teacher disciplinary content knowledge is important in general, how that knowledge is related to and impacts student learning is less than clear. Pedagogical content knowledge may be the crucial link between student learning and teacher content knowledge, and the structure of the NGSS classroom may highlight the importance of this paradigm (GessNewsome, 2015).

The identification of specific impediments to the reform process may guide administrators and professional development providers in providing the appropriate support for classroom teachers, while education research can provide additional insight to help guide all stakeholders in reform efforts.

\section{Research Question Five}

Research question five examined possible relationships between teachers' familiarity, attitudes and levels of agreements, professional development attendance, barriers to implementation of the NGSS and reported changes to classroom practices. The TCSR model framework exhibits the interrelationship between these factors that shape teacher thinking and actions. While the NGSS and companion documents like the Guide to Implementing the Next Generation Science Standards (2015) provide the parameters for reform, the observable change in practices that are the intention of the reform are the actions and therefore the thinking of the classroom teacher. Three sets of correlations were computed between the familiarity, attitudinal, and barrier item responses and the reported changes to classroom practices. Though correlation does not indicate causation, the results of this analysis suggest certain factors may attribute or inhibit to the implementation of the NGSS and reforms in general.

The first set of significant correlations was found between teacher comfort level using the NGSS to create full instructional plans and reported teachers' changes to instructional practices 
and classroom assessments (Table 22). Pearson $r$ values indicated a positive, moderate association between the variables (Salkind, 2017). The practical interpretation of these results is simple; if a teacher is comfortable with using the standards, then changes to practices is more likely. If a teacher is uncomfortable using the standards to plan instruction, then changes to instruction or assessments is less likely to occur.

The second set of significant correlations was found between teachers' preparedness level due to professional development activities and reported changes to instructional practices, curriculum materials, and classroom assessments. Though still considered moderately associated, the positive Pearson $r$ values for the three items were the highest among the tested variables (Table 22). The degree of perceived preparedness and the amount of professional development teachers received was positively correlated to changes to instructional practices, curriculum materials, and classroom assessments. Thus, teachers' beliefs related to their perceived level of preparedness and the personal factor of the amount and nature of their professional learning appeared to influence teachers' actions. This result supports the interrelatedness of contextual factors and teacher thinking and actions described by the TCSR model.

The third set of Pearson correlations indicated weak to moderate positive associations between the degree to which teachers agreed the NGSS are easy to understand and their use for instructional planning and the extent of changes made to instructional practices, curriculum materials, and classroom assessment (Table 23). Teachers who more strongly agreed the standards are easy for them to use indicated a higher degree of change to their classroom practices. Open-ended responses support this result, most notably by those who did not perceived the NGSS as intuitive: 
There were virtually no helpful professional development experiences that were beneficial, as the structure of the NGSS seems unnecessarily archaic. It should not be difficult to figure out, for example, at what minimum depth projectile motion, Newton's Laws, energy, etc. should be taught, nor should I have to flip between multiple sections, chapters, etc. in order to find all the things to do with energy or momentum, etc. I understand that there are "cross -cutting concepts" and all the other jargon. The organization, however, leaves a lot to be desired, especially for teachers less experienced than I - and I say this as a fairly new teacher.

While other responses express more favorable opinions of the NGSS, they are more prevalent among those who mentioned attending extended professional learning experiences like NGSX, which was primarily designed by a member of the NGSS development team. Perhaps a better understanding of the nuances of the NGSS improves the utility of the standards for planning instruction.

The fourth set of significant findings were found between teachers' level of agreement that the NGSS will lead to permanent changes to practices and the extent of changes to classroom instructional practices, curriculum materials, and assessments reported by respondents. Results indicated weak to moderate positive associations between the variables, which suggest that teachers who perceived the changes brought about by the NGSS as permanent, have amended more classroom practices to align with the standards. While this result doesn't necessarily mean that teachers agree with the NGSS reform, it may suggest that if teachers believe the changes in the NGSS are not temporary, then they may be more likely to put in the time and effort to align their classroom practices with the new standards. 
The fifth set of significant findings were found between the extent to which teachers agreed the NGSS encompasses what science education should be at the grade level they teach and the degree of change to classroom instructional practice and assessments. Weak, positive linear relationships were found between the variables suggesting that teachers who more strongly agree the NGSS are what science teachers should be striving to achieve are changing their instruction and assessments to align their practice with their thinking.

\section{Limitations of the Findings}

There are a number of factors that may reduce the utilization of study results. Supovitz (2001) and Desimone (2009) caution that the use of self-reporting surveys to gather data on educator practices can be less than reliable. Though the Consortium for Policy Research in Education (CPRE) (1999) and Pop, Dixon, and Grove (2010) maintain the utility of findings from self-reported survey data. Sources of survey error is a potential limiting factor. The intent of this research study is to generalize the results from survey to the larger population of science teachers throughout the country. Survey errors can reduce the inferential accuracy to a larger population from the sample (Vannette, 2015). Respondents may truly believe and therefore report their practices have indeed changed, but upon observation, changes may be negligible. The local context in which K-12 science teachers operate vary and their responses to reforms are tied to those contextual variables; therefore, educators' self-reported beliefs, understandings, and attitudes, then, are relevant to a comprehensive understanding of how educators react to reforms (Education Week, 2001; Spillane \& Zeuli, 1999). The addition of open-ended questions may provide more thorough insight into respondents' thinking and actions.

The utilization of the NSTA listserv for the solicitation of study participants may slightly skew the study's results. Teachers who are members of NSTA may be more motivated to amend 
their practices and have better access to information and professional development activities.

The perceptions of teachers who are not members of a professional organization are as important as those who are, potentially more so, but to gain access to these individuals and convince them to participate in a research study may be difficult.

\section{Implications of the Findings}

\section{Teacher Thinking and Changes in Practice}

In order to initiate real change, reforms must focus on communicating and supporting the modification of educator practices and related school structures (Woodbury \& Gess-Newsome, 2002). Several documents and videos have been released to support the transition to the NGSS, including a document and video to help teachers understand the structure of the standards, student evidence statements and the NRC's Guide to Implementing the Next Generation Science Standards (2015), but it is less clear if educators are using these resources to assist in the transition to the NGSS. Albeit none of the resources were specifically mentioned in the survey; only one open-ended response mentioned the use of student evidence statements and no responses referred to the Guide to Implementing the NGSS, though these resources have been available for nearly three years. Results from the survey indicate while teachers are familiar with the three dimensions of the NGSS, on average, respondents were less than comfortable using them for planning instruction and did not consider the NGSS easy to use and understand.

\section{Inquiry Versus Three-Dimensional Learning}

Though survey respondents indicated they were familiar with the science and engineering practices and several open-ended responses referenced the dimension, it is less clear whether the practices have been integrated into science classrooms as intended. Respondents described using the practices as "a means to engage students with science content, a mechanism to reimagine 
assessments in units, and a guide for our narratives for each student." The Guide to

Implementing the Next Generation Science Standards (2015) cautions perceiving the practices as equivalent to inquiry, though some teachers are interpreting them in that way:

I was doing inquiry-based science in my classroom already. The modifications I have made are minor and include allowing students to have a role in the development of experiments as well as incorporating more problem-based learning and practical assessments that address science skills included in the NGSS.

While some teachers may truly only need to make minor adjustments to align with the NGSS, it is also possible that teachers may underestimate the changes required to implement threedimensional learning. Other teachers, while intent on implementing the NGSS with fidelity are struggling with the availability of time and resources required to make the transition.

\section{Content Knowledge}

Although a teacher's disciplinary content knowledge in exceedingly important to students' understanding, teachers' pedagogical content knowledge, their ability to support students' sense making and connections to prior knowledge is just as important (Garet, Porter, Desimone, Birman \& Yoon, 2001). While teachers' content knowledge is acknowledged as important among educators and research alike, whether this advanced knowledge translates into improved student learning is less than clear. A review of relevant studies found only a weak association between student outcomes and teacher content knowledge; while the reviewed analyses revealed that student achievement increases when students are taught by teachers with degrees in mathematics, the same analyses were inconclusive for science (Wayne \& Youngs, 2003). As teacher thinking and actions are mitigated by personal and contextual factors, the same can be said for students. Learning outcomes are impacted by the "amplifiers and filters" 
students possess and are constructed through students' experiences (Gess-Newsome, 2015, p. 40).

\section{Planning NGSS Aligned Instruction}

The analysis of the survey items related to teachers' familiarity with NGSS components suggests respondents are familiar with the major components of the NGSS but less confident in their use of the standard to create complete instructional plans. Pruitt (2014) argues full instructional plans as the appropriate planning method for the NGSS, rather than individual lesson plans. Resources such as the Educators Evaluating the Quality of Instructional Products (EQuIP) rubric are available to assist teachers in assessing the alignment of lesson materials to the NGSS (Achieve, 2014).

While select NGSS professional development systems (Reiser, Fumagalli, Novak \& Shelton, 2016) suggest and promote the use of 3D storylines to develop NGSS aligned instructional plans, several respondents mentioned the continued use of the $5 \mathrm{E}$ lesson plan model. The Biological Science Curriculum Study (BSCS) group developed a science instructional model that is widely used among science teachers; the five phases of the instructional model-engage, explore, explain, elaborate, and evaluate are used to organize science learning cycles (Bybee, 2014). Several open-ended responses described the continued use of the 5E planning model. Though the main author of the 5E model argues its continued utility, it is unclear whether using the lesson planning model supports or inhibits proper planning and implementation of the NGSS (Bybee, 2014). Reiser, Fumagalli, Novak and Shelton (2016) argued the storyline planning process appeared to be the preferred learning progression planning tool by stakeholders of the NGSS. 


\section{Future Research Directions}

\section{State Assessments}

Several survey respondents noted resistance to changing practices to align with the NGSS without a standardized assessment in place. Though teachers could prepare for the new state assessments by aligning their own assessments and other practices to the PEs component of the NGSS, as they incorporate the three dimensions of the standards and are the assessment target of the NGSS (NRC, 2015).

The movement to align state assessments to the NGSS has been slow. It seems that state agencies are finding it arduous to design a NGSS aligned assessment that can be delivered and scored on a mass scale. Currently, only three states and the District of Columbia are administering a yearly assessment purportedly aligned to the NGSS (Loewus, 2017). Federal mandates that require states to assess students in science seem to be further complicating the transition to new assessments. Illinois was the first to administer a state assessment purportedly aligned to the NGSS to comply with the federal mandate (ISBE, 2016). The hasty development of the new assessment was questioned by experts and other state officials; to develop an assessment system aligned to the three-dimensional design of the NGSS is not an easy task to accomplish (Loewus, 2017). Further research is needed to examine state education agencies' efforts and practices as they transition their assessment systems to align with the NGSS.

\section{Planning NGSS Aligned Instruction}

Several open-ended responses described the continued use of the 5E planning model. Though the originator of the 5E model argues its continued utility, it is unclear whether using the lesson planning model supports or inhibits proper planning and implementation of the NGSS (Bybee, 2014). The storyline planning process seems to be the preferred learning progression 
planning tool by stakeholders of the NGSS (Reiser et al., 2016). The student evidence statements are a planning resource that may prove to be very useful to classroom teachers. Examination of the best methods for the development of full instructional plans and coherent alignment to assessments warrants further investigations.

\section{Professional Learning}

While there is general accord within recent science education literature that teachers require professional development to meet the demands of the NGSS (NGSS Lead States, 2013; Pruitt, 2014; Reiser et al., 2017) it is less clear whether the majority of classroom teachers agree with this consensus. This study's results support this argument. For example, the use of models is noted to be a particularly challenging practice for teachers to implement, though many respondents claimed to be incorporating it into their classrooms (Banilower et al., 2013). Study results suggest that a significant amount of professional learning is required to change teacher beliefs and provoke real change in classroom practices. However, changes to teacher practices should not be the end goal of a reform. Improved student learning should be the objective of any endeavor in education. The model of teacher professional knowledge and skill (TPK\&S) may provide a suitable framework for future research. The TPK\&S model may assist in the understanding of what skills and knowledge are most useful in producing improved student outcomes.

While teachers' content knowledge is acknowledged as important among educators, the resultant student learning impact is less than obvious. Considering relevant research, curricular, pedagogical, assessment, and other specific types of professional knowledge may be equally important. Research findings examining content knowledge and student outcomes are mixed. Wayne and Youngs' (2003) research review found only a weak relationship between student 
outcomes and teacher content knowledge, while Diamond, Maerten-Rivera, Rohrer and Lee (2014) found knowledge of science content to be the largest teacher-level predictor of elementary student outcomes. Science content knowledge is important, but more research needs to be done to fully understand the relationship between teacher content knowledge and student learning outcomes. While the disciplinary core ideas (DCIs) may be the dimension most directly related to content knowledge, deep understanding of the content may be equally paramount to facilitate student utilization of the science and engineering practices as well as making connections between the cross-cutting concepts.

Experienced teachers integrate new strategies and knowledge differently than new teachers (Borko \& Livingston, 1989). The management of a phenomenon-driven and studentinfluenced classroom required by the NGSS may seem daunting to the novice teacher. As with other personal and contextual factors, unequal implementation of the NGSS as intended may be the result. Differentiated professional learning experiences, including management strategies through peer collaboration and mentorship may be beneficial to support student engagement and implementation of the NGSS as intended (Windschitl, Thompson \& Braaten, 2008).

\section{Reform Evaluation and Guidance}

The TCSR model provided the framework of the study, which examined teachers' thinking and actions related to the NGSS. The model integrates the plethora of factors that impact teacher classroom practices. It provides an appropriate template for evaluating the effect of a reform initiative, though it also may be used to guide reform efforts. Other researchers may find utility in the TCSR model for examining the relationships between the many personal and contextual factors that influence teacher thinking and practice. As reform continues to proliferate public education, the factors that facilitate and impede positive change in the 
classroom should be regularly examined from the perspectives of those who are most affected by the reforms.

\section{Summary}

Teachers' knowledge and beliefs, their personal backgrounds, and the contextual factors that influence their practices provide a framework built from the interrelatedness of the varying perspectives of reform. While study results suggest that teachers generally perceive the changes brought about by the NGSS to be beneficial to students, uneven implementation seems to be inevitable. The three-dimensional design of the standards requires substantial changes in practice according to its developers, some teachers do not perceive the NGSS to be a second order change. The perceived assurance of proficient content knowledge by most respondents is a bit concerning, though perhaps it may be more of a pedagogical content knowledge matter, as deep content knowledge and the aptitude to approach disciplinary content in a way so it is accessible to students is imperative to facilitate learning in science.

In addition to the requirement of more time required for the transition to NGSS practices, the varying availability of quality professional learning opportunities and curricular materials appear to be the primary barriers to implementation. The standards also seem to be a bit troublesome to use for the planning of instruction, especially when attempting to do so using established planning models, like the $5 \mathrm{E}$ approach. While change is apparent by the accounts of phenomenon-based instruction by respondents, the slow development of state assessment systems may be an impediment to the adoption of the NGSS. Twenty of the fifty states, fewer than the twenty-six lead states have adopted the NGSS. While respondents were not overly concerned with the slow development of a standardized assessment in many states, the 
development of sound and informative assessments may prompt the adoption of the NGSS among non-adoptive states.

While teachers are reportedly making changes at the individual classroom level, the amount of collaboration and vertical alignment among K-12 science teachers is less clear. While the NGSS may not prove to be the cure-all to the country's economic and technological challenges, the NGSS may indeed lead to permanent changes in the science classroom. 


\section{REFERENCES}

Academic Benchmarks. (2015). Next Generation Science Standards adoption map. Retrieved from http://academicbenchmarks.com/next-generation-science-standards-adoption-map/

Achieve, Inc. (2013). Closing the expectations gap: 2013 annual report. Retrieved from https://www.achieve.org/files/2013ClosingtheExpectationsGapReport.pdf

Achieve, Inc. (2014). Educators evaluating the quality of instructional products [EQuIP] rubric for lessons and units: Science. [Version 2, Sept. 2014]. Retrieved from http://www.nextgenscience.org/resources

Achinstein, B., Ogawa, R., \& Spiegelman, A. (2004). Are we creating separate and unequal tracks of teachers? American Educational Research Journal, 41(3), 557-603.

American Association for the Advancement of Science. (1993). Benchmarks for science literacy. New York, NY: Oxford University Press.

Anderson, R. D. (2002). Reforming science teaching: What research says about inquiry. Journal of Science Teacher Education, 13(1), 1-12. Retrieved from http://mascil-toolkit.phfreiburg.de/wp-content/uploads/2014/03/Anderson-2002.pdf

Apple, M. W. (2012). Can education change society? New York, NY: Routledge.

Argyris, C., Putnam, R., \& McLain-Smith, D. (1985). Action science. San Francisco, CA: Jossey-Bass.

Banilower, E. R., Smith, P. S., Weiss, I. R., Malzahn, K. A., Campbell, K. M., \& Weis, A. M. (2013). Report of the 2012 national survey of science and mathematics education. Chapel Hill, NC: Horizon Research, Inc.

Bidwell, C. E. (2001). Analyzing schools as organizations: Long-term permanence and shortterm change. Sociology of Education, 74(1), 100-114. doi: 10.2307/2673256 
Black, P., \& Wiliam, D. (2010). Inside the black box: Raising standards through classroom assessment. Phi Delta Kappan, 92(1), 81-90. doi: 10.1177/003172171009200119

Blumenfeld, P.C., Krajcik, J.S., Marx, R.W., \& Soloway, E. (1994). Lessons learned: How collaboration helped middle grade science teachers learn project based instruction. Elementary School Journal, 94(5), 539-551.

Boyd, W. L. (1988). How to reform schools without half trying: Secrets of the Reagan administration. Educational Administration Quarterly, 24(3), 299-309.

Branch, G. (2013, April 9). Evolution and climate change in the NGSS. National Center for Science Education News. Retrieved from https://ncse.com/news/2013/04/evolutionclimate-change-ngss-0014800

Bryan, L. A. (2003). Nestedness of beliefs: Examining a prospective elementary teacher's belief system about science teaching and learning. Journal of Research in Science Teaching, 40(9), 835-868.

Bybee, R. W. (2014). The BSCS 5E instructional model: Personal reflections and contemporary implications. Science and Children, 51(8), 10-13.

Coburn, C. E. (2004). Beyond decoupling: Rethinking the relationship between the institutional environment and the classroom. Sociology of Education, 77(3), 211-244.

Cohen, D. K. (1990). A revolution in one classroom: The case of Mrs. Oublier. Educational Evaluation and Policy Analysis, 12(3), 311-329. Retrieved from http://www.jstor.org/stable/1164355

Cohen, D. K., \& Ball (1990). Policy and practice: An overview. Educational Evaluation and Policy Analysis, 12(3), 233-239. Retrieved from http://www.jstor.org/stable/1164349 
Consortium for Policy Research in Education. (1999). A close look at effects on classroom practice and student performance: A report of the fifth year of the Merck Institute for Science Education 1997-98. CPRE evaluation report: Author.

Crawford, B.A. (2000). Embracing the essence of inquiry: New roles for science teachers. Journal of Research in Science Teaching, 37(9). 916-937.

Crawford, B. A. (2007). Learning to teach science as inquiry in the rough and tumble of practice. Journal of Research in Science Teaching, 44, 613-642. doi: 10.1002/tea.20157

Cremin, L. A. (1990). Popular education and its discontents. New York, NY: Harper Collins.

Creswell, J. (2008). Educational research: Planning, conducting, and evaluating quantitative and qualitative research. ( $3^{\text {rd }}$ ed.). Upper Saddle River, NJ: Pearson.

Creswell, J. (2014). Research design: Qualitative, quantitative, and mixed methods approaches. Thousand Oaks, CA: Sage.

Croft, S. J., Roberts, M. A., \& Stenhouse, V. L. (2016). The perfect storm of education reform: High-stakes testing and teacher evaluation. Social Justice, 42(1), 70.

Cuban, L. (1993). How K-12 science teachers taught: Constancy and change in American classrooms, 1890-1990. New York, NY: K-12 science teachers College Press.

Cuban, L. (2008). Frogs into princes: Writings on school reform. New York, NY: K-12 science teachers College Press.

Cuban, L. (2009). Hugging the middle: How K-12 science teachers teach in an era of testing and accountability. New York, NY: K-12 science teachers College Press.

Cuban, L. (2013). Inside the black box of classroom practice: Change without reform in American education. Cambridge, MA: Harvard Education Press. 
Darling-Hammond, L. (2004). Standards, accountability, and school reform. K-12 science teachers College Record, 106(6), 1047-1085.

Demir, A. \& Abell, S. K. (2010). Mismatches between views of science education faculty and students of an alternative certification programs. Journal of Science Teaching, 47(6), 716-741.

Desimone, L. (2009). Improving impact studies of teachers' professional development: Toward better conceptualizations and measures. Educational Researcher, 38(3), 181-199. doi: $10.3102 / 0013189 X 08331140$

Desimone, L. (2013). Teacher and administrator responses to standards-based reform. Teachers College Record, 115(8), 1-53. Retrieved from http://www.tcrecord.org.libproxy.lib.ilstu.edu/Content.asp?ContentId=17083

Dewey, J. (1901). The situation as regards the course of study. Journal of the Proceedings and Addresses of the Fortieth Annual Meeting of the National Education Association. Detroit, MI: Graham Print.

Diamond, J. B. (2007). Where the rubber meets the road: Rethinking the connection between high-stakes testing policy and classroom instruction. Sociology of Education, 80(4), $285-$ 313. doi: $10.1177 / 003804070708000401$

Diamond, B. S., Maerten-Rivera, J., Rohrer, R. E., \& Lee, O. (2014). Effectiveness of a curricular and professional development intervention at improving elementary teachers' science content knowledge and student achievement outcomes: Year 1 results. Journal of Research in Science Teaching, 51(5), 635-658.

Driscoll, M. E. (1995). We have the right to be different: Educational community through a neoinstitutional lens. Journal of Education Policy, 10(5), 55-68. 
Education Week. (2001, January 11). Quality counts 2001: A better balance. Retrieved from http://www.edweek.org/media/ew/qc/archives/QC01full.pdf

Elmore, R. E., McLaughlin, M. W. (1988). Steady work: Policy, practice, and the reform of American education. Santa Monica, CA: Rand Corporation.

Enderle, P., Dentzau, M., Roseler, K., Southerland, S., Granger, E., Hughes, R., ... \& Saka, Y. (2014). Examining the influence of RETs on science teacher beliefs and practice. Science Education, 98(6), 1077-1108.

Fairman, J. C., \& Firestone, W. A. (2001). The district role in state assessment policy: An exploratory study. In S. H. Fuhrman (Ed.), From the capitol to the classroom: Standardsbased reform in the states (pp. 124-147). Chicago, IL: University of Chicago Press.

Fibkins, W. L. (2015). The graveyard of school reform: Why the resistance to change and new ideas. Lanham, MD: Rowman \& Littlefield.

Fullan, M. (2007). The new meaning of educational change. ( $4^{\text {th }}$ ed.). New York, NY: Teachers College Press.

Garet, M. S., Porter, A. C., Desimone, L., Birman, B. F., \& Yoon, K. S. (2001). What makes professional development effective? Results from a national sample of teachers. American educational research journal, 38(4), 915-945.

Germann, P. J., \& Aram, R. J. (1996). Student performances on the science processes of recording data, analyzing data, drawing conclusions, and providing evidence. Journal of Research in Science Teaching, 33(7), 773-798.

Gess-Newsome, J. (1999). Secondary teachers' knowledge and beliefs about subject matter and its impact on instruction. In J. Gess-Newsome \& N.G. Lederman (Eds.), Examining 
pedagogical content knowledge: The construct and its implications for science education (pp. 51-94). Dordrecht, Netherlands: Kluwer.

Gess-Newsome, J. (2015). A model of teacher professional knowledge and skill including PCK. In A. Berry, P. Friedrichsen, \& J. Loughran (Eds.), Re-examining pedagogical content knowledge in science education, (28-42). New York, NY: Routledge.

Gess-Newsome, J., Southerland, S., Johnston, A., \& Woodbury, S. (2003). Educational reform, personal practical theories, and dissatisfaction: The anatomy of change in college science teaching. American Educational Research Journal, 40(3), 731-767.

Glesne, C. (2011). Becoming qualitative researchers. ( $4^{\text {th }}$ ed.). Boston, MA: Allyn \& Bacon.

Grant, S. G., Peterson, P. L., \& Shojgreen-Downer, A. (1996). Learning to teach mathematics in the context of systemic reform. American Educational Research Journal, 33(2), 509-541.

Gregoire, M. (2003). Is it a challenge or a threat? A dual-process model of K-12 science teachers' cognition and appraisal processes during conceptual change. Educational Psychology Review, 15(2), 147-179.

Green, S. B., \& Salkind, N. J. (2014). Using SPSS for Windows and Macintosh: Analyzing and understanding data. New York, NY: Pearson.

Guskey, T. R., \& Bailey, J. M. (2009). Developing standards-based report cards. Thousand Oaks, CA: Corwin.

Hamilton, L. S., Stecher, B. M., \& Yuan, K. (2008). Standards-based reform in the United States: History, research, and future directions (No. RP-1384). Santa Monica, CA: RAND Corporation.

Hiebert, J., \& Stigler, J. W. (2000). A proposal for improving classroom teaching: Lessons from the TIMSS video study. The Elementary School Journal, 101(1), 3-20. 
Hlebowitsh, P. S., \& Wraga, W. G. (1989). The reemergence of the National Science Foundation in American education: Perspectives and problems. Science Education, 73(4), 405-418.

Illinois State Board of Education. (2016). Fact sheet: Illinois state learning standards in science. Retrieved from https://www.isbe.net/Documents/ILS-Science-fact-sheet-0216.pdf

Jaccard, J., \& Wan, C. K. (1996). LISREL approaches to interaction effects in multiple regression. Thousand Oaks, CA: Sage.

Jamieson, S. (2004). Likert scales: How to (ab)use them. Medical Education, 38(12), 1217-1218.

Johnson, L. B. (September 28, 1964). Remarks in Providence at the 200th anniversary convocation of Brown University. The American Presidency Project. Retrieved from http://www.presidency.ucsb.edu/ws/?pid=26534.

Jeanpierre, B., Oberhauser, K., \& Freeman, C. (2005). Characteristics of professional development that effect change in secondary science K-12 science teachers' classroom practices. Journal of Research in Science Teaching, 42(6), 668-690.

Keeney, S., Hasson, F., \& McKenna, H. (2011). The delphi technique. The Delphi technique in nursing and health research, 1-17. DOI: 10.1002/9781444392029.ch1

Kennedy, M. M. (1998). Education reform and subject matter knowledge. Journal of Research in Science Teaching, 35, 249-263.

Keys, C. W., \& Bryan, L. A. (2001). Co-constructing inquiry-based science with K-12 science teachers: Essential research for lasting reform. Journal of Research in Science Teaching, 38(6), 631-645.

Kliebard, H. M. (2002). Changing course: American curriculum reform in the 20th century. New York, NY: K-12 science teachers College Press. 
Kliebard, H. M. (2004). The struggle for the American curriculum: 1893-1958 (3 $3^{\text {rd }}$ ed.). New York, NY: RoutledgeFalmer.

Krejcie, R. V. \& Morgan, D.W. (1970). Determining sample size for research activities. Educational and Psychological Measurement, 30(3), 607-610.

Labaree, D. F. (1987). Politics, markets, and the compromised curriculum. Harvard Educational Review, 57(4), 483-495.

Labaree, D. F. (2012). Someone has to fail. Cambridge, MA: Harvard University Press.

Lauer, P.A., Snow, D., Martin-Glenn, M., Van Buhler, R.J., Stoutenmyer, K., \& Snow-Renner, R. (2005). The influence of standards on K-12 teaching and student learning: A research synthesis. Denver, CO: Mid-Content Research for Education and Learning.

Lee, O., Hart, J. E., Cuevas, P., \& Enders, C. (2004). Professional development in inquiry-based science for elementary K-12 science teachers of diverse student groups. Journal of Research in Science Teaching, 41(10), 1021-1043.

Lieberman, A., \& Mace, D. H. (2008). Teacher learning: The key to educational reform. Journal of Teacher Education, 59(3), 226-234. doi: 10.1177/0022487108317020

Loeb, H., Knapp, M. S., \& Elfers, A. M. (2008). K-12 science teachers' response to standardsbased reform: Probing reform assumptions in Washington State. Education Policy Analysis Archives, 16(9). Retrieved from http://epaa.asu.edu/epaa/v16n9

Loewus, L. (2017). In science new-wave tests slowly take shape: Few states so far have moved to assessments aligned to the Next Generation standards. Education Week, 36(32), 15-18.

Lund Research, Ltd. (2013). Measures of Spread. Retrieved from https://statistics.laerd.com/statistical-guides/measures-of-spread-range-quartiles.php 
Martens, M. L. (1992). Inhibitors to implementing a problem-solving approach to teaching elementary science: Case study of a teacher in change. School science and Mathematics, 92(3), 150.

Marx, R. W., Blumenfeld, P. C., Krajcik, J. S., Blunk, M., Crawford, B., \& Meyer, K. M. (1996). Enacting project-based science: Experience of four middle grade K-12 science teachers. The Elementary School Journal, 94(5), 517-538.

Massell, D., \& Perrault, P. (2014). Alignment: Its role in standards-based reform and prospects for the Common Core. Theory into Practice, 53(3), 196-203. doi:

$10.1080 / 00405841.2014 .916956$

McLaughlin, M. (1987). Learning from experience: Lessons from policy implementation. Educational Evaluation and Policy Analysis, 9(2), 171-178. Retrieved from http://www.jstor.org/stable/1163728

Mehta, J. (2013). The allure of order: High hopes, dashed expectations, and the troubled quest to remake American schooling. New York, NY: Oxford University Press.

Metz, M. H. (1989). Real school: A universal drama amid disparate experience. Politics of Education Association Yearbook, 4(5), 75-91.

Michaels, S., \& O’Connor, C. (2015). Conceptualizing talk moves as tools: Professional development approaches for academically productive discussion. Socializing intelligence through talk and dialogue, 347-362. Retrieved from https://www.ngsx.org/files/5414/24 63/8487/MichaelsOConnor_Talk_Moves_as_Tools_Resnick_Volume.pdf

Minner, D.D., Levy, A.J. \& Century, J. (2010). Inquiry-based science instruction-what is it and does it matter? Results from a research synthesis years 1984 to 2002. Journal of Research in Science Teaching, 47(4), 474-496. 
National Council for the Social Studies. (2010). Standards. Retrieved from http://www.socialstudies.org/standards

National Research Council. (1996). National science education standards. Washington, DC: The National Academies Press.

National Research Council. (2011). A framework for K-12 science education: Practices, crosscutting themes, and core ideas. Washington, DC: National Academies Press.

National Research Council. (2015). Guide to implementing the Next Generation Science Standards. Washington, DC: The National Academies Press.

National Science Teachers Association. (2014). About the Next Generation Science Standards. Retrieved from http://ngss.nsta.org/About.aspx

Newmann, F. M., Smith, B., Allensworth, E., \& Bryk, A. S. (2001). School instructional program coherence: Benefits and challenges. Chicago, IL: Consortium on Chicago School Research.

NGSS Lead States. (2013a). Appendix A: Conceptual shifts in the Next Generation Science Standards. Retrieved from http://www.nextgenscience.org/sites/ngss/files/Appendix\%20A\%20\%204.11.13\%20Conceptual\%20Shifts\%20in\%20the \%20Next\%20Generation\%20Scienc e\%20Standards.pdf

NGSS Lead States. (2013b). Final Release NGSS Front Matter. Retrieved from http://www.nextgenscience.org/sites/default/files/Final\%20Release\%20NGSS\%20Front \%20Matter\%20-\%206.17.13\%20Update_0.pdf. 
NGSS Lead States. (2013c). Support from the scientific, engineering, and education

communities. Retrieved from http://www.nextgenscience.org/support-scientificengineering-and-education-communities

NGSS Lead States. (2013d). Standards background: research and reports. Retrieved from http://www.nextgenscience.org/standards-background-research-and-reports

NGSS Lead States. (2013e). The need for new science standards. Retrieved from http://www.nextgenscience.org/overview-0

NGSS Lead States. (2013f). Three-dimensional learning. Retrieved from http://www.nextgenscience.org/three-dimensions

NGSS Lead States. (2013g). Response to public drafts. https://www.nextgenscience.org/sites/default/files/Appendix\%20B\%20\%20Responses\%20to\%20the\%20Public\%20Drafts.pdf

Oliveira, A. W., Wilcox, K. C., Angelis, J., Applebee, A. N., Amodeo, V., \& Snyder, M. A. (2013). Best practice in middle-school science. Journal of Science Teacher Education, 24(2), 297-322. doi:10.1007/s10972-012-9293-0

Pajares, M. F. (1992). Teachers' beliefs and educational research: Cleaning up a messy construct. Review of Educational Research, 62(3), 307-322.

Penuel, W. R., Harris, C. J., \& DeBarger, A. H. (2015). Implementing the next generation science standards. Phi Delta Kappan, 96(6), 45-49. doi:10.1177/0031721715575299

Pop, M. M., Dixon, P., \& Grove, C. M. (2010). Research experiences for teachers (RET): Motivation, expectations, and changes to teaching practices due to professional program involvement. Journal of Science Teacher Education, 21(2), 127-147. doi: $10.1007 / \mathrm{s} 10972-009-9167-2$ 
Popham, J. W. (2014). Classroom assessment: What teachers need to know ( $7^{\text {th }}$ ed.). Boston, MA: Pearson.

Porac, J. F., Thomas, H., \& Baden-Fuller, C. (1989). Competitive groups as cognitive communities: The case of Scottish knitwear manufacturers. Journal of Management studies, 26(4), 397-416.

Prawat, R. S. (1992). K-12 science teachers' beliefs about teaching and learning: A constructivist perspective. American Journal of Education, 100(3), 354-395.

Priestley, M. (2011). Schools, teachers, and curriculum change: A balancing act? Journal of Educational Change, 12(1), 1-23. http://dx.doi.org/10.1007/s10833-010-9140-z

Pruitt, S. L. (2014). The next generation science standards: The features and challenges. Journal of Science Teacher Education, 25(2), 145-156. doi:10.1007/s10972-014-9385-0

Ramberg, M. R. (2014). What makes reform work? School-based conditions as predictors of K12 science teachers' changing practice after a national curriculum reform. International Education Studies, 7(6), 46. doi:10.5539/ies.v7n6p46

Ravitch, D. (2010). The death and life of the great American school system: How testing and choice are undermining education. New York, NY: Basic Books.

Reese, W. J. (2002). Power and the promise of school reform: Grassroots movements during the progressive era. New York: K-12 science teachers College Press.

Reiser, B. J. (2013). What professional development strategies are needed for successful implementation of the Next Generation Science Standards? Retrieved from http://www.ets.org/Media/Research/pdf/reiser.pdf

Reiser, B. J., Fumagalli, M., Novak, M., \& Shelton, T. (2016). Using storylines to design or adapt curriculum and instruction to make it three-dimensional. Retrieved from 
https://www.academia.edu/24083676/Using_Storylines_to_Design_or_Adapt_Curriculu m_and_Instruction_to_Make_It_Three-Dimensional

Reiser, B.J., Michaels, S., Moon, J., Bell, T., Dyer, E., \& Edwards, K.D. (2017). Scaling up three-dimensional science learning through teacher-led study groups across a state. Journal of Teacher Education, 68(3), 280-298. doi: 10.1177/0022487117699598

Roseman, J., Fortus, D., Krajcik, J., \& Reiser, B. J. (2015). Curriculum Materials for Next Generation Science Standards: What the Science Education Research Community Can Do. Proceedings from NARST 2015: Northwestern University Symposium. Chicago, IL.

Rossi, P. H., Wright, J. D., \& Anderson, A. B. (Eds.). (2013). Handbook of survey research. New York, NY: Academic Press.

Salkind, N. J. (2017). Statistics for people who (think they) hate statistics $\left(6^{\text {th }}\right.$ ed.). Thousand Oaks, CA: Sage.

Sarason, S. (1996). Revisiting: The culture of school and the problem of change. New York, NY: Teachers College Press.

Schneider, R. M., Krajcik, J., \& Blumenfeld, P. (2005). Enacting reform-based science materials: The range of teacher enactments in reform classrooms. Journal of Research in Science Teaching, 42(3), 283-312.

Schön, D. A. (1973). Beyond the stable state. New York, NY: Norton.

Schön, D. A. (1987). Educating the reflective practitioner. San Francisco, CA: Jossey-Bass.

Slavin, R. E. (1989). PET and the Pendulum: Faddism in Education and how to Stop It. Phi Delta Kappan, 70(10), 752-58.

Smith M.S., \& O’Day, J. (1990). Systemic school reform. Journal of Education Policy, 5(5), 233-267. doi:10.1080/02680939008549074 
Spillane, J. P. (2000). Cognition and policy implementation: District policymakers and the reform of mathematics education. Cognition and Instruction, 18(2), 141-179. Retrieved from http://www.jstor.org/stable/3233866?origin=JSTOR-pdf

Spillane, J. P., Reiser, B. J., \& Reimer, T. (2002). Policy implementation and cognition: Reframing and refocusing implementation research. Review of Educational Research, 72(3), 387-431.

Spillane, J., \& Thompson, C. (1997). Reconstructing conceptions of local capacity: The local education agency's capacity for ambitious instructional reform. Educational Evaluation and Policy Analysis, 19(2), 185-203. Retrieved from http://www.jstor.org/stable/1164209

Spillane, J. P., \& Zeuli, J. S. (1999). Reform and teaching: Exploring patterns of practice in the context of national and state mathematics reforms. Educational Evaluation and Policy Analysis, 21(1), 1-27.

Stake, R. E., \& Easley, J. A. (1978). Case studies in science education (Vol. 2). Washington, D.C.: U.S. Government Printing Office. (No. 038-000-00376-3)

Stecher, B. M., Barron, S. L., Chun, T. \& Ross, K. (2000). The effects of the Washington state education reform on schools and classrooms (CSE Technical Report No. 525). Los Angeles, CA: UCLA National Center for Research on Evaluation, Standards and Student Testing.

Stecher, B. M., Epstein, S., Hamilton, L. S., Marsh, J. A., Robyn, A., McCombs, J. S., Russell, J., et al. (2008). Pain and Gain: Implementing No Child Left Behind in three states, 20042006. Santa Monica, CA: RAND Corporation. 
Stern, L., \& Roseman, J. E. (2004). Can middle-school science textbooks help students learn important ideas? Findings from Project 2061's curriculum evaluation study: Life science. Journal of Research in Science Teaching, 41(6), 538-568.

Supovitz, J. A. (2001). Translating teaching practice into improved student performance. In S. H. Fuhrman (Ed.), From the capitol to the classroom: Standards-based reform in the states (pp. 81-98). Chicago, IL: University of Chicago Press.

Supovitz, J. A., \& Turner, H. M. (2000). The effects of professional development on science teaching practices and classroom culture. Journal of Research in Science Teaching, 37(9), 963-980.

Tavakol, M., \& Dennick, R. (2011). Making sense of Cronbach's alpha. International journal of medical education, 2, 53-55. DOI: 10.5116/ijme.4dfb.8dfd

Taylor, M. W. (2016). From effective curricula toward effective curriculum use. Journal for Research in Mathematics Education, 47(5), 440-453. doi:10.5951/jresematheduc.47.5.0440

Tyack, D. B., \& Cuban, L. (1995). Tinkering toward utopia: a century of public school reform. Cambridge, MA: Harvard University Press.

Tyack, D. (1974). The one best system: A history of American urban education. Cambridge, MA: Harvard University Press.

Tyack, D., \& Hansot, E. (1981). Conflict and consensus in American public education. Daedalus, 110(3), 1-25.

Tyack, D., \& Tobin, W. (1994). The "grammar" of schooling: Why has it been so hard to change? American Educational Research Journal, 31(3), 453-479. 
Vanderhoek, A. J., Hammal, F., Chappell, A., Wild, T. C., Raupach, T., \& Finegan, B. A. (2013). Future physicians and tobacco: an online survey of the habits, beliefs and knowledge base of medical students at a Canadian University. Tobacco Induced Diseases, 11(1), 9. DOI: 10.1186/1617-9625-11-9

Vannette, D. (2015, April 15). Sources of error in survey research. [Blog]. Retrieved from https://www.qualtrics.com/blog/sources-of-error-in-survey-research/

Vaughan, D. (1996). The challenger launch decision: Risky technology, culture and deviance at NASA. Chicago, IL: University of Chicago Press.

Visser, P. S., Krosnick, J. A., \& Lavrakas, P. J. (2000). Survey Research. Retrieved from http://web.stanford.edu/dept/communication/faculty/krosnick/Survey_Research.pdf

Watzlawick, P., Weakland, J., \& Fisch, R. (2011). Change: Principles of problem formation and problem resolution. New York, NY: Norton.

Wayne, A. J., \& Youngs, P. (2003). Teacher characteristics and student achievement gains: A review. Review of Educational Research, 73(1), 89-122. Retrieved from http://www.jstor.org/stable/3516044

Welch, W. W. (1979). Twenty years of science curriculum development: A look back. Review of Research in Education, 7(1), 282-306.

Windschitl, M., Thompson, J., \& Braaten, M. (2008). Beyond the scientific method: Modelbased inquiry as a new paradigm of preference for school science investigations. Science education, 92(5), 941-967. doi 10.1002/sce.20259

Wilcox, J., Kruse, J. W., \& Clough, M. P. (2015). Teaching science through inquiry. The Science Teacher, 82(6), 62. 
Wilson, S. M. (2013). Professional development for science K-12 science teachers. Science, 340(6103), 310-313. doi: 10.1126/science. 1230725

Wilson, S.M., \& Floden, R.E. (2001). Hedging bets: Standards-based reform in classrooms. In S.H. Fuhrman (Ed.), From the capitol to the classroom: Standards-based reform in the states (pp. 193-216). Chicago, IL: The University of Chicago Press.

Wilson, C. D., Taylor, J. A., Kowalski, S. M., \& Carlson, J. (2010). The relative effects and equity of inquiry-based and commonplace science teaching on students' knowledge, reasoning, and argumentation. Journal of Research in Science Teaching, 47(3), 276-301. doi: $10.1002 /$ tea.20329

Woodbury, S. (2000). The reform of practice and the practice of reforms: Teachers and change in high school mathematics (Unpublished doctoral dissertation), University of Utah, Salt Lake City.

Woodbury, S., \& Gess-Newsome, J. (2002). Overcoming the paradox of change without difference: A model of change in the arena of fundamental school reform. Educational Policy, 16(5), 763-782.

Zhang, M. M., Parker, J., Koehler, M., \& Eberhardt, J. (2015). Understanding in-service science K-12 science teachers' needs for professional development. Journal of Science Teacher Education, 26(5), 471-496. 


\section{APPENDIX A: SURVEY}

\section{Attachment A: Recruitment (email) Letter}

Date:

Dear NSTA Member:

I am a currently pursuing my doctorate in curriculum and instruction through the School of Teaching and Learning at Illinois State University. I would like to invite you to participate in a brief, confidential survey to assist with my dissertation research.

I am conducting a research study to better understand educators' understandings and perceptions of the Next Generation Science Standards (NGSS). I intend to explore and examine the factors that contribute to or inhibit the changes to science teachers' curriculum and instructional practices in response to the NGSS. My objective is to examine the process of translating an educational reform policy into changes in classroom practices from the perspective of science teachers. I would like to invite you to participate in a brief, confidential survey to assist with my dissertation research.

If you would like to participate, please click the link below. The survey will be available now until Month day, 2017 at URL link.

Thank you for your time and assistance in this study. Your opinions will be invaluable to the success of this research study.

Sincerely,

Angela R. Bowden 
Survey of Curricular and Pedagogical Reform in the Science Classroom

Dear participant,

My name is Angela Bowden and I am a doctoral student under the direction of Dr. Steven Mertens in the School of Teaching and Learning at Illinois State University. I am conducting dissertation research examining teachers' perceptions and implementation of the Next Generation Science Standards (NGSS).

If you choose to participate, it will involve answering survey questions regarding your attitudes and practices concerning the Next Generation Science Standards. You will also be asked to provide some basic demographic information. This online survey should take approximately 15 minutes of your time. You can choose to skip those questions you do not wish to answer. I encourage you to complete the survey on a computer or tablet during one of your work-day breaks or at home.

Please be aware your participation in this study is completely voluntary. You are not expected to participate. If you choose not to participate or to withdraw from the study at any time, there will be no penalty. The results of the research study may be published, but all surveys are completely anonymous and your name will not be connected to results or used in any way. The information provided will not be used in any way to impact teacher evaluation.

The goal of the study is to benefit the field of teaching and learning; however, there may be no direct benefit to you. The possible benefit of your participation is through examining your own beliefs about instructional practices and the use of the NGSS, reflecting on your own teaching strategies. There are minimal physical, psychological, or social risks to the participants in this study. Some participants may be concerned about revealing their own knowledge, or lack of knowledge, with the NGSS, as well as any implications this may have as a reflection of their knowledge level.

If you would like to participate in this anonymous research study, please continue and follow the onscreen instructions.

If you have questions, please reply to this email or call me at (309) $* * * * * * *$ or Dr. Steven Mertens at (309) ******** with your interest. If you have any questions about your rights as a subject/participant in this research, or if you feel you have been placed at risk, you may also contact the Research Ethics and Compliance Office at Illinois State University (309_******** or rec@IllinoisState.edu).

Thank you for willingness and consideration to participate in this research study. Sincerely,

Angela R. Bowden 


\section{Survey of Curricular and Pedagogical Reform in the Science Classroom}

\section{Section 1 - Demographic and Professional Information}

1) In which state do you currently teach? - Drop down box

2) Your state has adopted the Next Generation Science Standards. (Select only one response)

$\square$ Yes

$\square$ No

$\square$ I don't know

3) What is your current role in education? (Select only one response)

$\square$ Classroom Teacher $\quad \square$ District Office Personnel

$\square$ Instructional Coach $\quad \square$ Higher Education Faculty Member

$\square$ Building Administrator $\quad \square$ Other

4) In what type of school do you teach? (Select only one response)

$\square$ Public

$\square$ Charter

$\square$ Private/Parochial

5) What is your school grade configuration? (Select only one response)

$\begin{array}{lll}\square \text { PreK-8 } & \square 5-8 & \square 9-12 \\ \square \text { PreK-5 } & \square 6-8 & \square \text { Other } \\ \square \text { PreK-6 } & \square 7-8 & \\ \square \text { PreK-12 } & \square 7-9 & \end{array}$

6) What content areas do you currently teach (Select all that apply)

General Science (e.g. K-5 curriculum)

$\square$ Life Sciences (e.g. biology)

$\square$ Physical Sciences (e.g. physics)

$\square$ Earth Sciences (e.g. geology)

7) Degree type/level of education (select only one)

$\square$ Bachelor's degree

$\square$ Master's degree

$\square$ Doctorate 
8) Years of teaching experience
$\square 0$ - 4 years
$\square 5-9$ years
$\square 10-14$ years
$\square 15-19$ years
$\square 20+$ years

\section{Section 2 - Familiarity with the Next Generation Science Standards}

RQ1: What is the level of familiarity with the Next Generation Science Standards among K-12 science teachers?

Instructions: Please indicate your level of agreement with the following statements regarding the NGSS. (Select only one response for each question)

\begin{tabular}{|c|c|c|c|c|c|}
\hline & & $\begin{array}{l}\text { Strongly } \\
\text { Disagree }\end{array}$ & Disagree & Agree & $\begin{array}{l}\text { Strongly } \\
\text { Agree }\end{array}$ \\
\hline 9) & $\begin{array}{l}\text { I am familiar with the NGSS performance } \\
\text { expectations for my grade level(s). }\end{array}$ & 0 & 0 & 0 & 0 \\
\hline 10) & $\begin{array}{l}\text { I am familiar with the Science and } \\
\text { Engineering Practices dimension of the } \\
\text { NGSS. }\end{array}$ & 0 & 0 & 0 & 0 \\
\hline 11) & $\begin{array}{l}\text { I am familiar with the Crosscutting Concepts } \\
\text { dimension of the NGSS. }\end{array}$ & 0 & 0 & 0 & 0 \\
\hline 12) & $\begin{array}{l}\text { I am familiar with the Disciplinary Core Ideas } \\
\text { dimension of the NGSS. }\end{array}$ & 0 & 0 & 0 & 0 \\
\hline 13) & $\begin{array}{l}\text { I am comfortable with reading and using the } \\
\text { NGSS performance expectations to create full } \\
\text { instructional plans. }\end{array}$ & 0 & 0 & 0 & 0 \\
\hline 14) & $\begin{array}{l}\text { As a result of your professional development } \\
\text { activities, I am prepared to teach to the Next } \\
\text { Generation Science Standards. }\end{array}$ & 0 & 0 & 0 & 0 \\
\hline 15) & \multicolumn{5}{|c|}{$\begin{array}{l}\text { Please provide an example of how you have used the NGSS performance expectations to create } \\
\text { instructional plans. }\end{array}$} \\
\hline
\end{tabular}

Please respond to the following items related to professional development.
Less than one day

\section{3 to 5 More than}


16) Please indicate the total amount of professional development you have received/attended related to classroom implementation of the Next Generation Science Standards.

17) Can you briefly describe a NGSS professional development experience that was beneficial?

\section{Section 3 - Attitudes Concerning the NGSS}

RQ2: What are the attitudes and levels of agreement concerning the NGSS amongst K-12 science teachers?

Instructions: Please indicate your level of agreement with the following statements regarding the NGSS (Select only one response for each question)

\begin{tabular}{|c|c|c|c|c|}
\hline & Not at all & Minimally & Moderately & Extensively \\
\hline $\begin{array}{l}\text { 18) The NGSS are easy for you to understand and } \\
\text { use for the development of full instructional } \\
\text { plans. }\end{array}$ & 0 & 0 & 0 & 0 \\
\hline $\begin{array}{l}\text { 19) You are confident in your ability to implement } \\
\text { the NGSS as intended by those who } \\
\text { developed the standards. }\end{array}$ & 0 & 0 & 0 & 0 \\
\hline $\begin{array}{l}\text { 20) The changes brought about by the NGSS will } \\
\text { be beneficial to students. }\end{array}$ & 0 & 0 & 0 & 0 \\
\hline $\begin{array}{l}\text { 21) The NGSS will lead to permanent changes in } \\
\text { teacher and classroom practices. }\end{array}$ & 0 & 0 & 0 & 0 \\
\hline $\begin{array}{l}\text { 22) The three-dimensional design of the NGSS } \\
\text { (practices, crosscutting concepts, and } \\
\text { disciplinary core ideas) requires K-12 science } \\
\text { teachers to change their current classroom } \\
\text { practices. }\end{array}$ & 0 & 0 & 0 & 0 \\
\hline $\begin{array}{l}\text { 23) The NGSS encompasses what science } \\
\text { education should be at the grade level I teach. }\end{array}$ & 0 & 0 & 0 & 0 \\
\hline $\begin{array}{l}\text { 24) The NGSS better specifies what is meant by } \\
\text { inquiry in the science classroom and what it } \\
\text { requires. }\end{array}$ & 0 & 0 & 0 & 0 \\
\hline $\begin{array}{l}\text { 25) The Framework for } K-12 \text { Science Education } \\
\text { provides information required to implement } \\
\text { the NGSS in your classroom. }\end{array}$ & 0 & 0 & 0 & 0 \\
\hline
\end{tabular}




\begin{tabular}{|l|c|c|c|c|}
\hline & Not at all & Minimally & Moderately & Extensively \\
\hline $\begin{array}{l}\text { 26) The NGSS can only be implemented when it } \\
\text { is known what the standardized assessment } \\
\text { will encompass. }\end{array}$ & $\circ$ & $\circ$ & $\circ$ & $\circ$ \\
\hline
\end{tabular}

\section{Section 4 - Changes in Classroom Practices}

RQ3: What changes, if any, have K-12 science teachers made to their classroom practices (pedagogy, curriculum, and assessment) in response to the NGSS?

Instructions: Please indicate your level of agreement with the following statements regarding the NGSS (Select only one response for each question)

\begin{tabular}{|c|c|c|c|c|}
\hline $\begin{array}{c}\text { 27) I have changed my classroom instructional } \\
\text { strategies and practices to align with the } \\
\text { expectations of the NGSS. }\end{array}$ & Not at all & Minimally & Moderately & Extensively \\
\hline $\begin{array}{c}\text { 28) I have changed my classroom curriculum } \\
\text { materials to align with the NGSS. }\end{array}$ & $\circ$ & $\circ$ & $\circ$ & $\circ$ \\
\hline $\begin{array}{c}\text { 29) I have changed my classroom assessments to } \\
\text { align with the expectations of the NGSS. }\end{array}$ & $\circ$ & $\circ$ & $\circ$ & $\circ$ \\
\hline
\end{tabular}

30) Please provide an example of a change you have made to instructional strategies, curriculum, or assessments to align them with the NGSS.

The following questions are related to school-level changes.

\begin{tabular}{|l|c|c|c|c|c|}
\hline & $\begin{array}{c}\text { Not at } \\
\text { all }\end{array}$ & Minimally & Moderately & Extensively & $\begin{array}{c}\text { I do not } \\
\text { know }\end{array}$ \\
\hline $\begin{array}{c}\text { 31) Your school's curriculum map is } \\
\text { aligned with the expectations of the } \\
\text { NGSS. }\end{array}$ & $\circ$ & $\circ$ & $\circ$ & $\circ$ & $\circ$ \\
\hline $\begin{array}{c}\text { 32) Curriculum materials at the school } \\
\text { level are aligned with the NGSS. }\end{array}$ & $\circ$ & $\circ$ & $\circ$ & $\circ$ & $\circ$ \\
\hline $\begin{array}{c}\text { 33) Assessments at the school level are } \\
\text { aligned with the NGSS. }\end{array}$ & $\circ$ & $\circ$ & $\circ$ & $\circ$ & $\circ$ \\
\hline
\end{tabular}

Please not the following questions are related to district-level changes.

\begin{tabular}{|l|c|c|c|c|c|}
\hline & $\begin{array}{c}\text { Not at } \\
\text { all }\end{array}$ & Minimally & Moderately & Extensively & $\begin{array}{c}\text { I do not } \\
\text { know }\end{array}$ \\
\hline
\end{tabular}




\begin{tabular}{|c|c|c|c|c|c|}
\hline $\begin{array}{c}\text { 34) Curriculum materials at the district } \\
\text { level are aligned with the NGSS. }\end{array}$ & $\circ$ & $\circ$ & $\circ$ & $\circ$ & $\circ$ \\
\hline $\begin{array}{c}\text { 35) Assessments at the district level are } \\
\text { aligned with the NGSS. }\end{array}$ & $\circ$ & $\circ$ & $\circ$ & $\circ$ & $\circ$ \\
\hline
\end{tabular}

\section{Section 5 - Barriers to Implementing the NGSS}

RQ4: What barriers prevent classroom K-12 science teachers from implementing the NGSS as intended by those who developed the standards?

Instructions: To what extent have each of the following factors affected your implementation of the NGSS? (Select only one response for each question)

\begin{tabular}{|c|c|c|c|c|}
\hline & $\begin{array}{c}\text { Not at } \\
\text { all }\end{array}$ & Occasionally & Moderately & Extensively \\
\hline 36) Large class size. & ० & ० & ० & 0 \\
\hline 37) Administration support. & o & o & ० & 0 \\
\hline $\begin{array}{l}\text { 38) Physical space not conducive to new } \\
\text { expectations. }\end{array}$ & o & ० & $\circ$ & ० \\
\hline $\begin{array}{l}\text { 39) Lack of availability or access to curriculum } \\
\text { materials aligned to NGSS. }\end{array}$ & 0 & $\circ$ & 0 & $\circ$ \\
\hline $\begin{array}{l}\text { 40) Difficulty aligning current curriculum } \\
\text { materials and instructional strategies to the } \\
\text { student performance expectations. }\end{array}$ & 0 & 0 & 0 & 0 \\
\hline $\begin{array}{l}\text { 41) Lack of disciplinary content knowledge } \\
\text { required to teach to new standards. }\end{array}$ & ० & ○ & ० & ० \\
\hline $\begin{array}{l}\text { 42) Lack of professional development } \\
\text { opportunities. }\end{array}$ & ० & o & 0 & o \\
\hline $\begin{array}{l}\text { 43) Lack of support or collaboration from } \\
\text { colleagues. }\end{array}$ & o & o & ० & ० \\
\hline \multicolumn{5}{|c|}{ 44) Please describe the primary barrier(s) that limit your ability to implement the NGSS. } \\
\hline
\end{tabular}

